\title{
ALTERNATIVE FUELS AND CHEMICALS FROM SYNTHESIS GAS
}

FINAL

Quarterly Status Report No. 6

For the Period 1 January - 31 March 1996

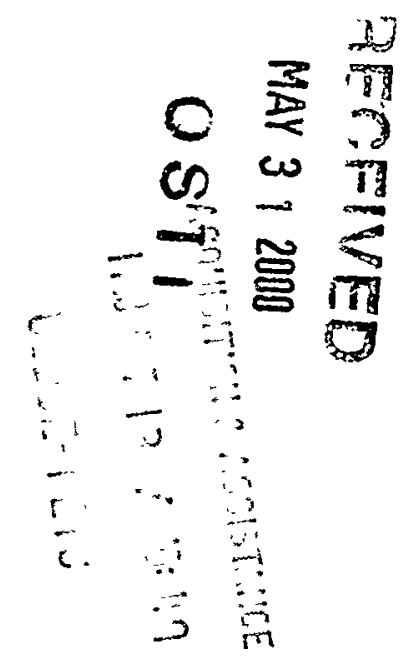

Contractor

AIR PRODUCTS AND CHEMICALS, INC.

7201 Hamilton Boulevard

Allentown, PA 18195-1501

Prepared for the United States Department of Energy

Under Contract No. FC22-95PC93052

Contract Period 29 December 1994 - 28 December 1997

August 1998

NOTE: THIS DOCUMENT HAS BEEN CLEARED OF PATENTABLE INFORMATION 


\section{DISCLAIMER}

This report was prepared as an account of work sponsored by an agency of the United States Government. Neither the United States Government nor any agency thereof, nor any of their employees, make any warranty, express or implied, or assumes any legal liability or responsibility for the accuracy, completeness, or usefulness of any information, apparatus, product, or process disclosed, or represents that its use would not infringe privately owned rights. Reference herein to any specific commercial product, process, or service by trade name, trademark, manufacturer, or otherwise does not necessarily constitute or imply its endorsement, recommendation, or favoring by the United States Government or any agency thereof. The views and opinions of authors expressed herein do not necessarily state or reflect those of the United States Government or any agency thereof. 


\section{DISCLAIMER}

Portions of this document may be illegible in electronic image products. Images are produced from the best available original document. 


\title{
ALTERNATIVE FUELS AND CHEMICALS FROM SYNTHESIS GAS
}

\author{
FINAL \\ Quarterly Status Report No. 6 \\ For the Period 1 January - 31 March 1996 \\ Contractor \\ AIR PRODUCTS AND CHEMICALS, INC. \\ 7201 Hamilton Boulevard \\ Allentown, PA 18195-1501 \\ Prepared for the United States Department of Energy \\ Under Contract No. FC22-95PC93052 \\ Contract Period 29 December 1994 - 28 December 1997
}

August 1998

NOTE: THIS DOCUMENT HAS BEEN CLEARED OF PATENTABLE INFORMATION 


\title{
Alternative Fuels and Chemicals from Synthesis Gas
}

\author{
Quarterly Technical Progress Report
}

\section{Contract Objectives}

\author{
1 January - 31 March 1996
}

The overall objectives of this program are to investigate potential technologies for the conversion of synthesis gas to oxygenated and hydrocarbon fuels and industrial chemicals, and to demonstrate the most promising technologies at DOE's LaPorte, Texas, Slurry Phase Alternative Fuels Development Unit (AFDU). The program will involve a continuation of the work performed under the Alternative Fuels from Coal-Derived Synthesis Gas Program and will draw upon information and technologies generated in parallel current and future DOE-funded contracts.

\section{Summary of Activity}

- The LaPorte Fischer-Tropsch III modification project was kicked off in January. A preliminary PFD and a list of modifications were issued. The modifications include a new high-pressure (1000 psig) filtration system. The filtration system will consist of a slurry degasser, a slurry cooler, a catalyst-wax circulation pump, and four cross-flow filters in series. In addition, some of the existing equipment will be lined up differently for wax handling. In order to recycle the unconverted syngas, the F-T train will be connected to the existing 01.20 Recycle Compressor. Miscellaneous changes include installation of instrumentation for water analysis during activation, DP taps on the 27.10 Reactor, radial thermocouples in the reactor, optical fiber probe to measure radial bubble size distribution, erosion test pieces, and a new sparger from Shell. The planned modifications were documented and sent to Radian Corporation to evaluate their impact on air emissions. Radian will evaluate the proposed modifications and operations to determine if we need a new exemption for this run or if a letter documenting that these changes is sufficient. Due to an anticipated long delivery time for the slurry pump, a process specification for the pump was quickly issued.

- Work continued through March on the modifications for the F-T III run. The PFD was completed and approved, while P\&ID development continued. Process specifications were issued on the 27.15 degasser. Kinetic and mass balance information was obtained from Shell and used to conduct ASPEN simulation work. Close agreement was obtained with Shell's gross predictions, and more detailed mass balance information was generated compared to Shell's simulation.

- Emission calculations were completed for a LaPorte F-T material balance case corresponding to maximum production and emissions. Both exemption and non-attainment estimates were made and transmitted to Radian. Radian will evaluate the estimates to determine if a new exemption is required for this run or a letter documenting these changes is sufficient. Our target date for completing any required action is 1 May. 
- A second trial in January of the new LPDMETM dual catalyst system showed the same excellent stability and high activity as reported in December. Increasing the reaction temperature led to an increase in dehydration activity, but gave rather high deactivation rates. Additional work on catalyst development is needed, but with the repetition of last month's results, we are confident in the observation that a catalyst with greatly increased life has been identified.

- February saw continued improvement of the aluminum phosphate dehydration catalyst in LPDME $^{\text {TM }}$ studies. Changing the solvent in the final step of the aluminum phosphate catalyst preparation gave a stable catalyst with higher activity than seen previously.

- In the higher alcohol work at Aachen, the effect of intraparticle diffusion on activity and selectivity in the gas phase reactor was measured. As expected, the trend in the PFR is the same as for the CSTR when the smallest size particles, which are not diffusion limited, are used. A new catalyst made with copper instead of manganese in the standard catalyst system shows higher activity at a relatively low temperature $\left(400^{\circ} \mathrm{C}\right)$. Testing of systematically varied components in the base catalyst continued through March. Several components (e.g., base) have been shown to have a positive influence on rate. Testing of catalyst at lower pressure shows a large effect. Decreasing pressure to 2500 psi reduces productivity to about $250 \mathrm{~g} \mathrm{IBOH} / \mathrm{kg}-\mathrm{hr}$. Further reduction of pressure results in a marked decrease in productivity.

- Lehigh University studies have shown that a dual bed of the same catalyst, $3 \mathrm{~mol} \%$ $\mathrm{Cs} / \mathrm{Cu} / \mathrm{ZnO} / \mathrm{Cr}_{2} \mathrm{O}_{3}$, held at two different temperatures $\left(325\right.$ and $\left.370^{\circ} \mathrm{C}\right)$ increases the productivity of isobutanol. As an example, synthesis gas consisting of $\mathrm{H}_{2} / \mathrm{CO}=0.75$ at 7.6 MPa with GHSV=18,375 l(STP)/kgcat-hr produces 369 and $180 \mathrm{~g} / \mathrm{kgcat}-\mathrm{hr}$ of methanol and isobutanol, respectively, at $6 \%$ CO conversion.

- In acetyl chemistry work at Air Products for the carbonylation of methyl acetate to acetic anhydride, the phosphinated heterogeneous catalyst proved to be slightly better than the Reillex catalyst with similar loadings of rhodium. For the hydrogenation of acetic anhydride, the rhodium on Reillex was found to be the best catalyst. Finally, for the DME to ethylidene diacetate (EDA) conversion, the Reillex catalyst proved to be the most stable under recycling conditions in contrast to the phosphinated heterogeneous catalyst that rapidly lost activity.

- The use organic bases to catalyze the cracking of EDA to VAM showed little potential, but led us to try organic iodides. Lithium iodide (LiI) was shown to be catalytic in the cracking of EDA. Other iodides and other lithium salts did not show this same activity. Lithium iodide also catalyzed the unwanted retro-reaction to acetaldehyde and acetic anhydride. Controlling the reaction profile with LiI has not been reported in the literature.

- Air Products continued to examine catalysts through March for the cracking of EDA to vinyl acetate (VAM) and acetic acid. The suppression of retro-reaction using acetic anhydride led to a decrease in performance for $\mathrm{LiI}$. $\mathrm{MgI}_{2}$ was shown to perform cracking of EDA. Addition of acetic anhydride resulted in a less significant drop in performance with $\mathrm{MgI}_{2}$. Several other iodide systems showed cracking, but also exhibited unwanted side reactions. 
- Eastman Chemical has continued its investigations of the hydrogenation of acetic acid to acetaldehyde and the subsequent conversion of acetic acid and acetaldehyde to vinyl acetate. Most of the progress has been in the latter reaction, in which yields for the conversion of acetic acid and acetaldehyde are now excellent. The process has been run on a continuous basis, and scale-up and designs amenable to commercial operation are being checked out.

Several catalysts have been identified that are able to facilitate the combination of acetaldehyde with "activated acetic acid," and an optimal class of catalysts has been selected. Yields are now good to excellent. Several reactor designs have been tested for utilizing the unique activation process in this reaction. The details of the activation process and their application to the generation of acetaldehyde and vinyl acetate are possibly patentable.

- Project review meetings were held in Bechtel's San Francisco office on 6 February and 28 March 1996. The major focus of the meetings was to present and discuss the material on Mixed Alcohol Synthesis and sulfur removal to be presented at the April DOE project review meeting in Allentown.

Task 4.2, Commercial Applications (Mixed Alcohol Synthesis). The latest results from the testing of the revised revenue models for the three scenarios for the production of gasoline blendstock ethers via mixed alcohol synthesis were discussed at the project review meeting. Comments were made to clarify some of the results and to add details to improve the presentation. The material is being revised subsequent to the presentation in Allentown.

Task 4.5, Syngas Generation and Cleanup. The revised results of the evaluation of deep sulfur acid gas removal designs versus mild sulfur removal to sulfur levels consistent with the operation of a sulfur-tolerant catalyst were presented. Comments are being incorporated into the presentation.

The six vendors who had supplied information on their contaminant removal systems later supplied information on their commercial experience. This commercial experience is being analyzed in an attempt to validate the process and cost details they originally supplied.

- Hazards review of the $\mathrm{AF}_{2} \mathrm{DU}$ (Alternative Fuels Field Development Unit) was completed in March. Everything is ready for an initial run beginning in April. The project is on schedule and on budget. Dialogue with Eastman has been initiated and no difficulties are anticipated in being on-site at Kingsport during April/May. 


\section{RESULTS AND DISCUSSION}

\section{TASK 1: ENGINEERING AND MODIFICATIONS}

\subsection{Liquid Phase Fischer-Tropsch Demonstration}

A meeting was held with DOE personnel on January 16 to discuss the Fischer-Tropsch III (F-T

III) run. The current plan as discussed between Air Products and Shell in mid-December was presented. In general, the plan was well received and DOE is looking forward to the run. Some issues raised by DOE need attention from Shell: DOE is going to need the LaPorte product and its analysis in order for DOE and its contractors to study downstream processing. DOE also suggested including a tracer study if Air Products/Washington University's current analysis of the 1995 hydrodynamic run shows significant understanding and the value of doing more under the F-T III program. ICI-Tracerco expenses can be covered under DOE's separate hydrodynamic program; however, operation time has to come out of the 30-day program. Data/results from the optical fiber probe (if obtained) need to be shared. Sparger information is needed to feed the data into DOE's hydrodynamic program. The information will have to be shared with other subcontractors.

The F-T III modification project was kicked off in January. A preliminary PFD and a list of modifications were issued. The modifications include installing a new high-pressure (1000 psig) filtration system. The filtration system will consist of a slurry degasser, a slurry cooler, a catalyst-wax circulation pump, and four cross-flow filters in series. In addition, some of the existing equipment will be lined up differently for wax handling. In order to recycle the unconverted syngas, the F-T train will be connected to the existing 01.20 recycle compressor. Miscellaneous changes include installation of instrumentation for water analysis during activation, DP taps on the 27.10 reactor, radial thermocouples in the reactor, optical fiber probe to measure radial bubble size distribution, erosion test pieces, and a new sparger from Shell.

Due to an anticipated long delivery time for the slurry pump, a process specification for the pump was quickly issued. Discussions were held on new equipment layout at LaPorte. The PFD was updated, and P\&ID development began. A Preliminary Hazards Review was conducted on 15 February. A Design Hazards Review will be conducted following completion of P\&ID development. HTRI heat exchanger simulations were performed for the 21.70 slurry cooler. Process specifications were issued for the cooler, as well as for the 22.62 cross-flow filters. The PFD was completed in March, while P\&ID development continued. Ideas were exchanged with Shell for the design of the 27.15 degasser, and a final design was agreed upon. A process specification was issued for the 27.15 degasser.

Mass balance simulation work continued on ASPEN in February. Kinetic and mass balance information became available from Shell in March. ASPEN simulation based on data from Shell resulted in close agreement with Shell's gross predictions. More detailed mass balance information was generated on ASPEN compared to Shell's simulation.

The planned modifications were documented and sent to Radian Corporation to evaluate their impact on air emissions. Radian will evaluate the proposed modifications and operation to 
determine if we need a new exemption for this run or if a letter documenting these changes is sufficient. Emission calculations were completed for a material balance case corresponding to maximum production and emissions in March. Both exemption and non-attainment estimates were made and transmitted to Radian. Our target date for completing the evaluation is 1 May.

A meeting was held with personnel from Energy International (E. I.) to discuss a Fischer-Tropsch demonstration run at LaPorte for E. I. Their overall process scheme and specific LaPorte objectives were discussed. Funding and timing for the run are key issues. The run must be fully funded by E. I. because all available DOE and Air Products funding is already committed. Furthermore, due to the existing schedule for F-T III and the Kingsport start-up, the next window for a LaPorte run is mid-97, and that window may be used for an oxygenates run such as DME synthesis. E. I. prefers the demonstration in a timeframe sooner than mid-97.

Task 1.2 AFDU Modifications - No progress to report this quarter.

Task 1.3 Fischer-Tropsch Support - No progress to report this quarter.

Task 1.4 AFDU R\&D Support - No progress to report this quarter.

TASK 2: AFDU SHAKEDOWN, OPERATIONS, DEACTIVATION AND DISPOSAL - No progress to report this quarter.

\section{TASK 3: RESEARCH AND DEVELOPMENT}

\section{Task 3.1 New Process for DME}

\section{Aluminum Phosphate}

Two repeat runs reproduced the excellent stability and high activity reported in the last quarterly from a dual catalyst system containing an aluminum phosphate dehydration catalyst (referred to as AP01 hereafter). Furthermore, another aluminum phosphate sample (referred to as AP02), when used along with BASF S3-86 methanol synthesis catalyst in a LPDME ${ }^{\mathrm{TM}}$ run, resulted in $6 \%$ higher productivity than AP01 at similar stability. With the repetition of the good results from different runs and different catalyst samples, we are confident that a new dual-catalyst system with greatly increased life has been identified.

The catalyst system performance, especially the stability of the methanol catalyst, was very sensitive to the preparation procedure for the aluminum phosphate catalyst. Washing with water gave a catalyst that performed better than a catalyst that had been washed with isopropanol. The dehydration activity of aluminum phosphate increased with increasing $\mathrm{Al} / \mathrm{P}$ ratio initially, reached a maximum at a ratio of about 1.6 and then dropped. The stability of the methanol catalyst decreased monotonically with increasing $\mathrm{Al} / \mathrm{P}$ ratio. The dehydration catalyst itself was always stable, regardless of the $\mathrm{Al} / \mathrm{P}$ ratio. In the catalyst preparation itself, reversing the order of solution addition in precipitation led to a very poor catalyst system. A catalyst prepared by using $\mathrm{Al}_{2}\left(\mathrm{SO}_{4}\right)_{3}$ as the aluminum precursor, instead of the standard $\mathrm{Al}\left(\mathrm{NO}_{3}\right)_{3}$, also resulted in a poor catalyst system. 
The stability of the dual catalyst system containing AP01 showed a strong dependence on the reaction temperature. While stable at $250^{\circ} \mathrm{C}$, both the methanol synthesis catalyst and the AP01 deactivated rapidly at 270 and $290^{\circ} \mathrm{C}$. This finding illustrates the need for developing a better understanding of the new catalyst system.

The other work covered in this quarterly includes the test of a single-particle, dual-function catalyst. In addition, the effort in understanding why catalysts deactivate more rapidly in reactors of smaller volume-to-surface ratios continues. The dual-function catalyst, $\mathrm{Pd}$ on $\mathrm{La}_{2} \mathrm{O}_{3}$-modified $\delta$-alumina, showed high selectivity toward DME, but low production rate and rapid aging.

\section{Stable Dual-Catalyst Systems Containing Aluminum Phosphate as the Dehydration Catalyst}

In the last quarterly, we reported excellent stability and high activity from a dual-catalyst system containing an aluminum phosphate dehydration catalyst (\#1407x1-1x1 or AP01). We repeated the experiment in the same reactor (\#1 300-cc autoclave) to demonstrate that the results are reproducible. We also repeated the run in the other 300-cc autoclave (Unit \#2), because all three runs in that unit using aluminum phosphate samples of small variation (Runs 14665-44, -47, -51) have shown poor methanol catalyst stability. We wanted to ensure that this poor stability was not an experimental artifact (e.g., poisoning) of the unit.

Both runs were conducted under syngas stream for $\sim 200$ hours. As shown in Figures 3.1 .1 to 3.1.3, the new data track the original data very well. Some discrepancy is observed in Figure 3.1.2. It appears that, in the repeat runs, the methanol catalyst deactivated more slowly than in the original run (14656-90) in Unit \#1, but more rapidly than in Unit \#2. This discrepancy can be attributed to the experimental noise caused by the large variation in the atmospheric pressure during the runs. (Both $\mathrm{GC}$ readings and flow rate measurements are affected by changes in atmospheric pressure, and this effect is more pronounced in the calculation of the methanol rate constant.) However, even in the worst case with Unit \#2, the deactivation rate was $0.051 \% / \mathrm{hr}$., falling into the range of methanol catalyst deactivation observed from lab $\mathrm{LPMEOH}^{\mathrm{TM}}$ runs $(0.042$ to $0.053 \% / \mathrm{hr}$.). This rate is definitely smaller than that of the other three aluminum phosphate samples tested in Unit \#2 $(>0.084 \% / \mathrm{hr})$, reported in the last quarterly. In summary, the repeat runs demonstrated that the good results reported previously are real and reproducible, and that Unit \#2 does not have an experimental artifact. Therefore, the previous results from that unit should be valid. 
Figure 3.1.1 Methanol Dehydration Rate Constant as a Function of Time on Stream

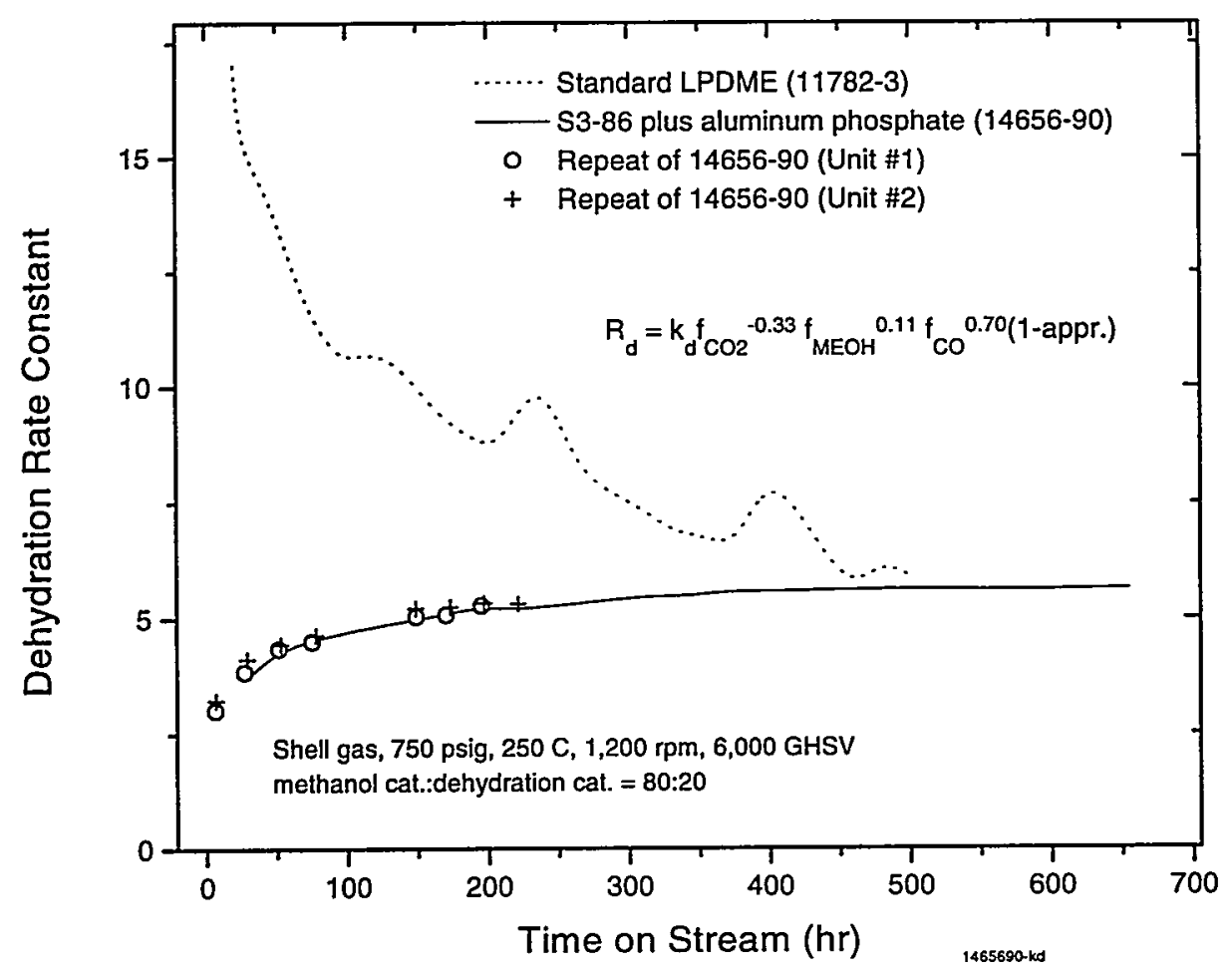

Figure 3.1.2 Normalized Methanol Synthesis Rate Constant as a Function of Time on Stream

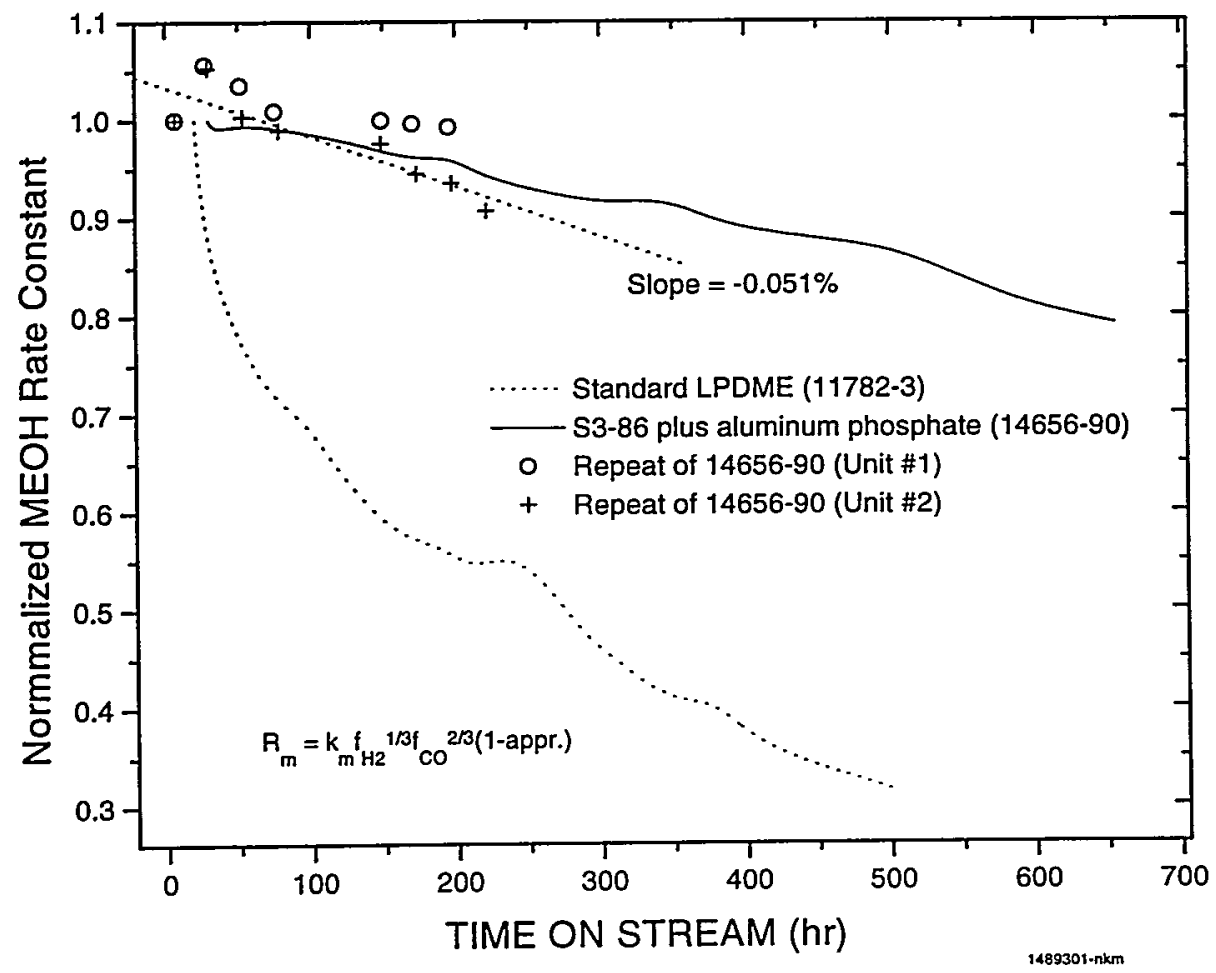


Figure 3.1.3 Methanol Equivalent Productivity as a Function of Time on Stream

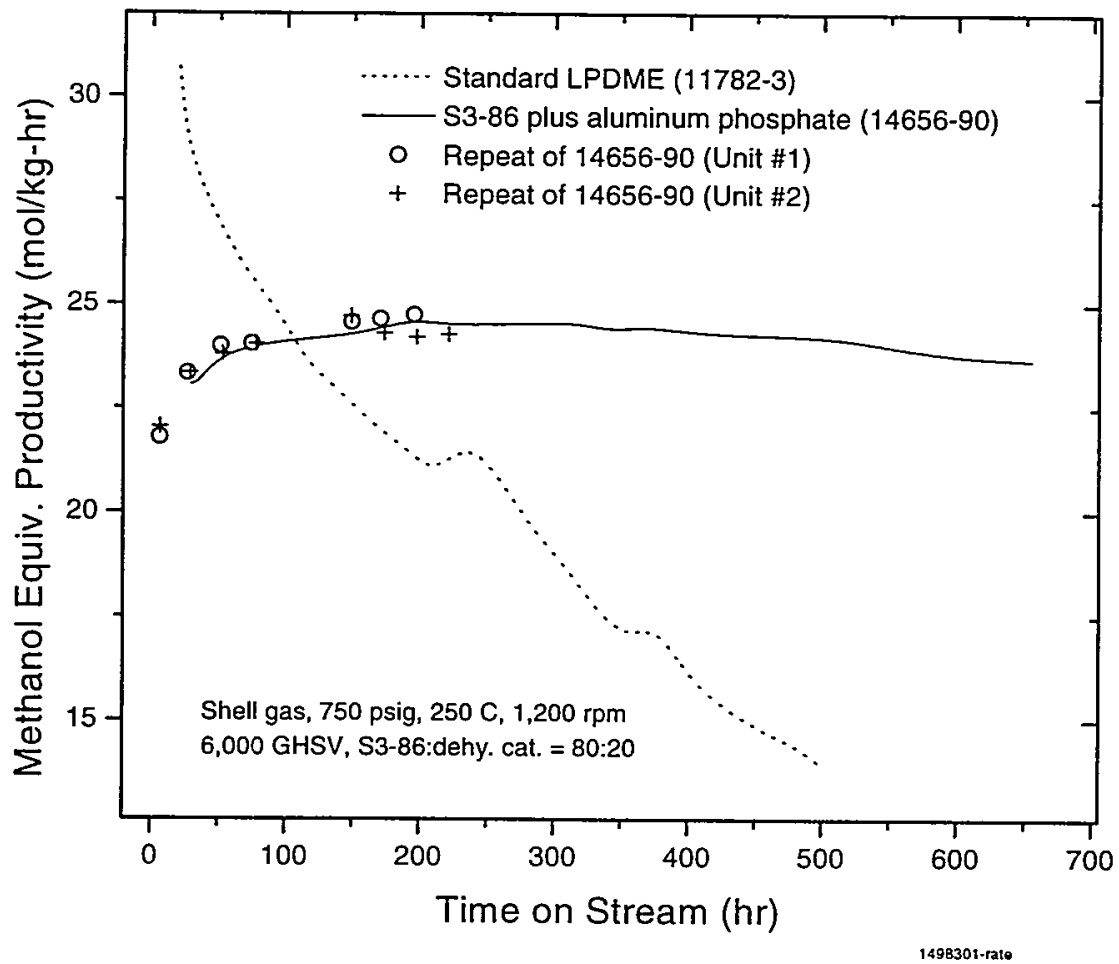

Performance similar to that of AP01 was observed from a different aluminum phosphate sample (\# 1416x1-1x1 or AP02). This sample was prepared according to similar procedures used for AP01, except that it was washed with water instead of isopropanol after filtration. The performance of AP02 under the standard LPDME ${ }^{\mathrm{TM}}$ conditions, along with that of AP01 and the original dual catalyst system containing $\delta$-alumina, is shown in Figures 3.1.4 to 3.1.6. Figure 3.1.4 shows that the dehydration activity of AP02 is higher than that of AP01. The methanol catalyst in this system has a slightly faster deactivation rate than the system containing AP01 (Fig. 3.1.5); however, the deactivation rate, $0.049 \% \mathrm{hr}^{-1}$ shown in Figure 3.1.5, is within the range of methanol catalyst deactivation in lab LPMEOH ${ }^{\top M}$ runs $\left(0.042-0.053 \% \mathrm{hr}^{-1}\right)$. The methanol equivalent productivity of this system, after the induction period, is $6 \%$ higher than the AP01-containing system (Fig. 3.1.6). The analysis shows that different washing procedures and/or solvent results in significantly different properties between AP01 and AP02, such as surface area and $\mathrm{Al}: \mathrm{P}$ ratio. 
Figure 3.1.4 Methanol Dehydration Rate Constant as a Function of Time on Stream

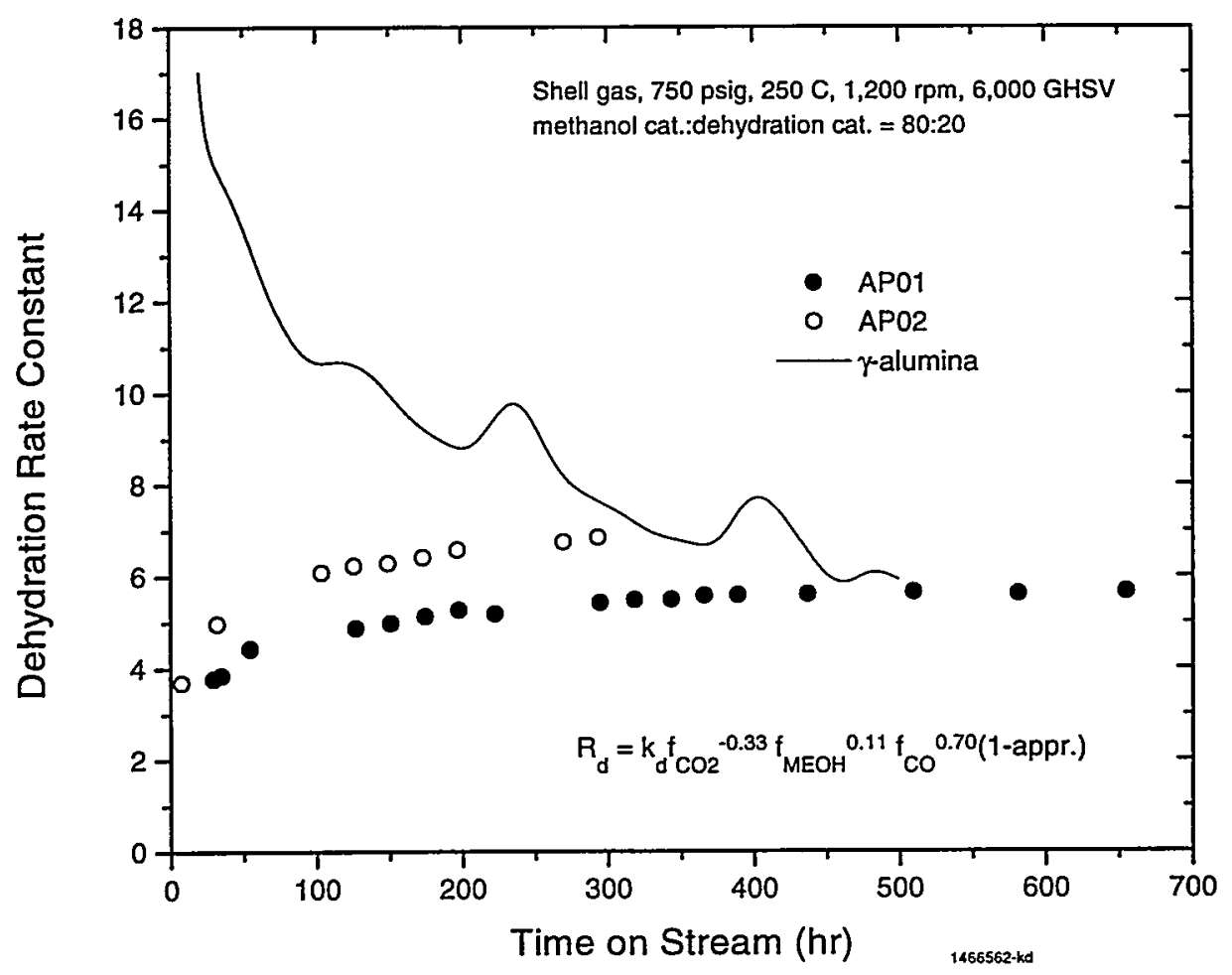

Figure 3.1.5 Normalized Methanol Synthesis Rate Constant as a Function of Time on Stream

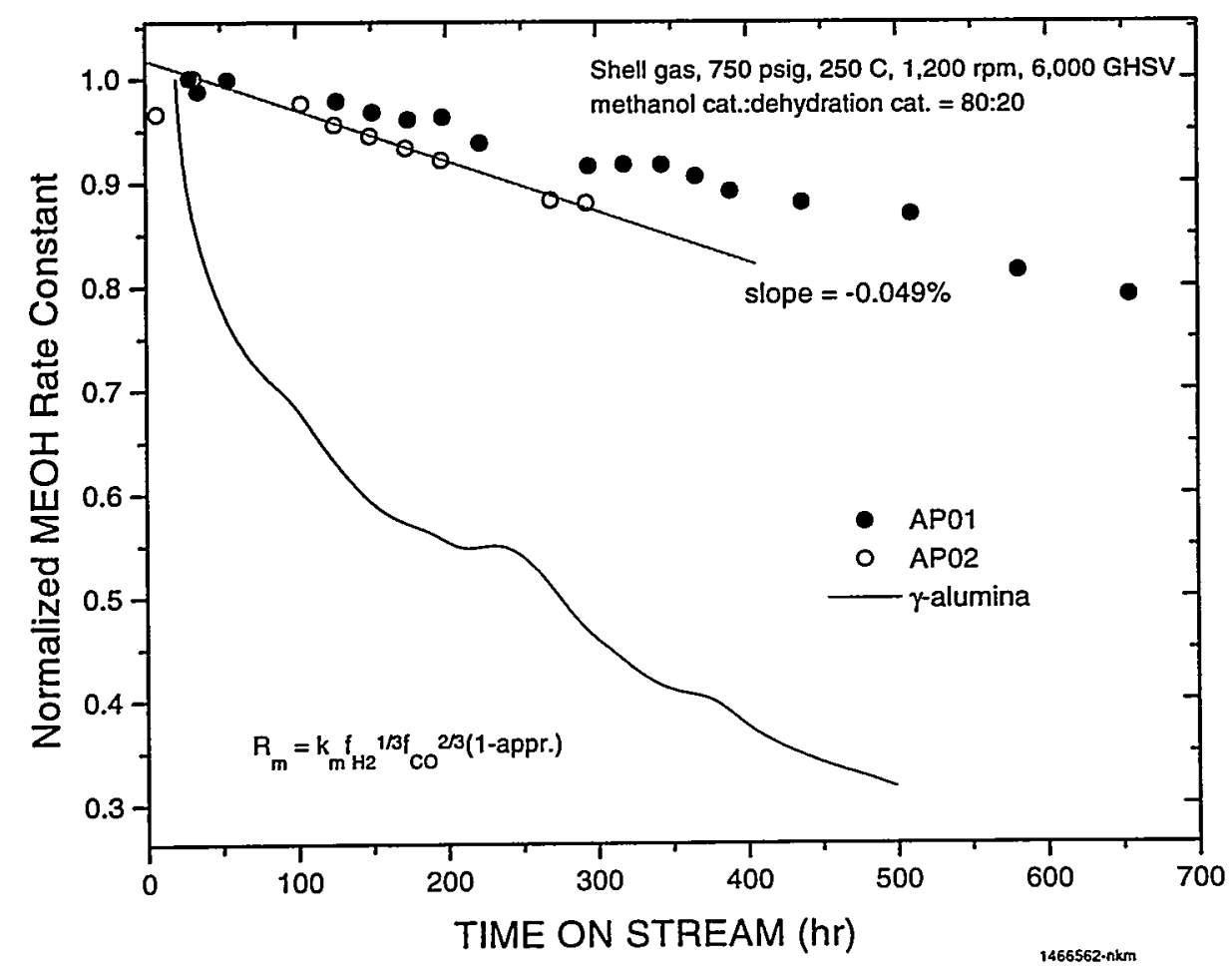


Figure 3.1.6 Methanol Equivalent Productivity as a Function of Time on Stream

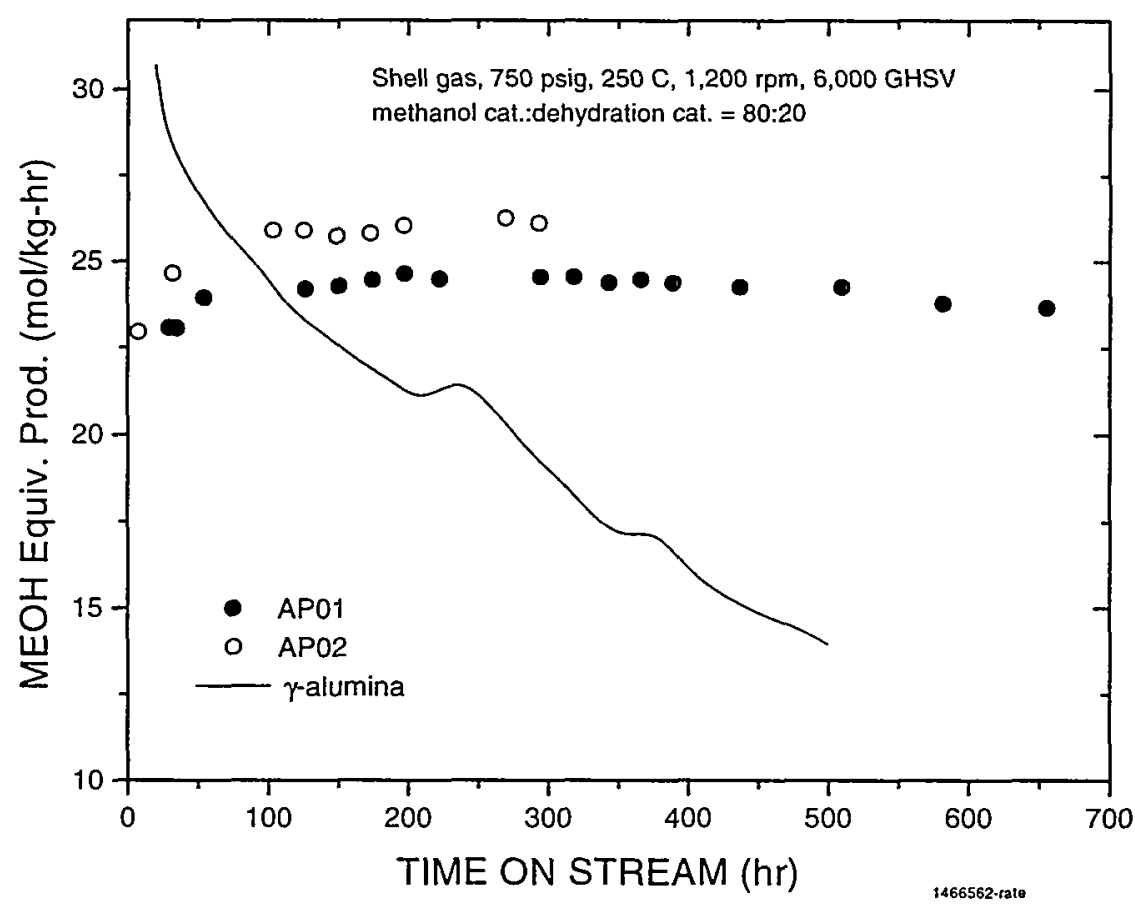

\section{Catalyst Performance as a Function of Preparation Parameters}

The results above show that catalyst performance is sensitive to washing variables during catalyst preparation. Other preparation parameters also have a large effect. An aluminum phosphate sample with an Al/P ratio equal to 1.64 was prepared according to the standard procedures (Sample \# 1427x1-1x1). This sample was tested along with BASF S3-86 methanol catalyst in a LPDME ${ }^{\mathrm{TM}}$ run (\#14665-71) under the standard conditions $\left(250^{\circ} \mathrm{C}, 750 \mathrm{psig}, 6,000 \mathrm{GHSV}\right.$, and 80:20 catalyst ratio) using Shell gas. As shown in Figures 3.1.7 to 3.1.9 by the open circles, the catalyst exhibited much higher dehydration activity than any other aluminum phosphate sample we have tested. In fact, the methanol equivalent productivity was similar to the initial productivity by the standard $\delta$-alumina-containing dual catalyst system. However, this dehydration catalyst caused a $40 \%$ faster deactivation of the methanol catalyst. The dehydration catalyst itself is stable. 
Figure 3.1.7 Methanol Dehydration Rate Constant as a Function of Time on Stream

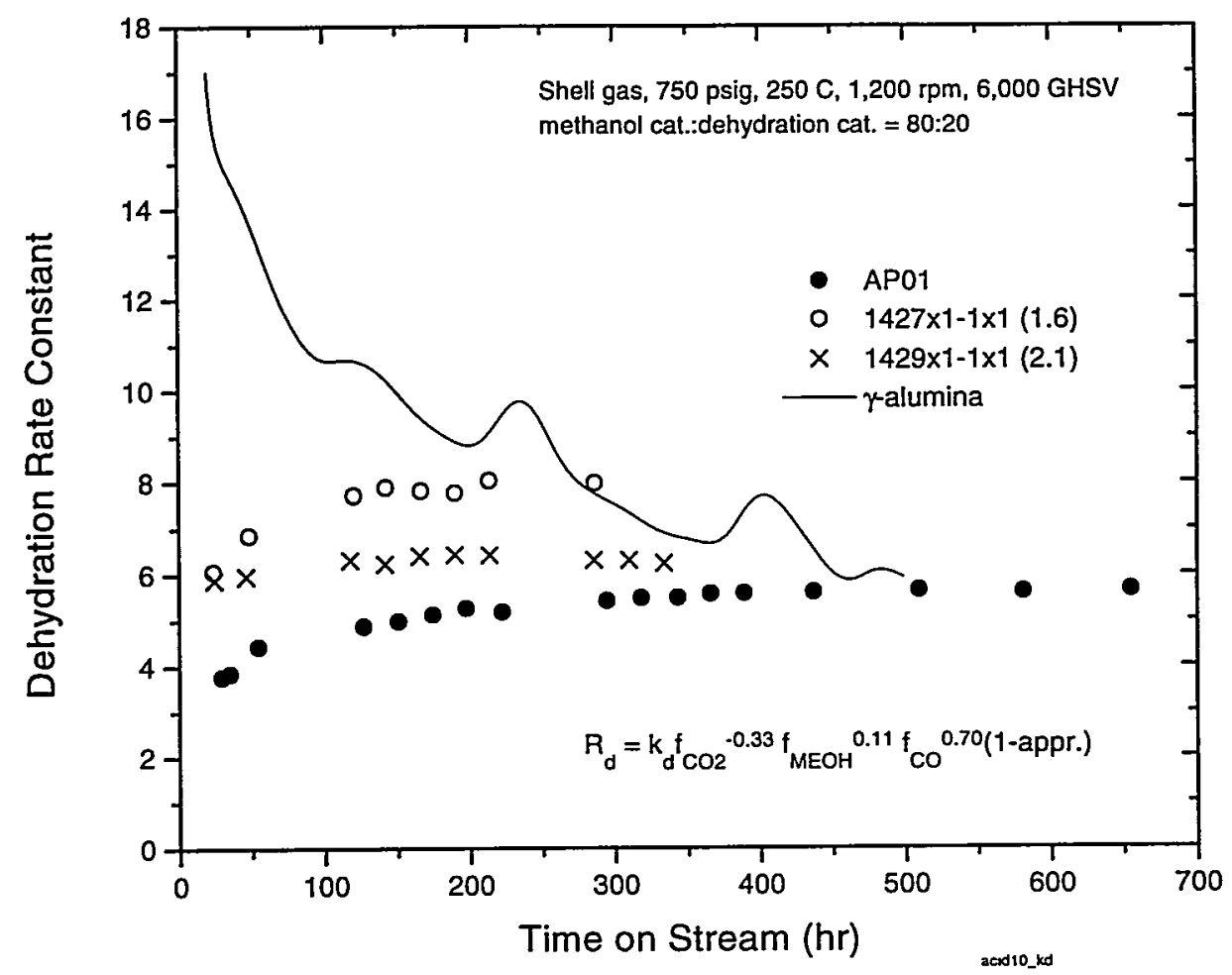

Figure 3.1.8 Methanol Equivalent Productivity as a Function of Time on Stream

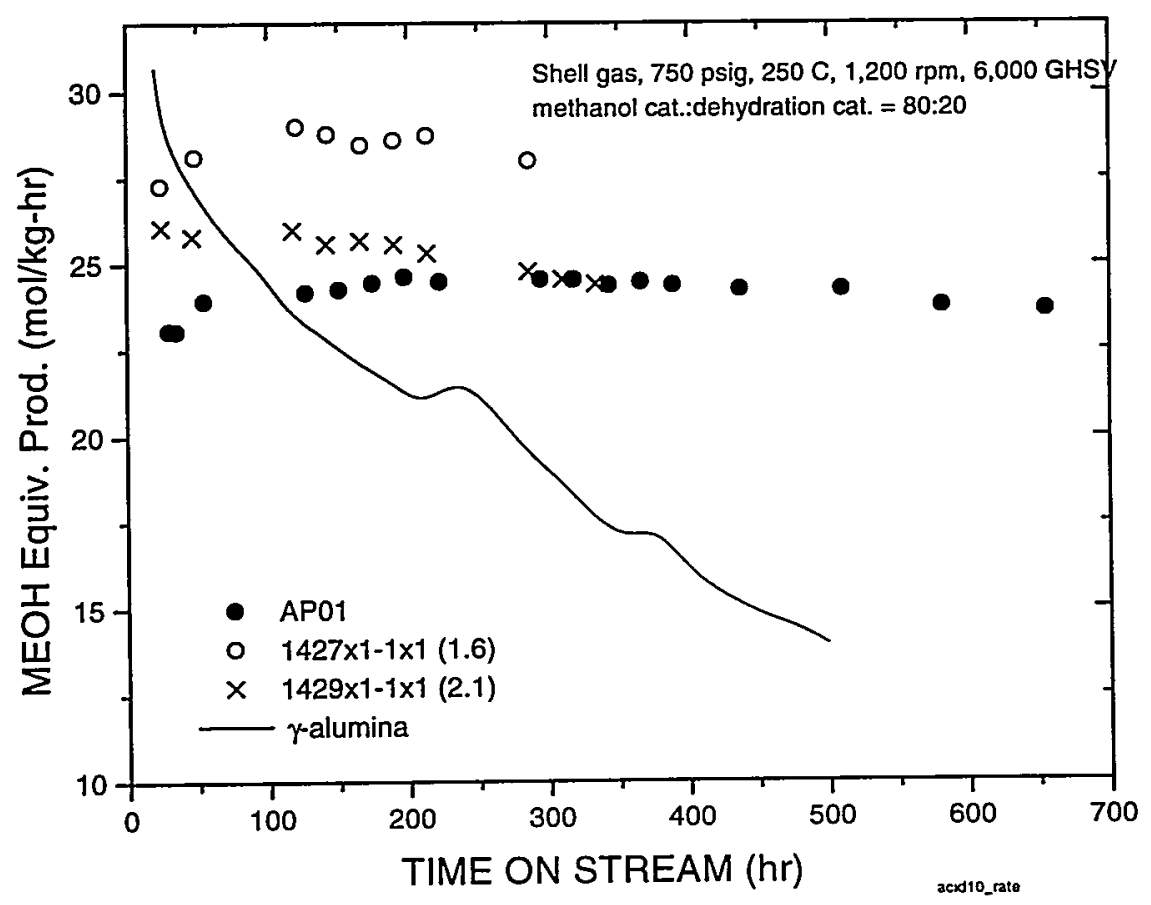


Figure 3.1.9 Normalized Methanol Synthesis Rate Constant as a Function of Time on Stream

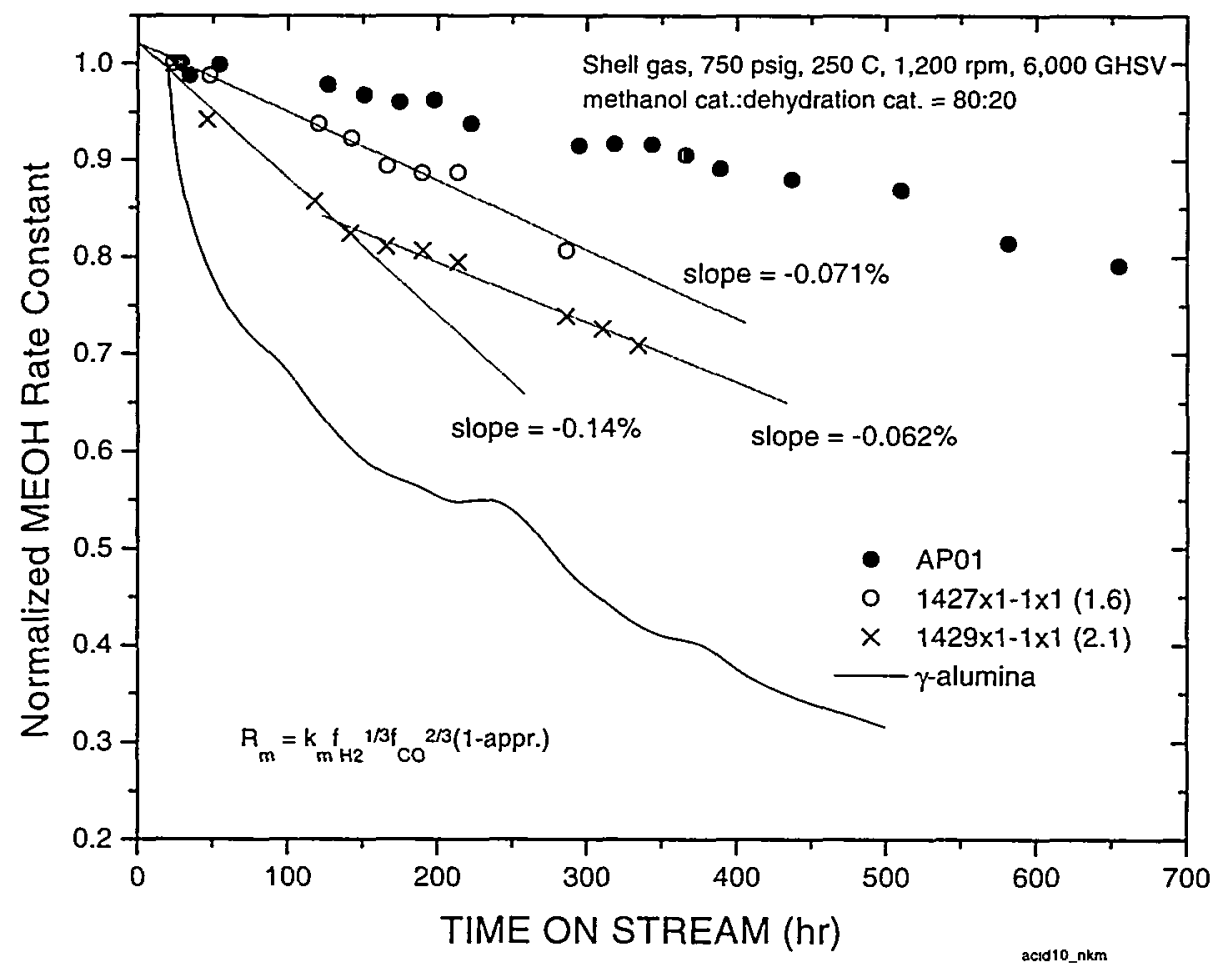

A further increase in the Al/P ratio to 2.1:1 (Sample \#1429x1-1x1) did not result in greater dehydration activity (Fig. 3.1.7), but caused more rapid deactivation of the methanol catalyst (Fig. 3.1.9). The negative effect on the methanol catalyst stability became smaller with increasing time on stream, stopping at a rate of $-0.062 \% \mathrm{hr}^{-1}, 24 \%$ higher than that of a $\mathrm{LPMEOH}^{\mathrm{TM}}$ run.

Table 3.1.1 summarizes dehydration activity, methanol equivalent productivity, and methanol catalyst stability as a function of $\mathrm{Al} / \mathrm{P}$ ratio for three samples prepared using similar procedures. The dehydration activity of aluminum phosphate increased with increasing $\mathrm{Al} / \mathrm{P}$ ratio initially, reached a maximum at a ratio of about 1.6, and then started to drop. The stability of the methanol catalyst decreased monotonically with increasing $\mathrm{Al} / \mathrm{P}$ ratio. The dehydration catalyst itself was always stable, regardless of the $\mathrm{Al} / \mathrm{P}$ ratio.

Table 3.1.1 Catalyst Performance as a Function of Al/P Ratio

\begin{tabular}{|l|l|l|l|}
\hline Al/P Ratio & $\begin{array}{l}\text { Dehydration } \\
\text { activity, } \mathrm{k}_{\mathrm{d}}\end{array}$ & $\begin{array}{l}\text { MEOH Equiv. } \\
\text { Prod. (mol/kg-hr) }\end{array}$ & $\begin{array}{l}\text { Stability of MEOH } \\
\text { catalyst (slope) }\end{array}$ \\
\hline 1.22 & 6.8 & 26.2 & $-0.049 \%$ \\
\hline 1.64 & 8.0 & 29.0 & $-0.071 \%$ \\
\hline 2.12 & 6.3 & 26.0 & $-0.14 \%$ \\
\hline
\end{tabular}


These results indicate that catalyst performance can be optimized by the following two approaches. First, we can work with the stable catalyst system containing aluminum phosphate samples with an Al/P ratio of about 1.2:1 and try to increase its dehydration activity, for example, by increasing the surface area. Second, we can work with the system with high activity (Al/P ratio about 1.6) and try to improve its stability. The fact that the dehydration catalyst itself is stable suggests that the active sites for dehydration are not involved in the accelerated deactivation of the methanol catalyst. Therefore, we can hopefully remove the sites on the phosphate sample that are harmful to the methanol catalyst without damaging the active sites for dehydration. Both approaches are being pursued along with other measures for optimization of the catalyst performance.

Three other phosphate samples were tested last quarter. The first was an aluminum phosphate with an Al/P ratio of 1:6, but prepared by reverse addition during precipitation (Sample \#1430x1$1 \times 1)$. This catalyst showed reasonable dehydration activity, but the stability of the methanol

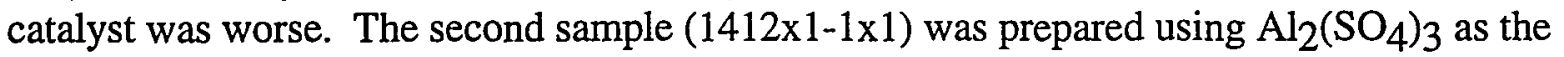
aluminum precursor, instead of the standard $\mathrm{Al}\left(\mathrm{NO}_{3}\right)_{3}$. The dehydration activity of this sample was low, one-half of that of AP01, and the methanol catalyst in this system was not stable. The

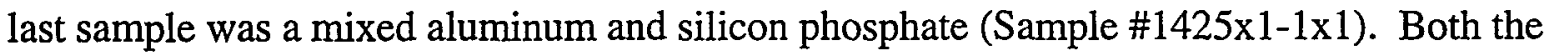
activity and the stability of the methanol catalyst from the dual catalyst system containing this sample were worse than pure aluminum phosphate samples of similar preparation.

\section{Catalyst Stability as a Function of the Reaction Temperature}

To determine if temperature ramping provides an additional means to maintain catalyst activity, or even a means to obtain higher productivity, we tested the dual-catalyst system containing AP01 at 270 and $290^{\circ} \mathrm{C}$, following the two repeat runs carried out in two 300-cc autoclaves at $250^{\circ} \mathrm{C}$. As shown in Figures 3.1.10 and 3.1.11, the activity of both catalysts increased when the temperature was raised to $270^{\circ} \mathrm{C}$. However, both catalysts deactivated rapidly at this temperature. Similar behavior with a faster decrease in activity was observed for the run at $290^{\circ}$ $\mathrm{C}$ (not shown). 
Figure 3.1.10 The Stability of the Methanol Catalyst at Different Temperatures

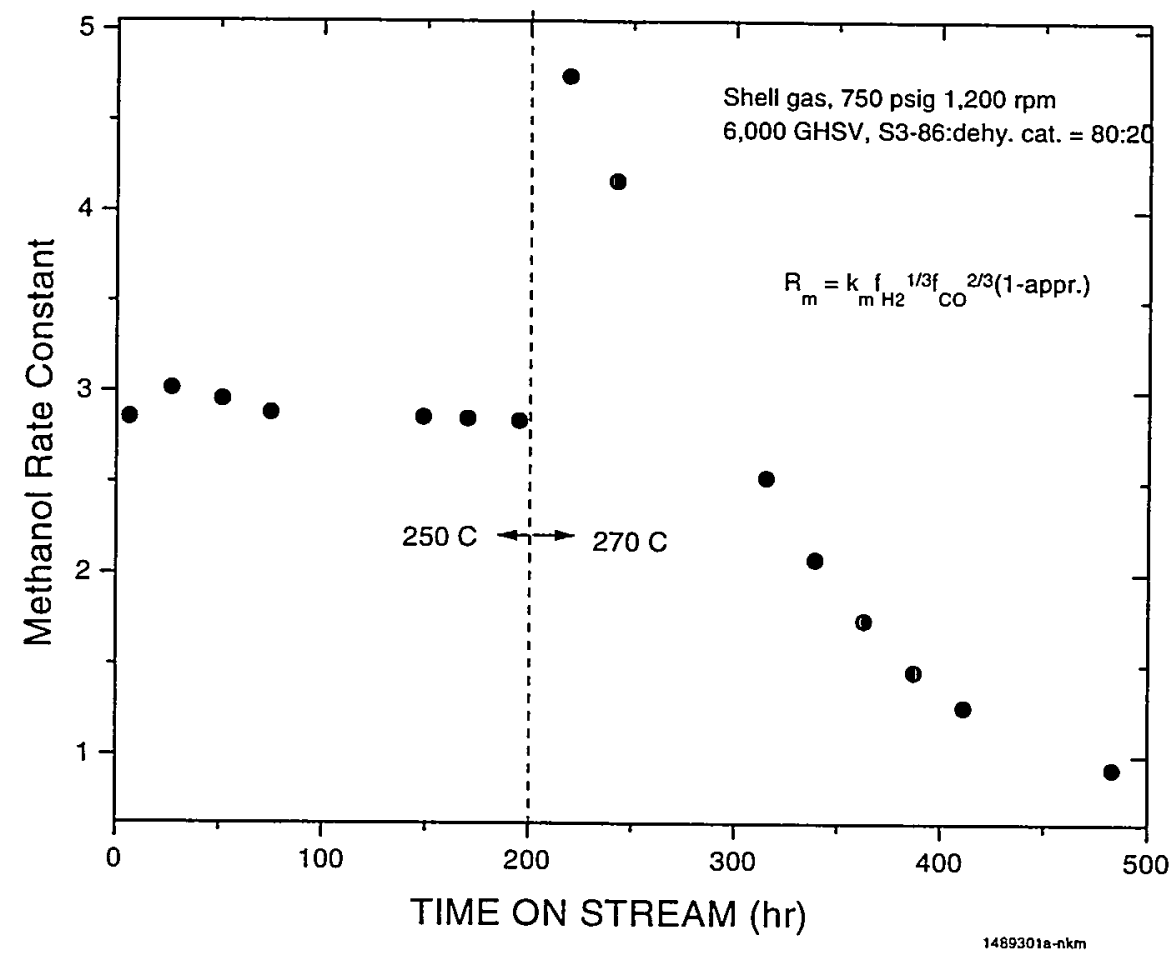

Figure 3.1.11 The Stability of the Dehydration Catalyst at Different Temperatures

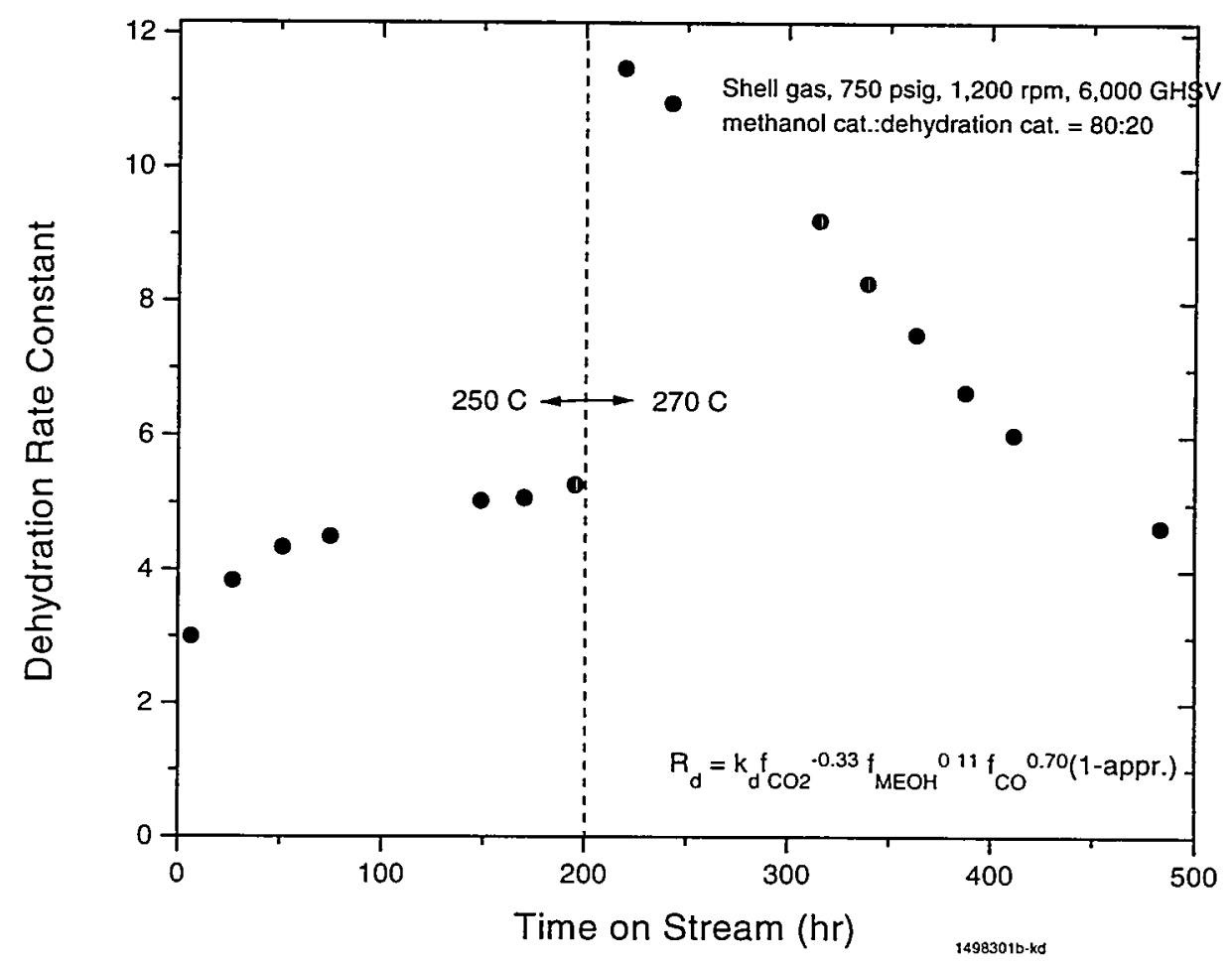


The apparent activation energies for the deactivation of the two catalysts can be estimated by assuming zero-order deactivation kinetics and representing the deactivation rate by $-\mathrm{d}\left(\mathrm{k} / \mathrm{k}_{0}\right) / \mathrm{dt}$, where $k$ is rate constant at any time $t$, and $k_{0}$ stands for the initial rate constant at a given temperature. They are summarized in Table 3.1.2.

Table 3.1.2 The Apparent Activation Energies for the Deactivation of the Methanol Synthesis Catalyst (S3-86) and AP01

\begin{tabular}{|l|l|l|l|l|}
\hline Catalyst & $\begin{array}{l}\text { Deactivation } \\
\text { Rate at } 250^{\circ} \mathrm{C}\end{array}$ & $\begin{array}{l}\text { Deactivation } \\
\text { Rate at } 270^{\circ} \mathrm{C}\end{array}$ & $\begin{array}{l}\text { Deactivation } \\
\text { Rate at } 290^{\circ} \mathrm{C}\end{array}$ & $\begin{array}{l}\mathrm{Ea} \\
(\mathrm{kcal} / \mathrm{mol})\end{array}$ \\
\hline S3-86 & 0.00044 & 0.00322 & 0.00712 & 40 \\
\hline AP01 & 0 & 0.00237 & 0.0044 & 90 \\
\hline
\end{tabular}

Excluding the runs using AP01 and $\mathrm{AP} 02$ at $250^{\circ} \mathrm{C}$, the runs thus far with aluminum phosphate dehydration catalysts exhibit two different patterns of accelerated catalyst deactivation. In the first pattern, only the methanol catalyst deactivates without simultaneous fast deactivation of the dehydration catalyst. This is the case for all phosphate samples we have tested at $250^{\circ} \mathrm{C}$. One of the samples with very low dehydration activity (\#7461-030.060) was even tested at $270^{\circ} \mathrm{C}$ and exhibited good stability (see October-December 1995 quarterly). The second pattern is the simultaneous deactivation of both catalysts as shown above in the runs using AP01 at 270 and $290^{\circ} \mathrm{C}$. The first deactivation pattern suggests that there is no detrimental interaction between the methanol catalyst and the dehydration sites on aluminum phosphate - it is the other functional groups or impurities in aluminum phosphate that cause the deactivation of the methanol catalyst. While this may still be true for these specific cases, the second pattern we observed indicates that the dehydration sites in aluminum phosphate could be part of the deactivation mechanism, given the right conditions. It is possible that the interaction between the methanol catalyst and the dehydration sites becomes significant at higher temperature due to the higher acid strength of these sites. (Coking is an unlikely cause of the deactivation of the phosphate catalyst considering the low acid strength of the catalyst as shown by $\mathrm{NH}_{3}$ adsorption experiments.) The data shown in the table above indicate that this is a highly activated process, that is, very sensitive to the reaction temperature.

We need to understand more about the deactivation mechanism for aluminum phosphatecontaining dual catalyst systems and to develop catalysts that are not as sensitive to the reaction temperature. The strong dependence of catalyst stability on temperature could also be a practical issue considering that over-heating may occur for commercial scale operations.

\section{A Single Particle, Dual Functional Catalyst - Pd on $\mathrm{La}_{2} \mathrm{O}_{3}$-Modified $\delta$-Alumina}

Palladium-based methanol catalysts have been reported in the literature. Although these catalysts in general are much less active than $\mathrm{Cu}$-based methanol catalysts, they might offer alternative LPMEOH ${ }^{\mathrm{TM}}$ or LPDME ${ }^{\mathrm{TM}}$ catalysts with possibly better stability. It has been reported by Ryndin et al. (J. Catal. 70 (1981) 287) that the greatest specific activity is observed with palladium supported on $\mathrm{La}_{2} \mathrm{O}_{3}$. However, the overall productivity from this catalyst is low due to the small 
surface area of the $\mathrm{La}_{2} \mathrm{O}_{3}$ support. We prepared an alumina support coated with a monolayer of $\mathrm{La}_{2} \mathrm{O}_{3}$, and impregnated the support with a $\mathrm{Pd}$ solution. In so doing, we hoped to obtain a large surface area support, as well as the desired synergism between $\mathrm{Pd}$ and $\mathrm{La}_{2} \mathrm{O}_{3}$. This $\mathrm{Pd}$ sample was tested in a 50-cc miniclave under the standard LPDME ${ }^{T M}$ conditions $\left(250^{\circ} \mathrm{C}, 750 \mathrm{psig}, 6,000\right.$ GHSV) using Shell gas. Methanol and DME were the predominant products from this catalyst. A direct comparison between this catalyst and the ones reported in the literature could not be made because of the lack of a Pd dispersion measurement of our sample. Table 3.1.3 compares the performance of the Pd catalyst with that of our standard dual catalyst system (S3-86 plus $\delta$ alumina).

Table 3.1.3 Productivity of Selected Catalyst Systems (gmol/kg-hr)

\begin{tabular}{|l|l|c|c|c|c|}
\hline & Run ID & TOS (hr) & methanol & DME & methane \\
\hline $\mathrm{Pd} / \mathrm{La}_{2} \mathrm{O}_{3} / \mathrm{g}^{-\mathrm{Al}_{2} \mathrm{O}_{3}}$ & $14667-18$ & 15 & 0.73 & 0.35 & 0.03 \\
\hline $\mathrm{S} 3-86+\mathrm{g}-\mathrm{Al}_{2} \mathrm{O}_{3-}-$ & $14047-61$ & 19.7 & 2.76 & 14.69 & 0.017 \\
\hline
\end{tabular}

The table shows that the activity of this Pd catalyst is an order of magnitude smaller than the standard dual catalyst system. The stability of this catalyst was poor; the methanol equivalent productivity dropped by $27 \%$ from 2 hours on stream to 15 hours on stream.

A commercial Pd catalyst (5\% Pd on alumina) used in Air Products hydrogenation plants was also tested under LPDME ${ }^{T M}$ conditions in this lab (Run 14656-40). No activity toward syngas conversion was detected.

\section{Investigation of an Experimental Artifact}

It was previously observed that, in $\mathrm{LPMEOH}^{\mathrm{TM}}$ runs, the methanol catalyst deactivates faster in lab 300-cc autoclaves than in the LaPorte bubble column reactor. It was also observed that, as shown in Figure 3.1.12, the catalyst system in $\mathrm{LPMEOH}^{\mathrm{TM}}$ and LPDMETM runs deactivated faster in a 50-cc microclave than in a 300-cc autoclave. This suggests the existence of an experimental artifact, or a deactivation mechanism, that becomes more pronounced in a reactor with a smaller volume-to-surface ratio. We continue to investigate the nature of this artifact or deactivation mechanism, and how much it contributes to the long-term deactivation in LPDME ${ }^{T M}$ runs. The factors we have examined include: abrasion, attrition, loss of catalysts to the walls of the reactor internals, and poisons in the feed gas. As shown below, none of these appears to be responsible for the experimental artifact. 
Figure 3.1.12 Catalyst Deactivation Rates in Different Reactors
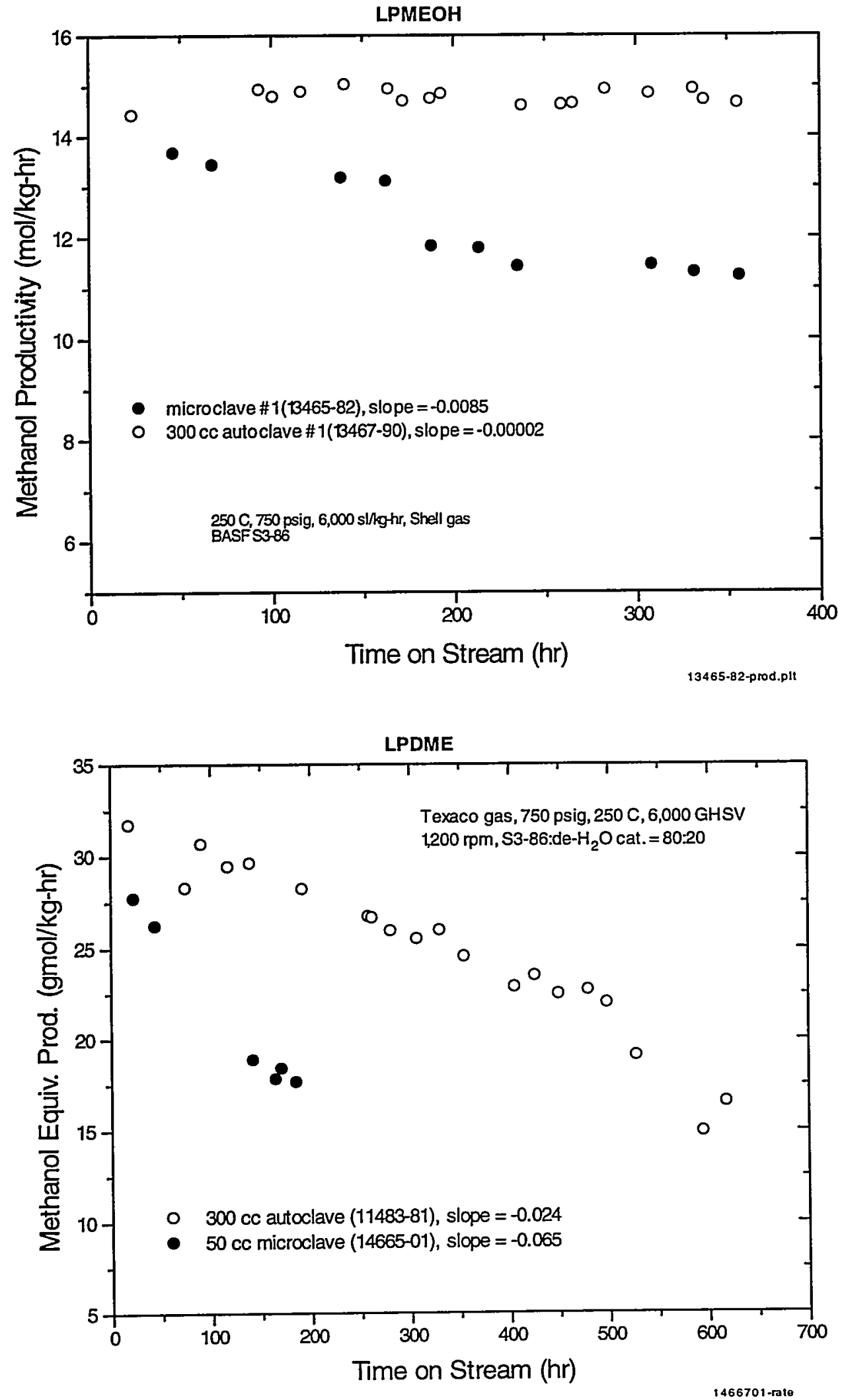


\section{Abrasion and Attrition}

Abrasion of the surface of the hardware inside the lab reactors might be the problem because this abrasion could continuously generate a new surface of stainless steel (300-cc autoclave) or Hastelloy C (50-cc microclave). This new surface might then react with $\mathrm{CO}$ to form iron and nickel carbonyls, which are known methanol catalyst poisons. To investigate this possibility, $\mathrm{LPMEOH}^{\mathrm{TM}}$ and LPDMETM runs were performed in a 300-cc autoclave with a copper liner inside the reactor. Little difference was observed between these runs and those without a copper liner. Mention needs to be made that other reactor internals used in these experiments, including the stirrer, dip tube, baffle blades, and thermocouple well, were made of steel, and were not shielded or replaced by benign materials.

Another way to investigate the abrasion hypothesis is to use different stirring rates, assuming that a higher stirring rate would cause more severe abrasion. Stirring could also accelerate the attrition of catalyst particles, which might then lead to faster deactivation of both methanol and dehydration catalysts because of more intimate contact between smaller particles. Since more rigorous stirring is used in smaller reactors to overcome mass transfer limitations, and since the smaller reactors have smaller volume-to-surface ratios, this theory predicts faster deactivation in smaller reactors.

To test these hypotheses, the standard catalyst mixture containing BASF S3-86 methanol catalyst and Catapal B $\delta$-alumina was loaded into two 50-cc miniclaves. The run in miniclave \#2 (1404761 ) used the normal rotational speed, $2,000 \mathrm{rpm}$. A lower stirrer rate, $500 \mathrm{rpm}$, was used for the run in miniclave \#1 (14667-20). However, during data acquisition, the stirrer rate in the reactor was increased to $2,000 \mathrm{rpm}$ to overcome the mass transfer limitation. In total, the \#1 miniclave stirrer speed was $500 \mathrm{rpm}$ for $90 \%$ of the time. The two runs were carried out in parallel, sharing the same feed gas and analytical system. The results from these parallel runs are shown in Figure 3.1.13. It can be seen that the methanol catalyst deactivates in a similar manner under different stirrer rates. The deactivation of the dehydration catalyst in the two reactors is also similar (not shown). These results indicate that more rigorous stirring in smaller reactors is not responsible for the faster catalyst deactivation. 


\section{Figure 3.1.13 Methanol Catalyst Deactivation under Different Stirrer Rates}

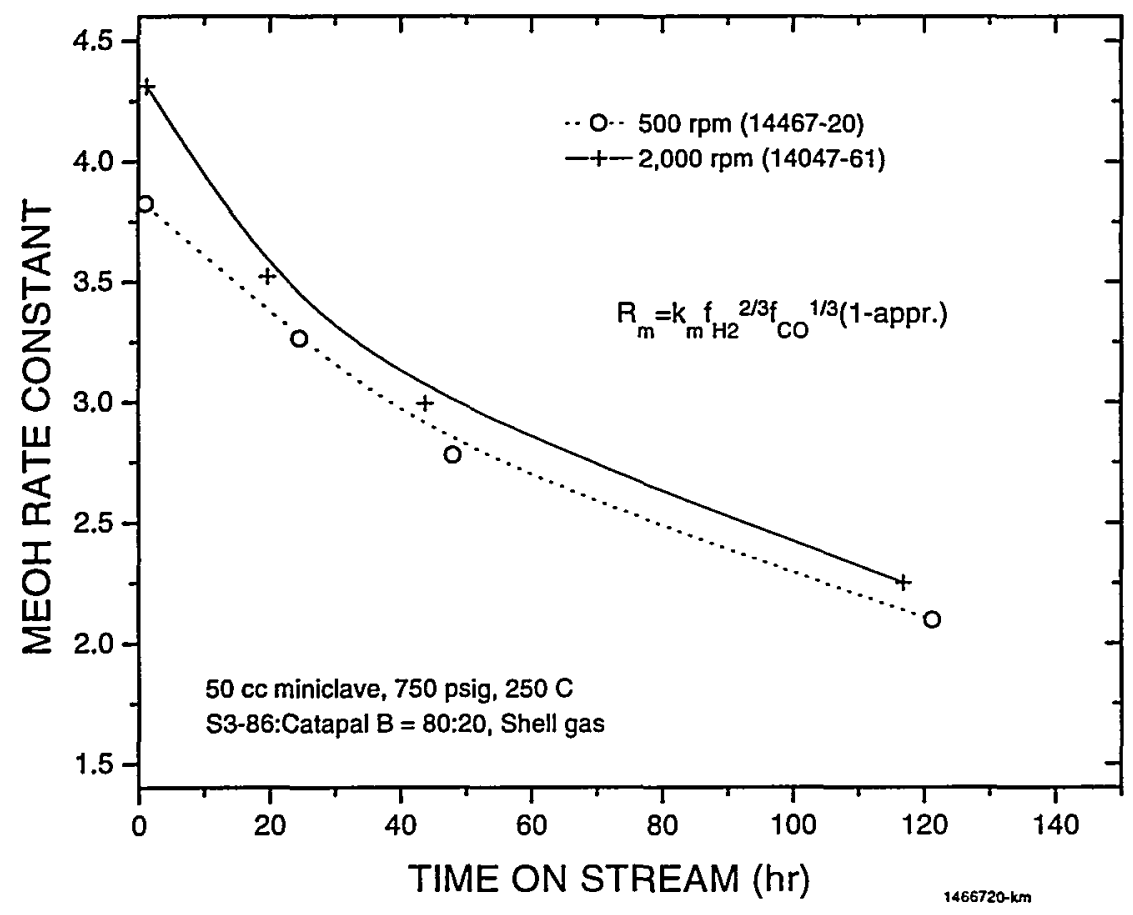

In summary, the experiments using the copper liner and different stirring rates suggest that surface abrasion of reactor internals and catalyst attrition do not play a significant role in the catalyst deactivation seen with both $L P M E O H^{\mathrm{TM}}$ and $\mathrm{LPDME}^{\mathrm{TM}}$ formation; therefore, they are unlikely to be the cause of the experimental artifact.

\section{Loss of Catalysts to the Walls of Reactor Internals}

Another possible cause of deactivation related to reactors of small volume-to-surface ratios is the loss of catalyst on the reactor internals. This can be caused by the caking of catalyst powders on the walls from the decrease in slurry level during the run, or from spattering of the slurry onto the section that is not covered by the slurry. It could also be due to clumping of the catalyst powders on the buffer blade, dip tube, thermocouple well, and the shaft of the stirrer. Both the caking and clumping described above have been observed; however, the amount of caking and clumping is small, and thus do not seem to be significant enough to account for the corresponding loss in activity. This possibility is still under investigation.

\section{Poisons from the Feed Gas}

We have also investigated possible poisons to the methanol catalyst in the feed gas. This seems to be very unlikely because carbon traps are used in the feed gas line to remove carbonyls. Furthermore, little deactivation was observed in the runs using Robinson-Mahoney basket internals. If the feed gas contained poisons, methanol catalyst deactivation should have been observed in these runs. To double check on this, we conducted two LPDME ${ }^{T M}$ runs in a microclave using different amounts of catalysts (by a factor of 2), but the same gas flow rate. If the artifact that causes the deactivation were due to the poisons in the feed gas, the run with a smaller amount of catalysts would have been exposed to more poisons, therefore, would shown a 
higher rate of deactivation. As displayed in Figure 14, the two runs have similar deactivation rates for the methanol catalyst (roughly two parallel curves). Therefore, the possible poisons from the feed gas is ruled out.

Figure 3.1.14 Methanol Catalyst Deactivation at Different Feed-to-Catalyst Ratios

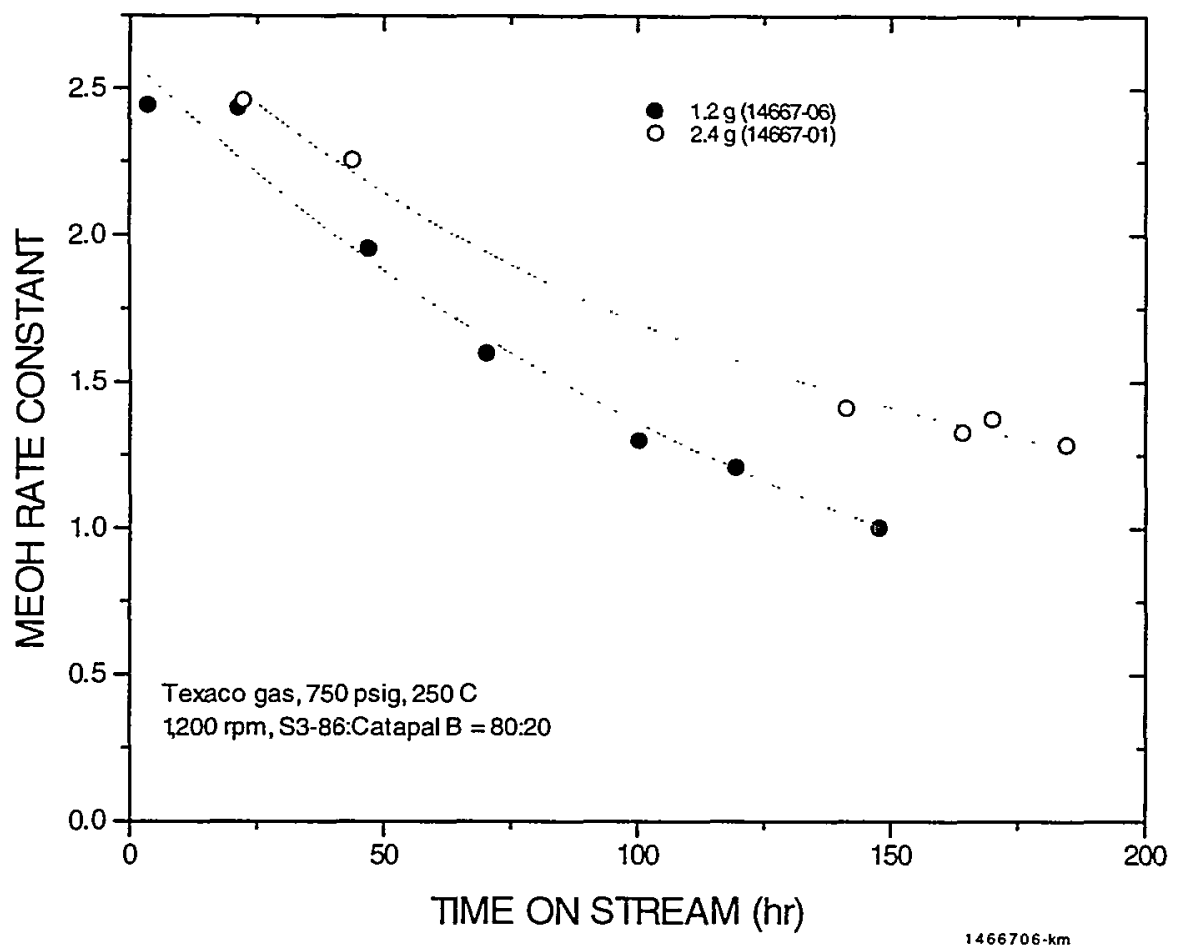

\section{Other Metal Sulphates}

Initial efforts this quarter focused on examining metal sulfates as potential methanol dehydration catalysts, working in parallel with the efforts on metal phosphates. Experiments were performed in the 50-ml microclave reactors using a 4:1 ratio of methanol synthesis catalyst (BASF S3-86) to metal sulfate, at standard reaction conditions $\left(250^{\circ} \mathrm{C}, 750 \mathrm{psig}, \mathrm{GHSV}=6000 \mathrm{l} / \mathrm{hr} \mathrm{kg}\right)$. Catalyst loading and stirrer speed were carefully selected to ensure that catalyst activity, not mass transfer, was rate-limiting.

Zinc sulphate, calcined at $175^{\circ} \mathrm{C}$ in accordance with literature data, was practically inactive for methanol dehydration, producing $0.03 \mathrm{gmol} / \mathrm{hr} \mathrm{kg}$ of DME. Aluminum sulfate (calcined at $350^{\circ} \mathrm{C}$ ), which has both a higher concentration of acid sites and sites of stronger acid strength, yielded $0.70 \mathrm{gmol} / \mathrm{hr} \mathrm{kg}$ of DME. The S3-86 was relatively stable in the presence of this catalyst; methanol synthesis deactivated only slightly faster than that observed in the absence of any dehydration catalyst. However, DME productivity with the aluminum sulfate was still roughly an order of magnitude below that seen with aluminum phosphates.

One possible reason for this is the low surface area of the aluminum sulfate. To combat this problem, two approaches were tried. The first approach was supporting aluminum sulfate on a large surface area support; $12.6 \% \mathrm{Al}_{2}\left(\mathrm{SO}_{4}\right) 3 / \mathrm{SiO}_{2}$ was prepared by a simple aqueous impregnation on Davison Grade 58 silica gel $(300 \mathrm{~m} 2 / \mathrm{g})$. The catalyst was then dried, ground 
and calcined at $350^{\circ} \mathrm{C}$. Microclave testing of the resulting material demonstrated a DME productivity of $0.9 \mathrm{gmol} / \mathrm{hr} \mathrm{kg}$ on a total catalyst weight basis; this corresponds to $7 \mathrm{gmol} / \mathrm{hr} \mathrm{kg}$ on an aluminum sulfate basis (silica gel has been shown to have no dehydration activity). These results appear to confirm that increasing the available surface area of aluminum sulfate could bring its dehydration activity in line with that observed with aluminum phosphate. However, this supported catalyst deactivated fairly quickly and also caused rapid deactivation of the methanol synthesis catalyst.

The second approach was to prepare a larger surface area aluminum sulfate catalyst via a precipitation route, similar to that used to prepare the aluminum phosphate materials. In this approach, precipitation is initiated by the addition of base $\left(\mathrm{NH}_{4} \mathrm{OH}\right)$ to an aqueous solution of aluminum sulfate. Although the primary product of this reaction is expected to be $\left[\mathrm{Al}\left(\mathrm{H}_{2} \mathrm{O}\right) \times(\mathrm{OH}) 6-\mathrm{x}\right] \mathrm{x}-3$, sulfate can "penetrate" this coordination sphere; thus, one would expect to find some degree of $\mathrm{Al}-\left(\mathrm{SO}_{4}\right)$-Al bonding in the final (calcined) material. This material was prepared and will be tested in late April; it will also be characterized to determine surface area and sulfate content. If this catalyst does not prove sufficiently active and stable for DME synthesis, priority will be shifted to investigating alternative metal phosphates, such as $\mathrm{LaPO}_{4}$ and $\mathrm{GaPO}_{4}$.

Eastman Chemical supplied five catalysts that they patented in 1993 for DME synthesis from hydrogen-rich feeds in a packed-bed reactor. These catalysts are $\mathrm{Zn} / \mathrm{TiO}_{2}$-based and perform both the methanol synthesis and dehydration functions at comparatively high temperatures and pressures $\left(325^{\circ} \mathrm{C}\right.$ and $\left.1200 \mathrm{psig}\right)$. The patented performance under these conditions was a methanol equivalent productivity of $76.8 \mathrm{gmol} / \mathrm{hr} \mathrm{kg}$ and equimolar production of DME and methanol. We tested the most promising of these materials (based on patent data) under the patent conditions in both a packed bed reactor and the well-stirred slurry phase microclave reactor using CO-rich feed. Very poor activity and selectivity were observed in the slurry experiment (methanol equivalent productivity of $6.7 \mathrm{gmol} / \mathrm{hr} \mathrm{kg}$ and DME/DME+MeOH of 0.30 ); this can be attributed at least in part to clumping of the catalyst in the slurry. The packed bed experiments did provide equimolar methanol and DME production, but the methanol equivalent productivity was still only $13.0 \mathrm{gmol} / \mathrm{hr} \mathrm{kg}$. Switching to a more hydrogen-rich feed slightly increased productivity, but lowered selectivity sharply (DME/DME+MeOH=0.22).

Air Products researchers observed stable activity for both methanol synthesis and dehydration when using the novel AP02 catalyst with S3-86 at $250^{\circ} \mathrm{C}$; however, the system rapidly deactivated when the temperature was raised to $270^{\circ} \mathrm{C}$. This raised the issue of whether our previous standard DME catalyst combination, S3-86 with Catapal-B alumina, might not be stable at slightly lower temperatures than $250^{\circ} \mathrm{C}$, yet still possess reasonable catalytic activity at these temperatures since its activity at $250^{\circ} \mathrm{C}$ is quite high. This hypothesis was tested in the microclave under standard conditions at $220^{\circ}, 230^{\circ}$ and $240^{\circ} \mathrm{C}$. These data, combined with our previous microclave data at $250^{\circ} \mathrm{C}$, are shown in Figures 3.1.15 and 3.1.16. It must be noted that the rates of deactivation measured in the microclaves are typically higher than those measured in the 300-ml autoclave reactors ; in Figure 3.1.15, note the relative positions of the "S3-86" points measured in the microclave and autoclave. The Arhennius plot, Figure 3.1.16, shows that the rate constants obey a simple Arhennius law and that an increase in stability is indeed observed at 
lower temperatures, together with a corresponding decrease in activity. However the magnitude of this stability increase does not quite offset the activity loss when this catalyst combination is compared to the S3-86/AP02 combination (Figure 3.1.15). The ratio of S3-86 to Catapal-B has not been adjusted to optimize productivity at $230^{\circ} \mathrm{C}$, as is evidenced by the high DME/methanol ratio that resulted $(>2)$. Given these results, we may pursue a $300-\mathrm{ml}$ autoclave run using the S386 with Catapal-B at $230^{\circ} \mathrm{C}$ to obtain directly comparable activity and catalyst stability data that will provide a clear "baseline" for evaluation of our improved dehydration catalysts.

Figure 3.1.15 Comparison of DME Catalyst Systems. LPMEOH ${ }^{\mathrm{M}}$ Data from Microclave and Autoclave Reactors provided for comparison

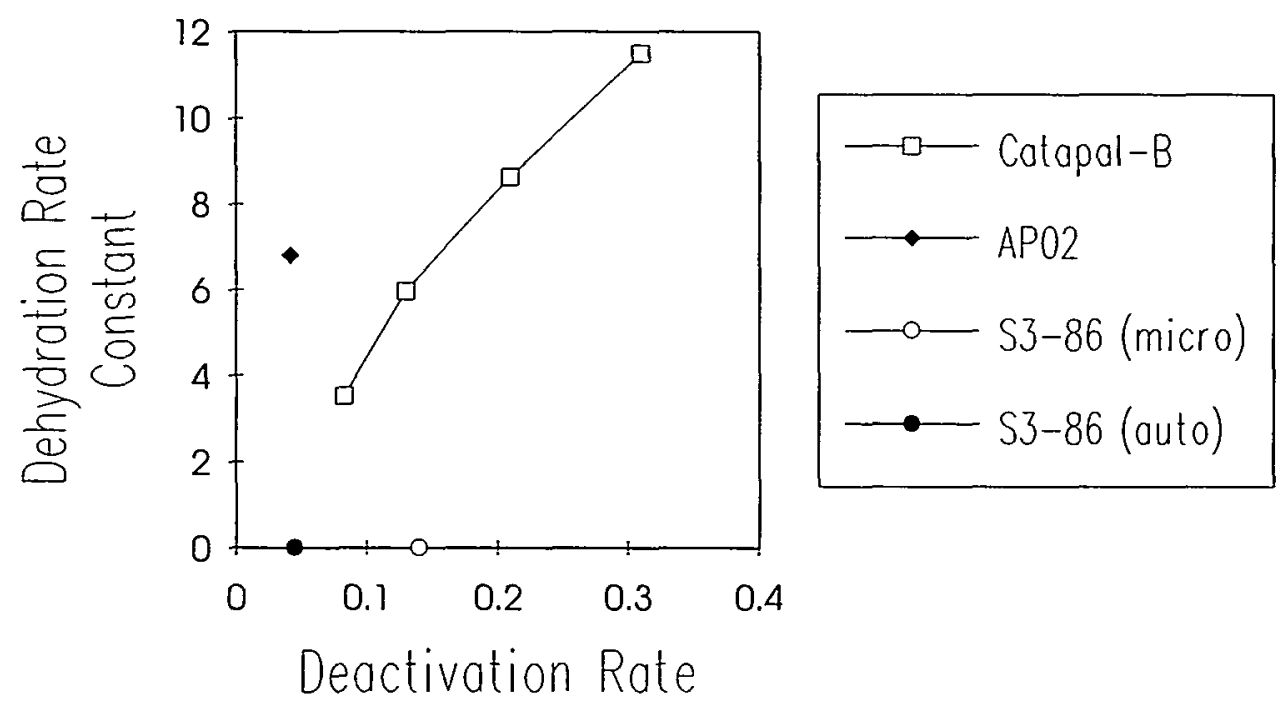

Figure 3.1.16 Arhennius Plot of LPDME ${ }^{\mathrm{TM}}$ Process Using S3-86 and Catapal-B

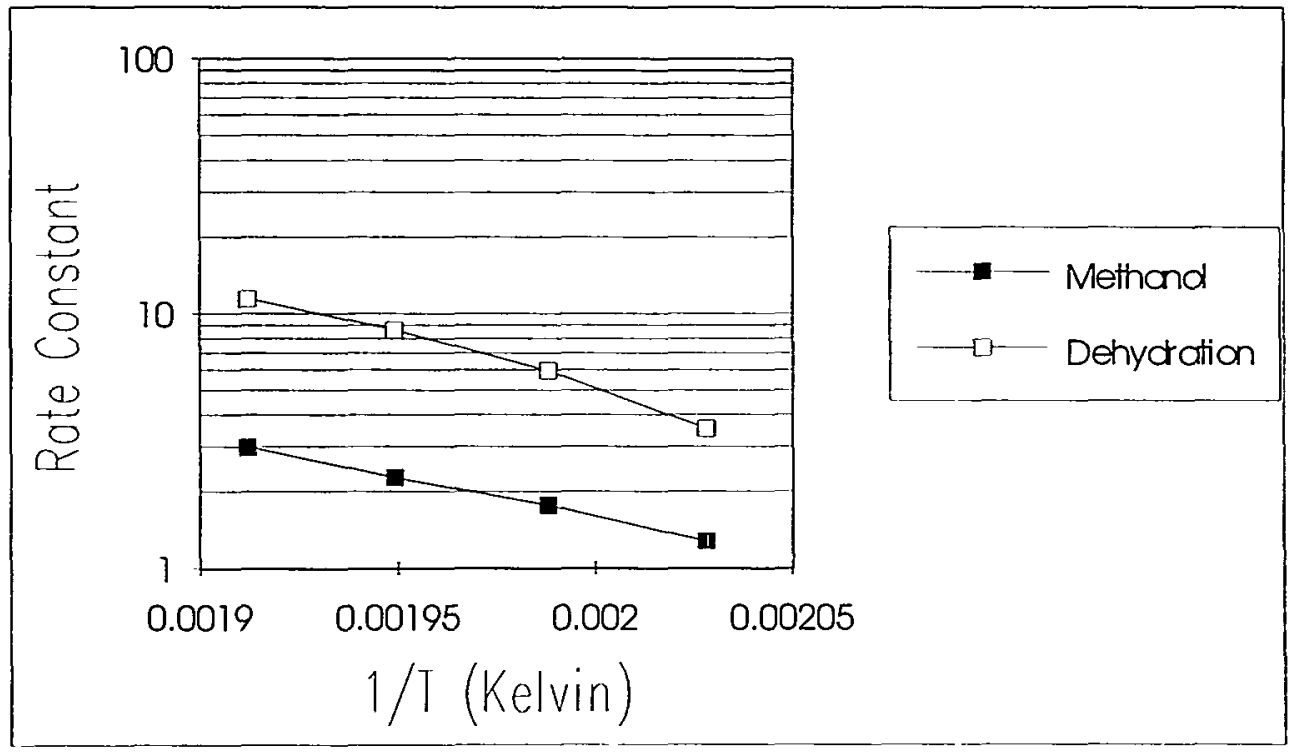




\section{Task 3.2 New Fuels from Dimethyl Ether (DME)}

\section{Overall 2QFY96 Objectives}

The following set of objectives appeared in Section III of Quarterly Technical Progress Report No. 5.

- Continue to screen immobilized catalyst candidates for hydrocarbonylation of dimethyl ether to ethylidene diacetate.

- Continue catalyst development work on the cracking of ethylidene diacetate to vinyl acetate and acetic acid.

\section{Chemistry and Catalyst Development}

\section{(i) Dimethyl Ether (DME) to Ethylidene Diacetate (EDA)}

This effort has focused on understanding the rhodium complexes anchored to the organic polymers for the catalytic conversion of DME to EDA and other single-step reactions that are involved in the overall DME to EDA net reaction.

\section{Results and Discussion for Ionic Bound Rh to Polymer Catalyst}

In previously reported work, the preparation of an ionically bound rhodium complex to a phosphinated Merrifield's resin was described. A series of experiments was performed to determine if there was leaching of rhodium from the resin during the catalytic runs. The experiments were conducted using a 300-cc reactor under the following conditions: acetic acid $(69 \mathrm{ml})$, methyl iodide $(2 \mathrm{ml}), \mathrm{DME}(5 \mathrm{~g})$, Merrifield's resin $(0.45 \mathrm{~g}$, containing $\sim 5 \% \mathrm{Rh}), 190^{\circ} \mathrm{C}$, $\mathrm{CO} / \mathrm{H}_{2}(1: 1,1500 \mathrm{psi})$ for 2 hours. The product was removed to a Whitey cylinder via a frit at the bottom of the reactor, leaving the catalyst in the reactor. The experiment was repeated with a fresh charge of reactants added to the reactor via the tube for the introduction of DME. After the reaction was repeated three times, there was a possibility that the catalyst was adhering to places in the reactor that the solution was not reaching. The reactor was therefore opened before the fourth run and rinsed with acetic acid, which was once again removed by the frit in the reactor, leaving the catalyst in the reactor. The reagents were then added as described above and the reaction was repeated. The results of the four experiments are shown in Table 3.2.1.

\begin{tabular}{|lllll|}
\hline \multicolumn{5}{|c|}{ Table 3.2.1 Hydrocarbonylation of DME to EDA with Phosphine Catalyst } \\
\hline $\begin{array}{l}\text { Experiment } \\
\text { no }\end{array}$ & Conv. \% & $\begin{array}{l}\mathrm{MeOAc} \\
\mathrm{Sel} \%\end{array}$ & $\begin{array}{l}\mathrm{Ac}_{2} \mathrm{O} \\
\mathrm{Sel} \%\end{array}$ & $\begin{array}{l}\text { EDA } \\
\mathrm{Sel} \%\end{array}$ \\
\hline 1 & 98.9 & 46.4 & 9.5 & 20.5 \\
2 & 98.2 & 51.8 & 12.5 & 17.9 \\
3 & 97.5 & 63.6 & 9.3 & 9.4 \\
4 & 97.8 & 42 & 5.9 & 5.8 \\
\hline
\end{tabular}


The results show that the catalytic activity of the resin decreased from experiment 1 to 3 . The methyl acetate concentration was observed to build up while the EDA conversion decreased. Between experiments 3 and 4, the reactor was washed with acetic acid, causing the product stream to be diluted and leading to a lower calculated selectivity for methyl acetate. Supporting this logic is that the methyl iodide concentration was also observed to be lower than the three previous runs, and the acetic acid concentration was higher. The conclusion from these experiments is that EDA selectivity did decrease for each run. This may have resulted from leaching of rhodium from the catalyst due to the inherent instability of resin at these temperatures. The solutions recovered from each run are being analyzed for rhodium, as is the recovered catalyst.

\section{New Catalysts for DME to EDA Conversion}

Thus far all the examples described involve anionically bound rhodium to a cationic polymer. In order to broaden our range of materials, it was decided to examine cationic rhodium complexes as catalysts. The complex $\left[\mathrm{Rh}(\mathrm{dppe})_{2}\right]+\mathrm{Cl}^{-}$, dppe $=$diphenylphosphinoethane has been reported as an efficient catalyst for the gas phase carbonylation of methyl acetate to acetic anhydride. The complex was prepared according to the following procedure:

$$
\begin{aligned}
& \stackrel{\mathrm{RhCl}_{3}+\mathrm{C}_{8} \mathrm{H}_{14} \longrightarrow\left[\mathrm{RhCl}\left(\mathrm{C}_{8} \mathrm{H}_{14}\right)_{2}\right]_{2}}{\longrightarrow} \\
& \stackrel{\left.\mathrm{RhCl}\left(\mathrm{C}_{8} \mathrm{H}_{14}\right)_{2}\right]_{2}+4 \mathrm{dppe} \longrightarrow\left[\mathrm{Rh}(\mathrm{dppe})_{2}\right]^{+} \mathrm{Cl}^{-}}{\longrightarrow}
\end{aligned}
$$

The product was characterized by its UV/VIS spectrum. The catalyst was tested as a homogeneous catalyst for DME to EDA conversion using the following procedure:

$0.2 \mathrm{~g}$ of catalyst, acetic acid $(69 \mathrm{ml})$, methyl iodide $(2 \mathrm{ml}), \mathrm{DME}(5 \mathrm{~g}), 190^{\circ} \mathrm{C}, \mathrm{CO} / \mathrm{H}_{2}(1: 1$, $1500 \mathrm{psi}$ ) for 2 hours.

Analysis of the product showed a $90 \%$ DME conversion; however, the selectivity was $76 \%$ methyl acetate and only $2.5 \%$ acetic anhydride and EDA. This shows that the catalyst has low activity in the hydrocarbonylation reaction.

\section{Methyl Acetate to Acetic Anhydride Heterogeneous Phosphine Catalyst versus Reillex Catalyst Comparative experiments were conducted to broaden the utility of the anionic type polymeric catalysts. For the carbonylation of methyl acetate to acetic anhydride, the phosphinated heterogeneous catalyst was compared with the Reillex and homogeneous catalysts. The procedure and results are shown below and in Table 3.2.2:}

300-cc reactor, $\mathrm{MeOAc}(0.695 \mathrm{~mol}), \mathrm{CH}_{3} \mathrm{I}(0.074 \mathrm{~mol}), \mathrm{HOAc}(0.29 \mathrm{~mol})$, catalyst $(0.8 \mathrm{~g}), \mathrm{CO} / \mathrm{H}_{2}$ $(95 / 5), 190^{\circ} \mathrm{C}, 750$ psi. Analysis after $4 \mathrm{~h}$. 


\begin{tabular}{|c|c|c|}
\hline Catalyst & MeOAc Conv \% & $\begin{array}{l}\mathrm{Ac}_{2} \mathrm{O} \text { Turnover } \\
\text { Frequency (hr-1) }\end{array}$ \\
\hline Phosphine $5.4 \% \mathrm{Rh}$ & 34 & 122 \\
\hline Recycle & 37 & 141 \\
\hline Reillex $2.24 \% \mathrm{Rh}$ & 45 & 159 \\
\hline Reillex 5.1\% & 36.5 & 110 \\
\hline Homogeneous, no LiI & 30 & 99 \\
\hline Homo, with $\mathrm{LiI}$ & 77 & 332 \\
\hline
\end{tabular}

Table 3.2.2 shows that for the carbonylation of methyl acetate to acetic anhydride, the turnover frequency of the phosphinated catalyst is slightly better than the heterogeneous catalyst at comparable $\mathrm{Rh}$ loadings (122 vs 110). Both catalytic systems are better than the homogeneous system without $\mathrm{LiI}$ (turnover freq $=99$ ). However, the homogeneous system with the Lil is still the best (turnover freq $=332$ ).

\section{Hydrogenation of Acetic Anhydride: Reillex vs Homogeneous}

The hydrogenation of acetic anhydride to EDA was also studied, and the results are shown in Table 3.2.3. The experimental procedure is the following:

300-cc reactor, $\mathrm{Ac}_{2} \mathrm{O}(0.22 \mathrm{~mol}), \mathrm{AcOH}(2.4 \mathrm{~mol}), \mathrm{RhCl}_{3} .3 \mathrm{H}_{2} \mathrm{O}(0.76 \mathrm{mmol}), \mathrm{LiI}(0.1 \mathrm{~mol})$, $\mathrm{LiOAc}(7.8 \mathrm{mmol}), \mathrm{CH}_{3} \mathrm{I}(0.063 \mathrm{~mol}), \mathrm{CO} / \mathrm{H}_{2}(1: 1), 190^{\circ} \mathrm{C}, 1500 \mathrm{psi}, 2$ hours.

\begin{tabular}{|lcccc|}
\hline \multicolumn{5}{|l|}{ Table 3.2.3 Hydrogenation of Acetic Anhydride to EDA } \\
\hline Catalyst & $\mathrm{Ac}_{2} \mathrm{O}$ Conv \% & EDA Sel \% & $\begin{array}{l}\text { Turnover } \\
\text { Frequency } \\
\left(\mathrm{hr}^{-1}\right)\end{array}$ & Mass Bal. \% \\
\hline homo & 85 & 47 & 29 & 72 \\
hetero* & 60 & 64 & 59 & 87 \\
homo, no Li & 58.8 & 17.5 & 7 & 62 \\
salts & 1 & 100 & 0.8 & 100 \\
hetero, no $\mathrm{CH}_{3} \mathrm{I}$ & 1 & & & \\
\hline
\end{tabular}

*Heterogeneous---use $1.8 \mathrm{~g}$ of Reillex polymer containing $2.24 \% \mathrm{Rh}$ by weight 
The results show that the Reillex catalyst is still best for the hydrogenation of acetic anhydride. The presence of $\mathrm{Li}$ salts is essential for the homogeneous reaction to proceed and to a greater extent than in the carbonylation of methyl acetate. Methyl iodide was found to be necessary even for the heterogeneous reaction to proceed.

\section{Recycle Experiments for DME to EDA using Heterogeneous Catalysts}

In previous recycle experiments the assumption was made that if the rhodium leaches from the catalyst, the EDA concentration at a particular time will decrease with each successive run. This assumption was tested by performing catalytic runs with different amounts of catalyst and then determining if the response of EDA is linear or not.

The results in Figure 3.2.1 show that our assumption that the EDA concentration will increase as a function of the amount of rhodium present is a valid one. However, the graph shows that the amount of acetic anhydride at any one time cannot be correlated with the amount of rhodium.

\section{Figure 3.2.1 Concentration Profile at 2 Hours versus Amount of Catalyst}

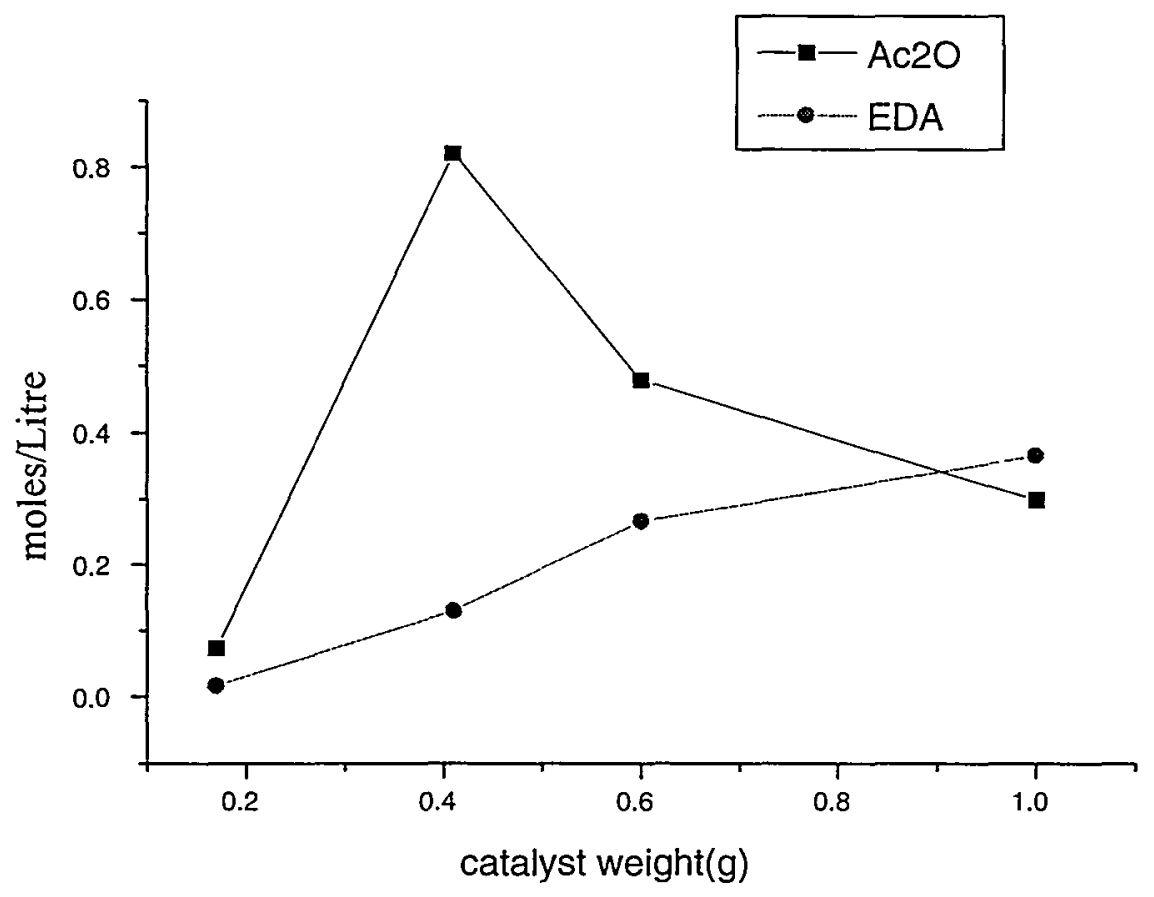

The recycling experiments were performed as follows. In a 300-cc autoclave, acetic acid (1.2 $\mathrm{mol})$, DME (0.12 mol), methyl iodide $(0.03 \mathrm{~mol})$, and catalyst (phosphinated or Reillex) were added. The contents were pressurized with $\mathrm{CO} / \mathrm{H} 2(1: 1)$ at $1500 \mathrm{psi}$ at $190^{\circ} \mathrm{C}$ for two hours. The products were removed via a frit, and the catalyst was left in the reactor. The product concentrations were determined via GC, and the solutions were analyzed for rhodium. The experiment was repeated three times; the catalyst was recovered and analyzed for rhodium. The results of the experiments are shown in the Tables 3.2.4 and 3.2.5. 


\begin{tabular}{|c|c|c|c|c|}
\hline \multicolumn{5}{|c|}{$\begin{array}{l}\text { Table 3.2.4 Recycle Experiments for DME to EDA Using Heterogeneous } \\
\text { Phosphine Catalyst }\end{array}$} \\
\hline Exp. No & Conv\% & $\begin{array}{l}\mathrm{MeOAc} \\
\% \text { sel }\end{array}$ & $\begin{array}{l}\mathrm{Ac}_{2} \mathrm{O} \\
\% \text { sel }\end{array}$ & EDA \% sel \\
\hline 1 & 98.9 & 46.4 & 9.5 & 20.5 \\
\hline Recycle & 98.2 & 51.9 & 12.5 & 17.9 \\
\hline Recycle & 97.5 & 63.6 & 9.28 & 9.35 \\
\hline Recycle* & 97.8 & 42 & 5.9 & 5.8 \\
\hline
\end{tabular}

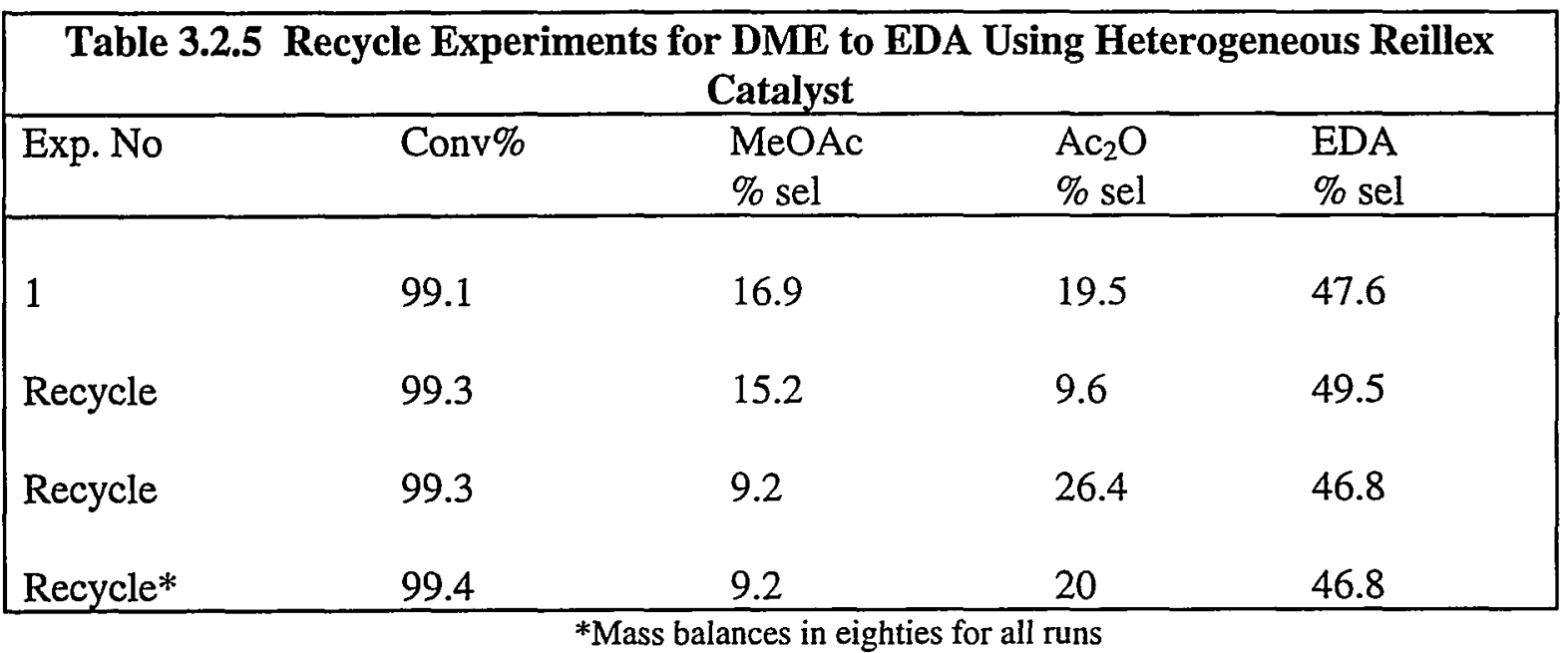

The results clearly show that the Reillex catalyst is a much better performer than the phosphinated heterogeneous catalyst in terms of selectivity to EDA. The Reillex catalyst decreased from $47.6 \%$ to $46.8 \%$ EDA selectivity by the third recycle, which was only a $1.5 \%$ loss. One could even make the case that this was within experimental error. The elemental analysis of the Reillex catalyst before the run was $2.56 \% \mathrm{Rh}$, and the recovered catalyst gave $2.26 \% \mathrm{Rh}$. Normally, we would expect a drop in this number after a run due to incorporation of methyl iodide in the polymer. However, if we assume that this is due to a loss of rhodium, then this amounts to a $11 \%$ loss based on initial Rh content. We should then have seen at least a $20 \%$ loss in EDA selectivity based on the graph showing concentration of EDA versus amount of catalyst. Since there is not such a large loss in activity for the Reillex material, it could be concluded that the elemental analysis of the Reillex was lower in rhodium after the run because of the incorporation of methyl iodide in the polymer. The elemental analyses of the recovered solutions did not support or disprove this point for the following reasons. If we assume the rhodium leached into the solution, this would give a value of $10 \mathrm{ppm}$ in solution. The detection limit for the technique used was $50 \mathrm{ppm}$, and so a conclusive answer could not be obtained. 
The selectivity towards EDA decreased from 20.5 to $5.8 \%$ by the third recycle for the phosphinated catalyst, which is a $72 \%$ loss in activity based on initial selectivity. The elemental analysis of the catalyst before the run was $6.6 \% \mathrm{Rh}$, and after the run it was $5.23 \% \mathrm{Rh}$. As discussed previously, we would expect a drop in $\mathrm{Rh}$ content due to methyl iodide incorporation in the polymer. However, if we assume loss of rhodium from the polymer due to leaching, this amounts to a $21 \%$ loss of $\mathrm{Rh}$ based on initial value. It seems unlikely that this would lead to such a dramatic loss in EDA selectivity (i.e.,72\%). It is more likely that the catalyst is itself unstable in the hydrogen atmosphere, leading to a major loss in activity. Once again, the analysis of the recovered solutions did not support or disprove this point because the detection limit is $50 \mathrm{ppm} \mathrm{Rh}$, and we calculated the solution to have a maximum of $20 \mathrm{ppm} \mathrm{Rh}$.

Based on the data we have obtained, the Reillex polymer is the best catalyst for DME to EDA conversion. A long-term stability test is planned for this catalyst. The analysis of the solutions for rhodium proved to be difficult due to the detection limits. We are planning to concentrate these solutions and repeat the analyses. One possible solution to this problem might be to prepare the catalyst in the reactor, and then analyze it for rhodium. After a few recycles, the rhodium content should not decrease due to methyl iodide incorporation, as this was done in the first step. If a significant loss is not seen, then leaching of $\mathrm{Rh}$ is not a problem.

\section{(ii) Ethylidene Diacetate to Vinyl Acetate}

\section{Background for EDA Cracking}

Ethylidene diacetate (EDA) $\left\{\mathrm{CH}_{3} \mathrm{CH}\left(\mathrm{O}_{2} \mathrm{CCH}_{3}\right)_{2}\right\}$ can be cracked to vinyl acetate (VAM) $\left\{\mathrm{CH}_{2}=\mathrm{CHO}_{2} \mathrm{CCH}_{3}\right\}$ and acetic acid $(\mathrm{AcOH})\left\{\mathrm{CH}_{3} \mathrm{CO}_{2} \mathrm{H}\right\}$. Ethylidene diacetate also reacts to yield acetic anhydride $\left(\mathrm{Ac}_{2} \mathrm{O}\right)\left\{\left(\mathrm{CH}_{3} \mathrm{CO}\right)_{2} \mathrm{O}\right\}$ and acetaldehyde $(\mathrm{AcH})\left\{\mathrm{CH}_{3} \mathrm{C}(\mathrm{O}) \mathrm{H}\right\}$. Reaction 1 depicts this series.

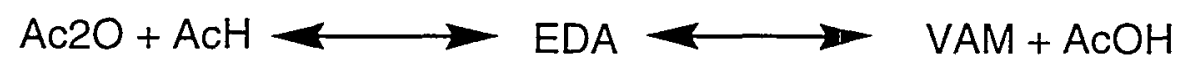

Rxn. 1

In the last report, results of distillation cracking were discussed using iodide salts, particularly LiI. LiI was shown to crack EDA to VAM. LiI also catalyzed the retro-reaction to acetic anhydride and acetaldehyde. Several other lithium salts and several iodides were shown to be inactive.

Working from the assumption that the catalyst must be an iodide with a small cation, several additional materials were examined.

\section{HI (Hydrogen Iodide)}

In order to generate $\mathrm{HI}$ in situ, $1.75 \mathrm{~g}$ of $57 \mathrm{wt} \% \mathrm{HI}$ solution were reacted with $4.25 \mathrm{~g}$ of acetic anhydride. This creates $1 \mathrm{~g}$ of $\mathrm{HI}$ in $5 \mathrm{~g}$ of acetic acid. The HI was then added to EDA and distilled at atmospheric pressure. VAM was observed in the distillate. However, the VAM peak was observed to disappear over the course of several injections. HI appears to cause further reaction of the VAM. 


\section{Ammonosorb Carbon}

A 1g sample of Ammonosorb Activated Carbon was loaded with 20g of EDA and distilled at atmospheric pressure. The quaternary salt was soluble in the EDA, but yielded no reaction.

\section{Calcium Iodide}

A $1 \mathrm{~g}$ sample of $\mathrm{CaI}_{2}$ was loaded with $20 \mathrm{~g}$ EDA and distilled.. A small amount of cracking to VAM was observed. Selectivity to VAM was only $4 \%$. Retro-reaction was observed.

\section{Iodine}

A $1 \mathrm{~g}$ sample of $\mathrm{I}_{2}$ was tested as a catalyst. VAM was observed, but disappeared over time, as in the HI case.

\section{Zinc Iodide}

Based upon the known acidity of $\mathrm{Zn}$ ions, this material was tested. VAM was observed in the distillate. However, this material was very effective at catalyzing the retro-reaction, yielding acetaldehyde and acetic anhydride. Additionally, acetone was observed in the distillate.

Attempts to control the chemistry by addition of acetic anhydride were unsuccessful. Acetone, as well as a peak consistent with DME, was observed.

\section{Lithium Iodide}

The cracking of EDA with LiI was reported last time. In order to suppress retro-reaction, the experiment was repeated using a 5:1 molar ratio of acetic anhydride to EDA. The acetic anhydride was effective at reducing the production of acetaldehyde via the retro-reaction. Unfortunately, the catalyst activity was lowered significantly as well. Conversion dropped from 20 to $10 \%$, selectivity was increased slightly to $50 \%$, and the turnover was reduced from 30 to 4 .

\section{Magnesium Iodide}

Based upon ionic radii, $\mathrm{Li}^{+}$and $\mathrm{Mg}^{++}$are very similar. The higher charge may help to increase solubility. With this in mind, $\mathrm{MgI}_{2}$ was examined as a cracking catalyst.

A $1 \mathrm{~g}$ sample of $\mathrm{MgI}_{2}$ was loaded with $20 \mathrm{~g}$ of EDA and distilled at atmospheric pressure. VAM was observed in the distillate. Retro-chemistry was also observed. $\mathrm{MgI}_{2}$ had a conversion of $51 \%$ with $27 \%$ selectivity to VAM. Turnover was calculated at 98 .

The same material was tested with a feed consisting of 5:1 molar ratio of $\mathrm{Ac}_{2} \mathrm{O}$ :EDA as described previously. Conversion of EDA was up slightly to 59\%, while selectivity to VAM was 78\%. Turnover dropped from 98 to 73 .

The effect of higher acetic anhydride ratios is being explored.

\section{Analytical Results}

When performing many of the distillations described in these reports, we observed a low boiling fraction in the $35^{\circ} \mathrm{C}$ range. This fraction consisted of three components. The first two were 
assumed to be acetaldehyde and vinyl acetate based upon their retention times in the GC. The third material was tentatively identified as 3-acetoxy-2-butanone.

NMR has confirmed the GC data for acetaldehyde and vinyl acetate. The third component was identified as metaldehyde. Metaldehyde is a cyclic trimer of acetaldehyde. This finding is consistent with the appearance of this peak only when acetaldehyde is a principal component. Previous work on suppressing acetaldehyde formation by addition of acetic anhydride also caused suppression of this unidentified peak.

\section{QFY96 Objectives}

Future plans for Task 3.2 will focus on the following areas:

- Continue to screen immobilized catalyst candidates for hydrocarbonylation of dimethyl ether to ethylidene diacetate

- Continue catalyst development work on the cracking of ethylidene diacetate to vinyl acetate and acetic acid.

\section{Value Added Acetyls From Syngas (Eastman Chemical Company)}

\section{A. Introduction}

The overall objective of this project is to produce a commercially viable process for the generation of vinyl acetate monomer (VAM) based entirely upon coal-generated syngas. Previous attempts at this objective have generally involved the combination of acetic anhydride (generated by carbonylation of either dimethyl ether or methyl acetate) with acetaldehyde (generated by either hydrogenation of acetic anhydride $\left(\mathrm{Ac}_{2} \mathrm{O}\right)$ or hydrocarbonylation of either methanol $(\mathrm{MeOH})$ or a methyl ester) to generate ethylidene diacetate (EDA), which is subsequently cracked to form VAM in a separate step. An exemplary process is shown below.

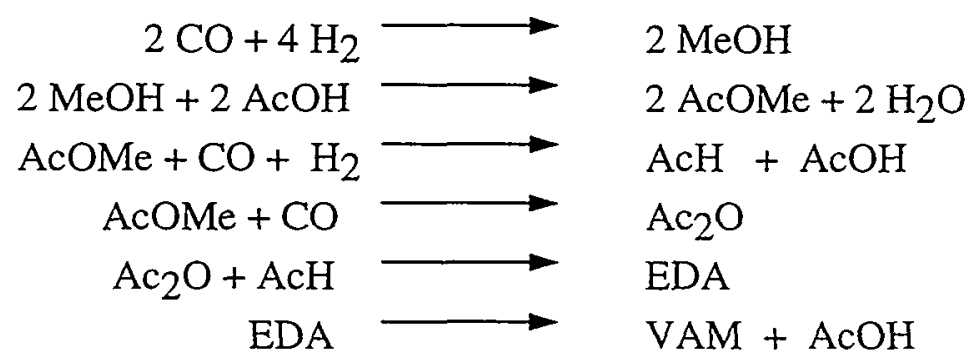

$\mathrm{AcH}=$ acetaldehyde

$\mathrm{AcOMe}=$ methyl acetate

These efforts have failed to generate a commercially viable process to date. One of the key reasons for this failure was the very large quantities of recycled acetic acid (and consequently large commercial facilities) inherent in the earlier proposed processes. 
Eastman's proposal was to circumvent the recycle problem by generating $\mathrm{AcH}$ via hydrogenation of acetic acid ( $\mathrm{AcOH})$ instead of via reductive carbonylation. Unfortunately, this process is thermodynamically disfavored and, even if acetic acid is hydrogenated, the conditions required generally favor further hydrogenation to form ethanol and ethyl acetate, which are the thermodynamically favored products. Currently, any processes that have successfully hydrogenated a carboxylic acid circumvent this problem by operating at unacceptably high pressures and temperatures to overcome the thermodynamic constrictions and by operating at low conversion to minimize over-hydrogenation to the alcohol.

Eastman's proposed solution to this dilemma was to convert the acetic acid to ketene (a very well known process) and utilize the high energy content of the unstable ketene intermediate to overcome the thermodynamic constrictions to hydrogenation. The key task would be to identify catalysts that hydrogenated the ketene intermediate selectively to acetaldehyde (particularly did not generate ethanol or ethyl acetate) and would do so at commercially desirable temperatures and pressures.

Several restrictions are inherent in the contemplated conversion. Due to the unstable nature of ketene, the vapor pressure of ketene in the process should be less than atmospheric and its conversion should be reasonably high. Further, recovery of acetaldehyde will require that there not be excessive amounts of additional hydrogen present. Prior to this study, no catalyst was known for accomplishing this task.

Whereas the hydrogenation of acetic acid represents the linchpin technology in the proposal, also included were some proposed advances in the subsequent conversion of acetaldehyde to VAM. Obviously, the acetaldehyde thus formed could be converted to EDA and subsequently to VAM by known methods; Eastman proposed several improvements upon this known process. However, Eastman also proposed a very speculative application of ketene for the direct esterification of acetaldehyde to yield VAM without the intermediate generation of significant amounts of EDA. If this overall speculative conversion came to fruition, the process would be represented by the following relatively simple scheme:

\section{Scheme 1. Conversion of Syngas to VAM from Acetic Acid via Ketene}
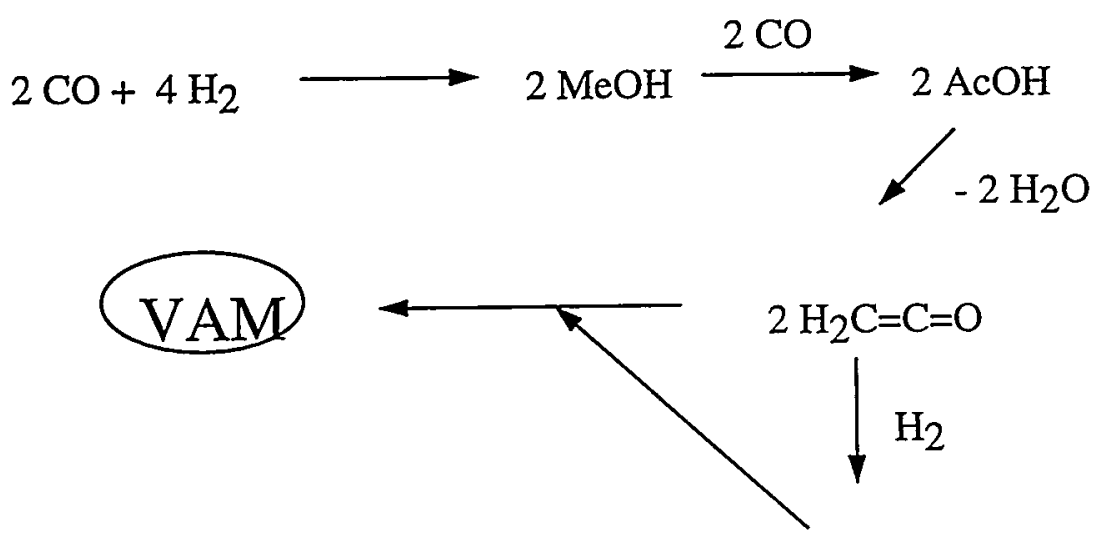

$\mathrm{AcH}$ 
It is particularly important to point out that this scheme does not have any significant recycle loops. Further, due to the nature of the process, there are numerous opportunities to reduce capital costs through proper integration, and there is a notable economy of scale associated with the size of the intermediate steps.

Consistent with these goals, Eastman has pursued the following tasks in the 1st quarter of 1996: Task 1.1. Examine hydrogenation of $\mathrm{AcOH}$ to acetaldehyde via ketene.

Task 2.1. Examine the direct conversion of AcH and ketene to VAM.

Task 3.1.a. Assess preliminary economics for a process based on ketene hydrogenation.

In addition, Eastman has begun to reconsider the role reductive carbonylation of methanol (or its derivatives) might play in this process as a means of generating acetaldehyde for the process, given the success of Task 2.1 .

\section{B. Results and Discussion}

General. Eastman is now operating three reactors. The two smaller scale reactors are set up to separately investigate hydrogenation (particularly heterogeneous hydrogenation) of ketene, and the gas stripped reactor is designed for the direct conversion of ketene and acetaldehyde to VAM. The larger scale reactor (0.6-0.8 moles/hr) is set up to be more flexible in its operation and should be useful in examining scaleup or alternative reactor designs for either conversion.

Task 1.1. Hydrogenation of AcOH via Ketene Intermediates. In its previous report, Eastman described a series of Pd-based catalysts for the hydrogenation of ketene to acetaldehyde. Within the report, Eastman described a procedure that isolated ketene at dry ice temperatures and then slowly metered ketene into the hydrogenation unit using a stream of nitrogen nearly saturated in ketene. Although these runs were successful, Eastman sought to scale up the process and eliminate the large volume of diluent gas associated with this method of introduction.

To do this Eastman constructed two continuous ketene generators that utilized acetone as a source of ketene. (One of these units represented a scaleup factor of ca. 10 over its previous units.) A ketene generation rate was established for each and, using the smaller reactor, a continuous feed of freshly generated, undiluted ketene was introduced to the hydrogenation reactor.

The catalyst deactivated rapidly with the freshly generated, undiluted ketene feed. However, this deactivation was readily reversible by simply cutting off the ketene feed (while maintaining the hydrogen feed) for a period of time. After reactivation, catalyst activity (measured by the older method of ketene introduction) was virtually the same as the original catalyst. The likely cause of this deactivation was carbon monoxide, which is an inevitable consequence of ketene generation. (Generally, 1-3\% of the feed to a ketene reactor is lost to the formation of CO.) In the earlier experiments, Eastman separated the ketene from the carbon monoxide co-product by condensation at dry ice temperatures and, therefore, this mode of deactivation was not operable.

This observation has several important ramifications. If the catalyst is to be used as it currently exists, the hydrogenation must be conducted either using two reactors (one is undergoing 
reactivation while the other is in use) or by utilizing a cryogenic separation of ketene. Neither is as desirable as identifying a CO-tolerant catalyst.

The advent of a CO-tolerant catalyst would simplify the process, but would also cut costs by allowing the use of less pure hydrogen (i.e., allow some carbon monoxide content). Eastman will be devoting significant efforts to identifying a CO-tolerant catalyst in the near future and has envisioned a host of candidates from classical homogeneous and heterogeneous catalysts with which the presence of $\mathrm{CO}$ might actually be advantageous. (A final alternative that will not be discussed in detail at this time is the use of a $\mathrm{CO}$ absorbing unit.)

In the interim, Eastman has designed and constructed a bench-scale unit that allows the continuous cryogenic separation of ketene from the $\mathrm{CO}$ impurity, as well as any other noncondensable gases. This unit, which is depicted in Figure 3.2.2, has been used to demonstrate hydrogenation at higher feed rates in the absence of significant diluents. The unit is fairly new, and its usefulness, while demonstrated, has not yet been completely exploited. As demonstrated by the comparison shown below, the unit has been used to successfully examine the hydrogenation of ketene in the absence of diluent gases; a comparison is made between undiluted feeds using the cryogenic separator and previous runs in the presence of copious quantities of diluent gas.

\section{Ketene Hydrogenation Experiments}

Hydrogenation with Undiluted Feed:

Conditions:

$0.633 \mathrm{mmol}$ ketene/minute

$2.0 \mathrm{mmol} \mathrm{H} /$ minute

$1.001 \mathrm{~g}(2.6 \mathrm{~mL}) 5 \% \mathrm{Pd} / \mathrm{C}$ catalyst

$98^{\circ} \mathrm{C}$

Results:

Space velocity $=1850 \mathrm{hr}^{-1}$

HAc space time yield $=495 \mathrm{~g}-\mathrm{L}^{-1}-\mathrm{hr}^{-1}$

Ketene conversion $=77 \%$

Ketene accountability $=100 \%$

HAc selectivity $=100 \%$

Hydrogenation with Diluted Feed Evaluated Previously:

Conditions:

$1.0 \mathrm{mmol} \mathrm{ketene} / \mathrm{minute}$

$2.0 \mathrm{mmol} \mathrm{H}_{2} /$ minute

$6.2 \mathrm{mmol} \mathrm{He}+\mathrm{N}_{2} /$ minute

$1.003 \mathrm{~g}(2.6 \mathrm{~mL}) 5 \% \mathrm{Pd} / \mathrm{C}$ catalyst

$98^{\circ} \mathrm{C}$

Space velocity $=6400 \mathrm{hr}^{-1}$ 
Results:

HAc space time yield $=610 \mathrm{~g}-\mathrm{L}^{-1}-\mathrm{hr}^{-1}$

Ketene conversion $=100 \%$

Ketene accountability $=60 \%$

HAc selectivity $=60 \%$

\section{Figure 3.2.2 Continuous Benchscale Cryogenic Separator for Ketene}

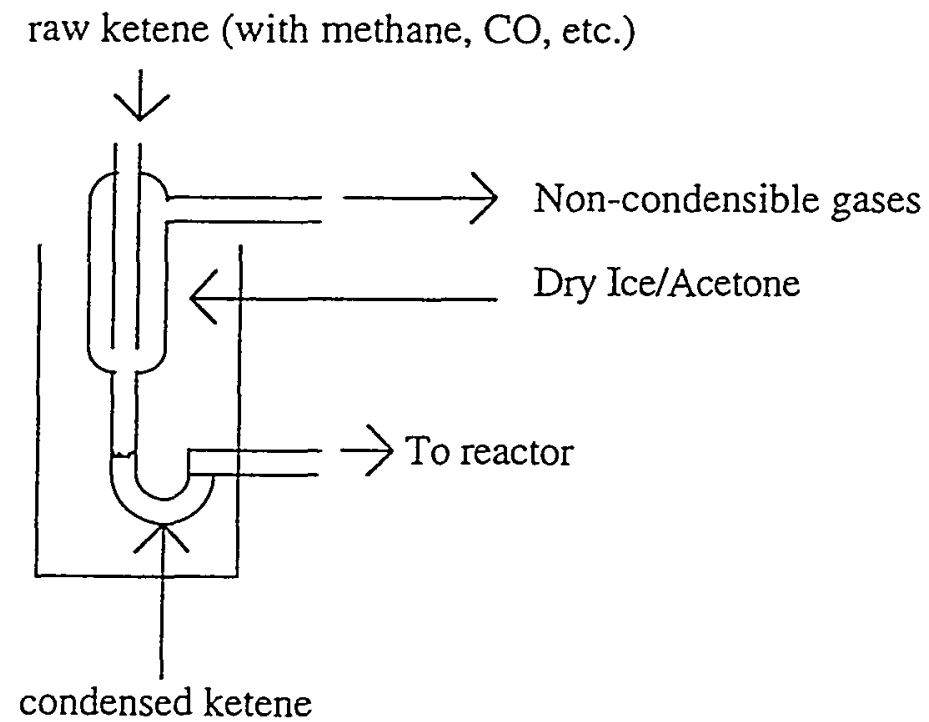

Task 2.1. Direct Conversion of Ketene and Acetaldehyde to VAM. Although methods existed for the conversion of acetaldehyde and syngas-derived acetic anhydride to VAM, Eastman perceived a potential advantage to using the ketene directly for the conversion of acetaldehyde to vinyl acetate. Traditionally, the conversion was carried out by mixing acetic anhydride and acetaldehyde and isolating the vinyl acetate from the equilibrium mixture (represented by the two equations shown below), even though the equilibria favored EDA formation.

$$
\begin{aligned}
& \mathrm{Ac}_{2} \mathrm{O}+\mathrm{AcH} \rightleftarrows \mathrm{EDA} \quad \mathrm{K}_{140^{\circ} \mathrm{C}}=25 \\
& \mathrm{EDA} \rightleftharpoons \mathrm{VAM}+\mathrm{AcOH} \quad \mathrm{K}_{140^{\circ} \mathrm{C}}=0.01
\end{aligned}
$$

Eastman envisioned this addition as a means to consume the $\mathrm{AcOH}$ in situ by reaction of ketene as follows:

$$
\mathrm{H}_{2} \mathrm{C}=\mathrm{C}=\mathrm{O}+\mathrm{AcOH} \longrightarrow \mathrm{Ac}_{2} \mathrm{O}
$$

At the operating temperatures of this reaction $\left(<140^{\circ} \mathrm{C}\right)$, the reaction would be essentially irreversible, and the process should be driven toward the generation of previously disfavored vinyl acetate by the continuous consumption of acetic acid. This process not only has the 
potential advantage of improving the efficiency of VAM formation, but would replace the acetic anhydride generation facility in earlier concepts with a simplified acetic acid process. (Purity requirements for ketene generation are much less strict than for other acetic acid applications.)

In the previous quarterly, Eastman reported the initial demonstration of this significant advance in VAM generation using a gas stripped reactor, such as the one diagrammed in Figure 3.2.3. Over the last quarter, Eastman examined a number of additional catalysts and conditions for this conversion using this gas stripped reactor. As can be seen from the results below, the optimal catalysts are aromatic sulfonic acids and the optimal solvent is acetic anhydride.

\section{Figure 3.2.3 Gas Stripped Reactor for Direct Conversion of Ketene and Acetaldehyde to Vinyl Acetate}

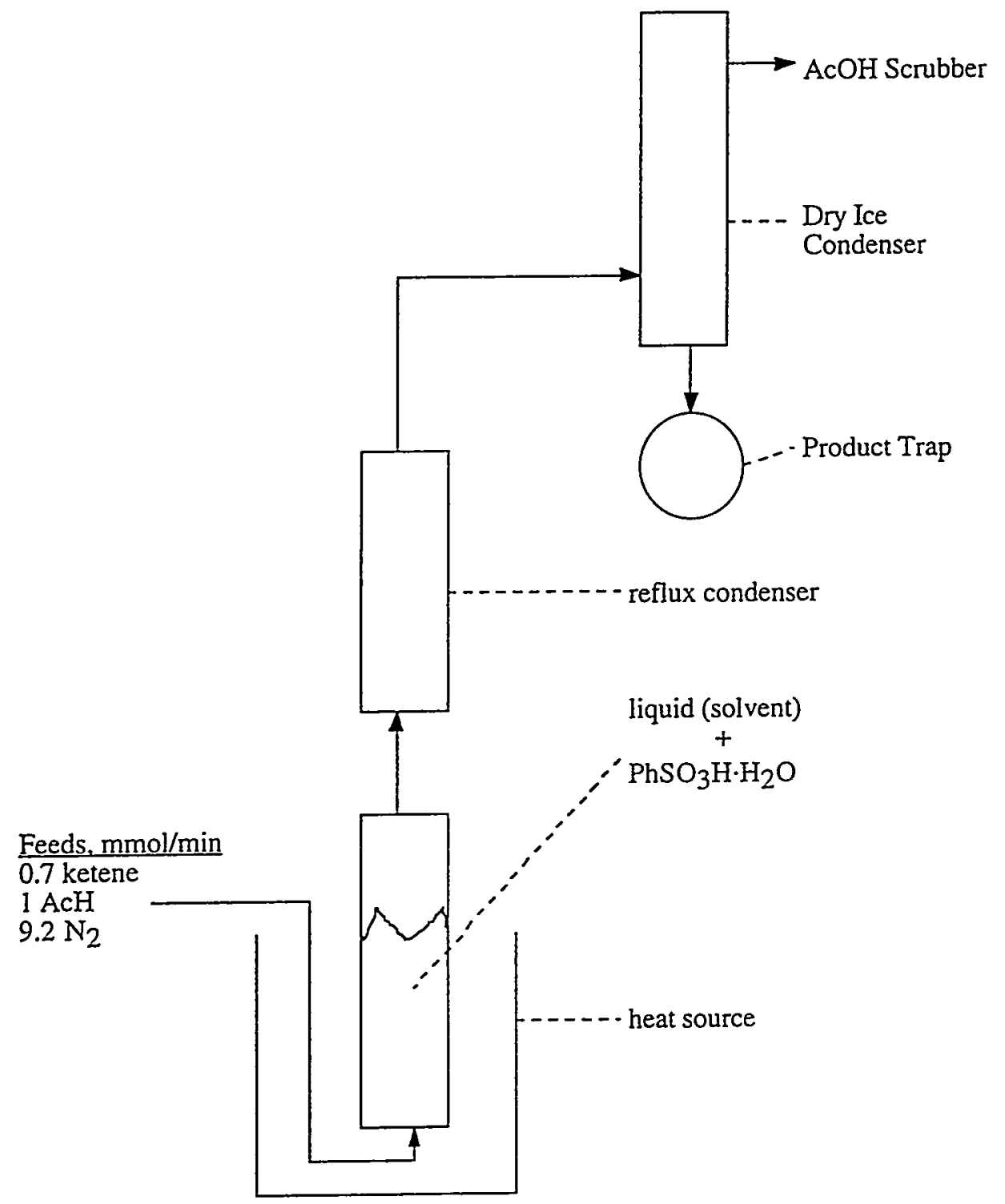




\section{Results for Task 2.1.}

A. Gas Stripped Reactor for The Production of VAM

1. Arene Sulfonic Acids

a) Acetic Anhydride as Solvent

Conditions:

$30.6 \mathrm{mmol}$ arenesulfonic acid. $\mathrm{H}_{2} \mathrm{O}$

$61.6 \mathrm{mmol}$ acetic acid

$583 \mathrm{mmol}$ acetic anhydride

$0.7 \mathrm{mmol}$ ketene/minute

$1.0 \mathrm{mmol}$ acetaldehyde/minute

$9.2 \mathrm{mmol} \mathrm{N}_{2} /$ minute

$150^{\circ} \mathrm{C}$

Run 5-6 hours per day for 1 to 4 days

1) Results with benzenesulfonic acid

VAM yield from ketene:

$$
\begin{aligned}
& 1 \text { st day }=50 \% \\
& \text { 2nd day }=90 \% \\
& \text { 3rd day }=92 \% \\
& 4 \text { th day }=78 \%
\end{aligned}
$$

Accountability for the whole run:

$$
\begin{aligned}
& \text { ketene }=107 \% \\
& \text { acetaldehyde }=106 \%
\end{aligned}
$$

2) Results with p-toluenesulfonic acid

VAM yield from ketene:

1 st day $=41 \%$

2nd day $=86 \%$

3 rd day $=95 \%$

4 th day $=87 \%$

Accountability for the whole run:

ketene $=119 \%$

acetaldehyde $=114 \%$

NMR of trap material of 4th day:

$60.9 \%$ VAM

$36.7 \%$ acetaldehyde

$2.4 \%$ acetic anhydride,

no acetic acid or any other species

Can account for the components of $80.1 \mathrm{~g}$ of the $80.6 \mathrm{~g}$ heel (diff. $0.5 \mathrm{~g}$ ).

Heel contained 35.7 wt \% EDA. 
b) Using NMP as Solvent (with p-toluenesulfonic acid)

Conditions:

$638 \mathrm{mmol} \mathrm{NMP,}$

$30.6 \mathrm{mmol}$ p-toluenesulfonic acid

$0.7 \mathrm{mmol}$ ketene/minute

$1.0 \mathrm{mmol}$ acetaldehyde/minute

$9.2 \mathrm{mmol} \mathrm{N}_{2} /$ minute

$150^{\circ} \mathrm{C}$

Run 5-6 hours per day for 1 to 5 days

VAM yield from ketene:

1 st day $=59 \%$

2nd day $=76 \%$

3rd day $=77 \%$

4th day $=71 \%$

5 th day $=68 \%$

Accountability for the whole run:

ketene $=103 \%$

acetaldehyde $=90 \%$.

Can account for $75.5 \mathrm{~g}$ of the $80.8 \mathrm{~g}$ heel (diff $5.3 \mathrm{~g}$ ).

Heel contained 1 wt \% EDA.

c) Using NMP/Ac $c_{2} O$ as Solvent (with p-toluenesulfonic acid)

Conditions:

$436 \mathrm{~mol} \mathrm{NMP}$

$254 \mathrm{mmol} \mathrm{Ac}_{2} \mathrm{O}$

$30.6 \mathrm{mmol}$-toluenesulfonic acid

$0.7 \mathrm{mmol}$ ketene/minute

$1.0 \mathrm{mmol}$ acetaldehyde/minute

$9.2 \mathrm{mmol} \mathrm{N}_{2} /$ minute

$150^{\circ} \mathrm{C}$

Run 5-6 hours per day for 1 to 5 days

VAM yield from ketene:

1 st day $=59 \%$

2nd day $=90 \%$

3 rd day $=88 \%$

Accountability for the whole run:

ketene $=105 \%$

acetaldehyde $=105 \%$ 
Can account for $81.9 \mathrm{~g}$ of the $85.3 \mathrm{~g}$ heel (diff. $3.4 \mathrm{~g}$ ).

Heel contained 8.3 wt \% EDA.

2. Other Catalyst Systems (with gas stripped operation):

All use the following conditions:

$30.6 \mathrm{mmol}$ acid catalyst

$61.6 \mathrm{mmol}$ acetic acid

$583 \mathrm{mmol}$ acetic anhydride

$0.7 \mathrm{mmol} \mathrm{ketene/minute}$

$1.0 \mathrm{mmol}$ acetaldehyde/minute

$9.2 \mathrm{mmol} \mathrm{N}_{2} /$ minute

$150^{\circ} \mathrm{C}$

Run 5-6 hours per day for 1 to 5 days

a) Sulfuric acid catalyst (I day):

VAM yield from ketene $=41 \%$

Extensive coking, reactor plugged.

b) Phosphoric acid catalyst ( 2 days):

Best VAM yield from ketene $=30 \%$

Extensive coking, reactor plugged.

c) Methanesulfonic acid catalyst ( 3 days):

Best VAM yield from ketene $=32 \%$

Low tar, low activity.

d) Boric acid catalyst (1 day):

VAM yield from ketene $=2 \%$

Low activity, but heel contained 18 wt \% EDA.

e) Zeolite HY catalyst (calcined, 15.7g, no HOAc used, I day):

VAM yield from ketene $=4 \%$

Low activity.

B. Plugged Flow Reactor with Reflux and Heterogeneous Catalyst

Conditions:

Catalyst $=17 \mathrm{ml}(10.26 \mathrm{~g})$ Amberlyst 15 (ca. $\left.30.6 \mathrm{meq}-\mathrm{SO}_{3} \mathrm{H}\right)$, diluted with $15 \mathrm{ml} 16 \times 24$ mesh quartz chips.

$0.7 \mathrm{mmol} \mathrm{ketene/minute}$

$1.0 \mathrm{mmol}$ acetaldehyde/minute

$9.2 \mathrm{mmol} \mathrm{N}_{2} /$ minute

$98^{\circ} \mathrm{C}$ (steam-heated reactor)

Run 5-6 hours per day for 5 days 


\section{Results:}

VAM yield from ketene:

$$
\begin{aligned}
& 1 \text { st day }=10 \% \\
& 2 \text { nd day }=44 \% \\
& 3 \text { rd day }=37 \% \\
& 4 \text { th day }=34 \% \\
& \text { 5th day }=31 \%
\end{aligned}
$$

Accountability for the whole run:

ketene $=111 \%$

acetaldehyde $=78 \%$

Recovered from non-volatiles trap:

$8.1 \mathrm{~g}$ containing

39.9 wt \% EDA,

$2.0 \mathrm{wt} \% \mathrm{Ac}_{2} \mathrm{O}$,

1.2 wt $\%$ HOAc

3.5 wt $\%$ HAc.

Eastman will continue to optimize this process using the gas-stripped reactor, but has also begun to examine alternative reactor designs under scaled-up conditions. To date, Eastman has only tested several polymeric sulfonic acid resins in a heterogeneous variation using this unit. These catalysts were inferior to the soluble arylsulfonic acids since the arylsulfonic acid resins were unable to tolerate the reaction conditions without significant degradation. Eastman will continue to examine alternative reactor designs over the next quarter using this scaled-up reactor.

Task 3.1.a. Preliminary Economics for a Ketene Based Process. Having identified operable processes at the bench scale for both the hydrogenation of ketene and the direct esterification of acetaldehyde with ketene, Eastman now has sufficient information to undertake preliminary economic estimates for the overall process. The conceptual flowsheet is in place. Eastman already has estimates for an appropriately sized acetic acid plant and ketene furnace, although the models will require some updating. Further, designs for the conversion of acetaldehyde and ketene to VAM are well underway. Preliminary estimates will not account for the available synergies between the components of the facility and will purposely be conservative.

Task 3.2. Assessment of Reductive Carbonylation. Eastman has also begun to look at what information will be needed for a direct comparison of ketene hydrogenation vs. reductive carbonylation of methanol as a source of acetaldehyde and has concluded that the literature does not contain all the pertinent information, particularly with respect to kinetics and gas pressures, required for an adequate economic estimate. Given that the hydrogenation of ketene may require an expensive cryogenic separation and that Eastman can already eliminate the acetic recycle loops through the direct esterification of acetaldehyde with ketene, this may be a critical point in discovering the best possible process. Therefore, Eastman is proposing to undertake some related investigations into the reductive carbonylation of methanol to clarify the key variables 
and examine some potentially new technologies before undertaking this estimate. (This is consistent with the original proposal.)

\section{Future Directions}

Task 1.I. Hydrogenation of Ketene. Over the next quarter Eastman will be:

a) pursuing a detailed study of the Pd catalysts.

b) examining potential CO-tolerant catalysts, including homogeneous catalysts and reactor designs for this hydrogenation.

Task 2.1. Conversion of Acetaldehyde and Ketene to VAM. Over the next quarter, Eastman expects to continue its investigation of gas-stripped reactors and examine alternative designs for conducting these reactions.

Task 3.1.a. Preliminary Economics. Eastman expects to have a preliminary estimate completed by the end of the next quarter.

Task 3.2. Economic Comparison to Reductive Carbonylation. As discussed above, the technology descriptions given in the prior art are insufficiently detailed for an estimate, and Eastman has some new concepts that may make this the preferred acetaldehyde source. Therefore, Eastman will dedicate some of its effort to measuring the key variables in the best processes from the prior art and testing some novel concepts for the reductive carbonylation of methanol to acetaldehyde.

\section{Summary}

Over the last quarter, Eastman has extended its knowledge related to the hydrogenation of ketene to acetaldehyde and has identified a key knowledge gap related to poisoning by carbon monoxide. Eastman has also begun the long process of optimizing the direct esterification of acetaldehyde with ketene to produce VAM. These form a very simple overall process for the generation of VAM. Eastman will further optimize these processes over the next several months and will be generating initial cost estimates for the production of VAM from syngas by this method. This now provides two alternative methods of consuming acetic acid in the production of VAM and eliminates the large recycle loops.

\section{Task 3.3 New Processes for Alcohols and Oxygenated Fuel Additives}

\subsubsection{Isobutanol Synthesis in a Three Phase System--Institute for Technical Chemistry and Petroleum Chemistry (RWTH Aachen-Germany)}

\section{Catalyst Preparation}

A first goal to improve the $\mathrm{Zr} / \mathrm{Zn} / \mathrm{Mn}$ system has been to determine the influence of different synthesis methods. Coprecipitation, complexation and sol-gel methods were chosen for this purpose. In the last quarter, the focus was primarily on complexation catalysts. In this quarter, we concentrated on sol-gel methods. In addition the influence of alkali promoters was evaluated. Furthermore new catalyst systems have been tested and will be reported here. Future work 
includes determination of the optimum composition and the role of additional transition and rare earth metal promoters.

\section{Sol-Gel Catalysts}

One of the methods chosen to determine the influence of preparation is sol-gel synthesis. This method involves the formation of an oxide network via zirconium alkoxides into which the other components are incorporated. In previous quarterly reports (July-Sept., Oct.-Dec. 1995) the influence of modifying agents and acids on gel formation was reported. In this report, surface characteristics and catalysis behavior are presented.

In Table 3.3.1 the BET surface areas and pore size diameters of differently prepared gels are shown. It can be seen that a supercritical drying step seems to be necessary for the development of a large surface area. A normal air drying procedure (NL72) leads to a small surface area. The use of acetic acid, which can alter gel formation by complexing to the zirconium metal or by changing $\mathrm{pH}$, leads to a maximum surface area. Changing the anions of the simultaneously added zinc and manganese salts has only a slight influence on pore size and surface area. Nitric acid and acetylacetone modification leads to broader pore size distributions and smaller surface areas. From these data it can be concluded that this method provides a way to generate catalysts with specifically defined surface areas and pore size distributions over a large range.

XRD data showed that supercritical extraction leads in part to the development of crystalline zinc oxide species. Zirconium and manganese oxide seem not be affected by this treatment, showing only poor crystallization. The effect of this phenomenon on catalyst stability is currently being investigated.

Table 3.3.1 Effect on Pore Size and Surface Area by Variation of Sol-Gel Parameters

\begin{tabular}{|c|c|c|c|c|}
\hline & Metal Salt & Modifying Agen & $\begin{array}{l}{ }^{b} \text { Surface Areac } \\
\text { in [m2.g-1] }\end{array}$ & $\begin{array}{l}\text { Mean Pore Size } \\
\text { in }[\AA]\end{array}$ \\
\hline $\mathrm{NL72}^{2}$ & nitrate & HOAc & 17 & $40(35-45)$ \\
\hline NL73 & nitrate & HOAC & 113 & $55(30-80)$ \\
\hline NL82 & acetate & HOAC & 122 & $40(30-50)$ \\
\hline NL84 & nitrate & HNO3 & 80 & $90(50-130)$ \\
\hline NL90 & nitrate & HNO3 / acac & 41 & $210(50-330)$ \\
\hline
\end{tabular}

a Air dried instead of supercritically dried.

b HOAc: acetic acid; HNO3: nitric acid; acac: acetylacetone.

c Measured after calcination in air at $400^{\circ} \mathrm{C}$.

$\mathrm{d}$ Range is given in parentheses

The unpromoted sol gel materials were tested in a syngas reaction. Table 3.3.2 shows the catalysis results. The air-dried catalyst (NL72) showed only poor activity and high methane production In contrast, the acetic acid-modified gels showed the highest activity (NL73) and selectivity(NL82) towards isobutanol, with concomitant low methane production. Again the importance of the supercritical drying step becomes evident. Acetylacetone modification led to 
decreased activity. In general it can be concluded that a large surface area leads to higher productivity, as expected

Table 3.3.2 Catalysis Behavior on Variation Sol Gel Parameters ${ }^{\mathrm{a}}$

\begin{tabular}{|c|c|c|c|c|c|}
\hline Cat. $\mathrm{Zr} / \mathrm{Zn} / \mathrm{Mn}-$ & NL72 & NL73 & NL82 & NL84 & NL90 \\
\hline $\mathrm{STY}^{\mathrm{b}} \mathrm{MeOH}$ & 134 & 968 & 574 & 601 & 544 \\
\hline STY iBuOH & 23 & 135 & 159 & 143 & 102 \\
\hline STYAlcohols (Rest) & 13 & 22 & 32 & 27 & 18 \\
\hline STY Methane & 890 & 27 & 67 & 127 & 123 \\
\hline STYAlcohols & 160 & 1125 & 765 & 771 & 664 \\
\hline STY Total Liquid & 223 & 1371 & 990 & 989 & 817 \\
\hline Selectivity $\mathrm{CO}_{2}$ & 49 & 35 & 42 & 40 & 40 \\
\hline Conversion $\mathrm{CO}$ & 55 & 24 & 26 & 25 & 23 \\
\hline
\end{tabular}

a GHSV: $20000 \mathrm{~h}-1 ; \mathrm{T}: 450^{\circ} \mathrm{C} ; \mathrm{p}: 250 \mathrm{bar} ; \mathrm{CO} / \mathrm{H}_{2}: 1: 1$; particle size: $0.25-0.50 \mathrm{~mm}$.

$\mathrm{b}$ in [g.kg-1 (cat).h-1]

Alkali promotion has been shown to be an important factor in increasing higher alcohol production. Therefore the effect of potassium and cesium on sol-gel catalysts was examined. In contrast to the $\mathrm{Cu} / \mathrm{Zn}$ oxide system, Table 3.3.2 shows that unpromoted $\mathrm{Zr} / \mathrm{Zn} / \mathrm{Mn}$ oxide catalysts are still able to produce fair amounts of isobutanol. Therefore, the question is whether alkali promotion can bring about a large selectivity shift for these systems as well.

A nitric acid-modified catalyst was chosen for this promoter study, having threshold surface area and pore size distribution values. Promotion was done by impregnation with the necessary amount of alkali acetates, followed by calcination. Catalysis results are displayed in Figures 3.3.1 and 3.3.2. 
Figure 3.3.1 Influence of Potassium Promotion on Catalyst Behavior

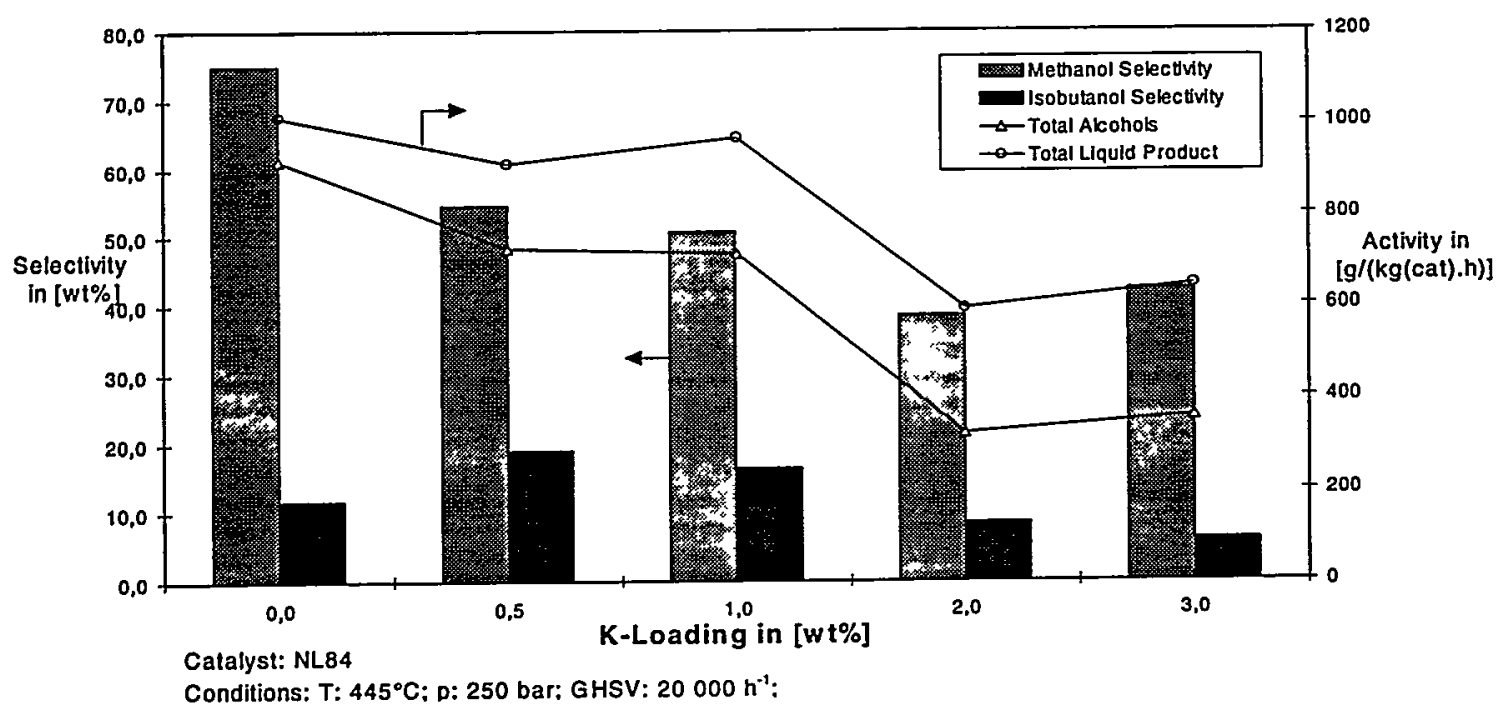

Increasing potassium impregnation leads to a gradual activation decrease. This is probably caused by increased coverage of active sites in combination with a decrease in surface area.

A distinct maximum in isobutanol selectivity and activity is observed at a potassium promotion of $0.5 \mathrm{wt} . \%$.

Figure 3.3.2 Influence of Cesium Promotion on Catalyst Behavior

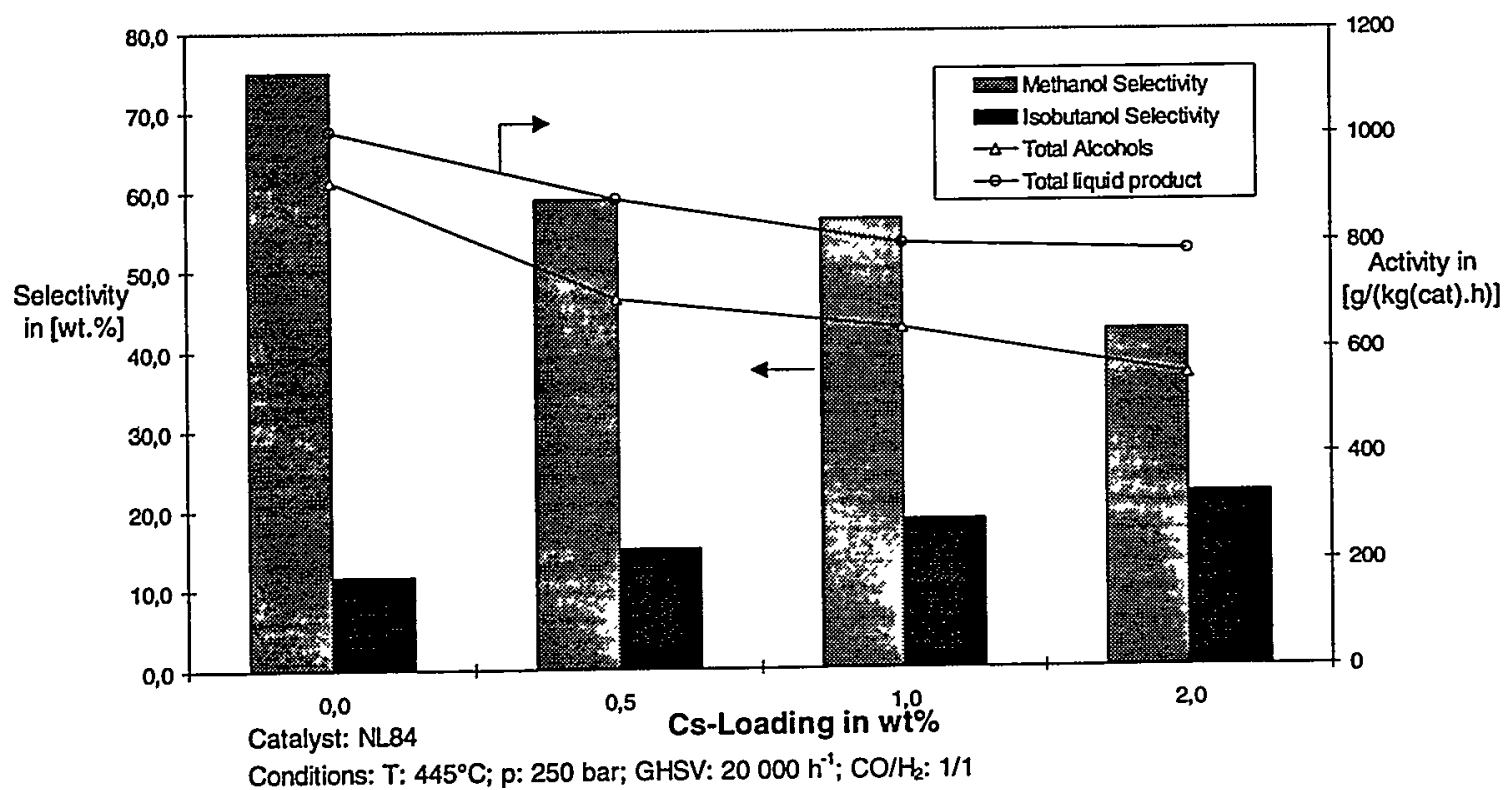

Cesium promotion shows a different dependence in comparison with potassium promotion. A decrease in activity is also observed, but it is not so drastic as observed for potassium. In contrast, there is no clear maximum in isobutanol selectivity. Increased promotion leads to 
higher selectivity for isobutanol. Future work will address this behavior, testing higher cesium loadings and catalyst stability.

\section{Potassium-Promoted $\mathrm{ZrO} 2 / \mathrm{ZnO} / \mathrm{Cu} 2 \mathrm{O}$ Catalysts}

Due to the need to develop catalysts that are active at lower temperatures, potassium-promoted $\mathrm{ZrO} 2 / \mathrm{ZnO} / \mathrm{Cu} 2 \mathrm{O}$ catalysts were prepared. These catalysts can easily be synthesized by supercritical extraction from solutions of metal nitrates in solvents with low critical temperatures. The following catalysts were prepared and tested under standard conditions (GHSV $=20000$ $\mathrm{h}-1, \mathrm{p}=25 \mathrm{MPa}, \mathrm{T}=400^{\circ} \mathrm{C}$, Dcat $=0.25-0.50 \mathrm{~mm}, \mathrm{Vcat}=2.5 \mathrm{ml}$ ):

BJ 27: Coprecipitated $\mathrm{ZrO} 2 / \mathrm{ZnO} / \mathrm{MnO} / \mathrm{K}$ - Catalyst sent to Air Products

BJ 45: "Supercritical" $\mathrm{ZrO} 2 / \mathrm{ZnO} / \mathrm{MnO}$ - Catalyst with $1.0 \mathrm{wt} \% \mathrm{~K}$

BJ 47: "Supercritical" $\mathrm{ZrO} 2 / \mathrm{ZnO} / \mathrm{Cu} 2 \mathrm{O}$ - Catalyst with $1.0 \mathrm{wt} \% \mathrm{~K}$

$(\mathrm{Zr}: \mathrm{Zn}: \mathrm{Cu}=1: 3: 1)$

BJ 49: "Supercritical" $\mathrm{ZrO} 2 / \mathrm{ZnO} / \mathrm{Cu} 2 \mathrm{O}$ - Catalyst with $1.5 \mathrm{wt} \% \mathrm{~K}$

$(\mathrm{Zr}: \mathrm{Zn}: \mathrm{Cu}=1: 3: 1)$

BJ 50: "Supercritical" $\mathrm{ZrO} 2 / \mathrm{ZnO} / \mathrm{Cu} 2 \mathrm{O}$ - Catalyst with $1.0 \mathrm{wt} \% \mathrm{~K}$

$$
(\mathrm{Zr}: \mathrm{Zn}: \mathrm{Cu}=1: 1: 3)
$$

As shown in Figures 3.3.3 and 3.3.4, the potassium promoted $\mathrm{ZrO} 2 / \mathrm{ZnO} / \mathrm{Cu} 2 \mathrm{O}$ catalysts are higher in selectivity and activity to isobutanol and methanol than the comparable $\mathrm{ZrO} 2 / \mathrm{ZnO} / \mathrm{MnO}$ catalysts when run at $400^{\circ} \mathrm{C}$.

Figure 3.3.3 Space Time Yields to Isobutanol with Different Catalysts at $400^{\circ} \mathrm{C}$

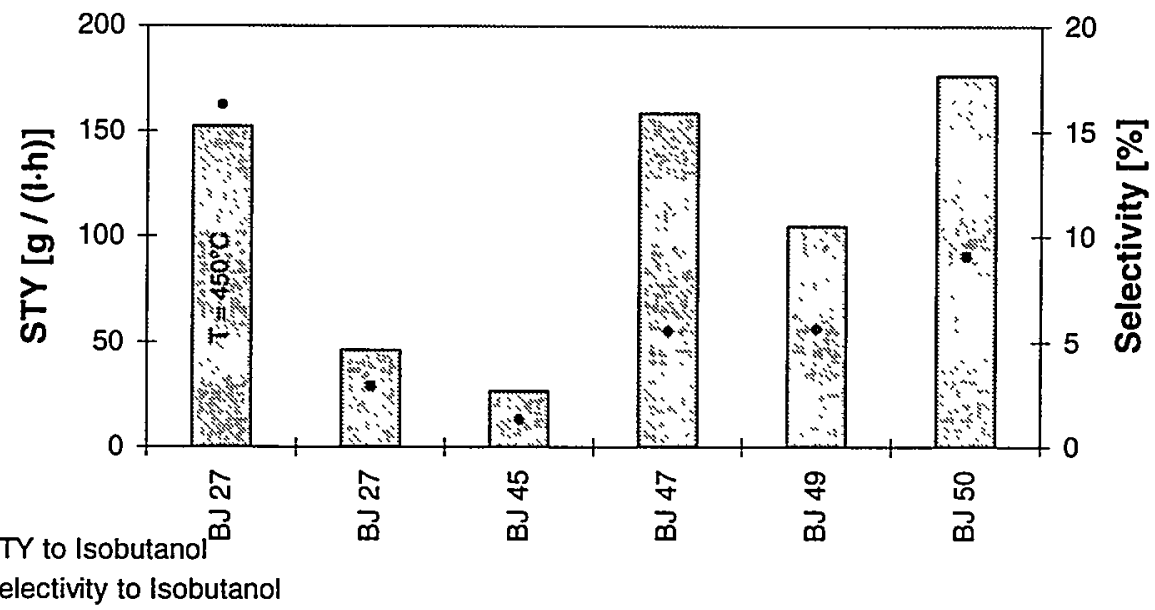


Figure 3.3.4 Space Time Yields to Methanol with Different Catalysts at $400^{\circ} \mathrm{C}$

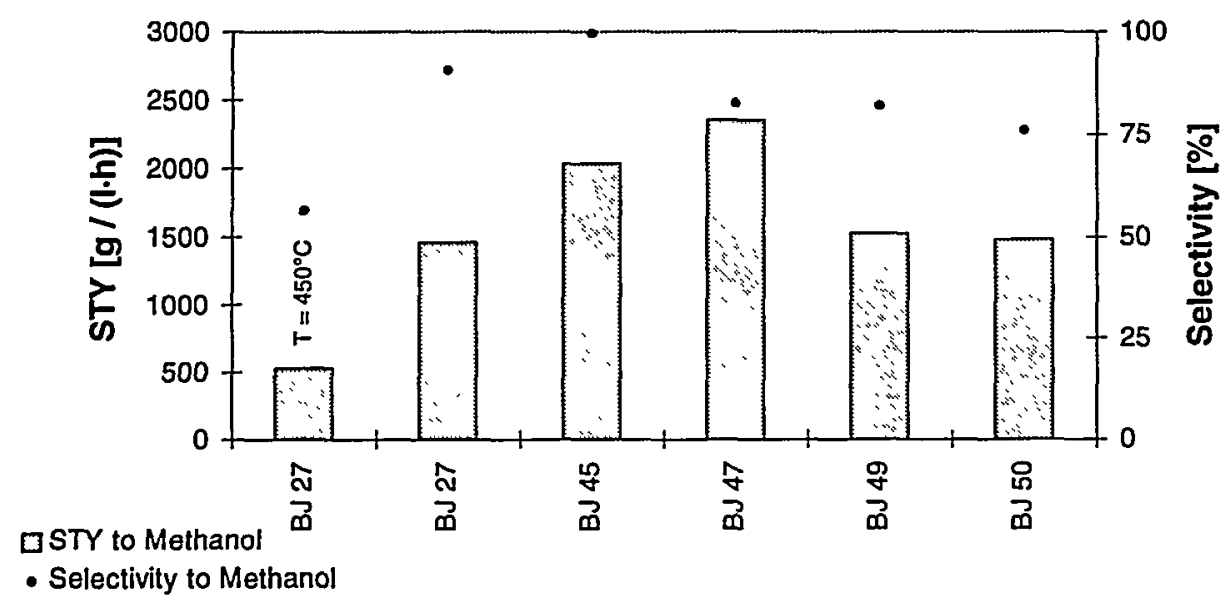

To date, only a first screening could be performed with this new type of catalyst. Further tests with different compositions are under way. The optimized catalyst will then be used for more precise investigations varying temperature, pressure and linear velocity.

\section{Fixed Bed Reactor Runs}

A fixed bed reactor study with the potassium-promoted $\mathrm{ZrO} / \mathrm{ZnO} / \mathrm{MnO}$ catalyst was performed with different particle sizes and linear velocities. These tests provided data to study the behavior of residence time and temperature on reaction products. Furthermore, mass transfer limitations that affect activity and selectivity can be determined.

For this purpose, after calcination, the catalyst was powdered, pressed and sieved to sizes of $0.25-0.50 \mathrm{~mm}$ and $1.60-2.0 \mathrm{~mm}$. Catalyst activations and reactions were carried out in a fixedbed reactor of stainless steel with an inner diameter of $9 \mathrm{~mm}$. Catalyst particles were mixed with an equal amount of copper particles of the same size. Quartz particles were added on top as a preheating zone.

The catalyst was activated in situ by pressurizing with hydrogen ( $30 \mathrm{Nl} \cdot \mathrm{h}-1,3 \mathrm{MPa})$ and heated to $225^{\circ} \mathrm{C}$ at a rate of $4 \% \mathrm{~min}$, keeping this temperature constant for $120 \mathrm{~min}$. Subsequently, the reactor was pressurized with $\mathrm{H}_{2} / \mathrm{CO}(1 /: 1)$ to $25 \mathrm{MPa}$ while temperature was increased to reaction conditions at $4 \% \mathrm{~min}$.

All reactions were conducted at $25 \mathrm{MPa}$, varying temperature from 430 to $370^{\circ} \mathrm{C}$ in steps of $30^{\circ}$. Afterwards the measurements at $430^{\circ} \mathrm{C}$ were repeated to test reproducibility. At each temperature, linear gas velocity was changed in six steps from 24 to $227 \mathrm{Nl} \cdot \mathrm{h}-1$. All setpoints were allowed to come to steady state for $75 \mathrm{~min}$. Then the first on-line measurement was started, followed by the collection of one off-line sample. A second on-line measurement 75 minutes later ended each analysis.

With this procedure, four test runs were performed, changing bed volume from 2 to $4 \mathrm{ml}$ of catalyst and particle sizes from $0.25-0.50$ to $1.60-2.00 \mathrm{~mm}$. 
The fixed-bed reactor study showed that the CO conversion towards alcohols demonstrates a clear dependence upon particle size. All measurements show that activity increases with decreasing particle size, which can be interpreted as mass transfer limitation by pore diffusion.

As presented in Figure 3.3.5, CO conversion to isobutanol shows this behavior in a typical way. Activity increases with increasing temperature following Arrhenius' law. The smaller particle sizes show higher conversions than the larger ones, which is an effect of mass transfer limitation. The difference in activity between the two particle sizes grows with temperature due to temperature dependence, which is smaller for mass transfer than for chemical reaction kinetics.

\section{Figure 3.3.5 Effect of Particle Size on CO Conversion to Isobutanol (VCat $=4 \mathrm{ml}$ )}

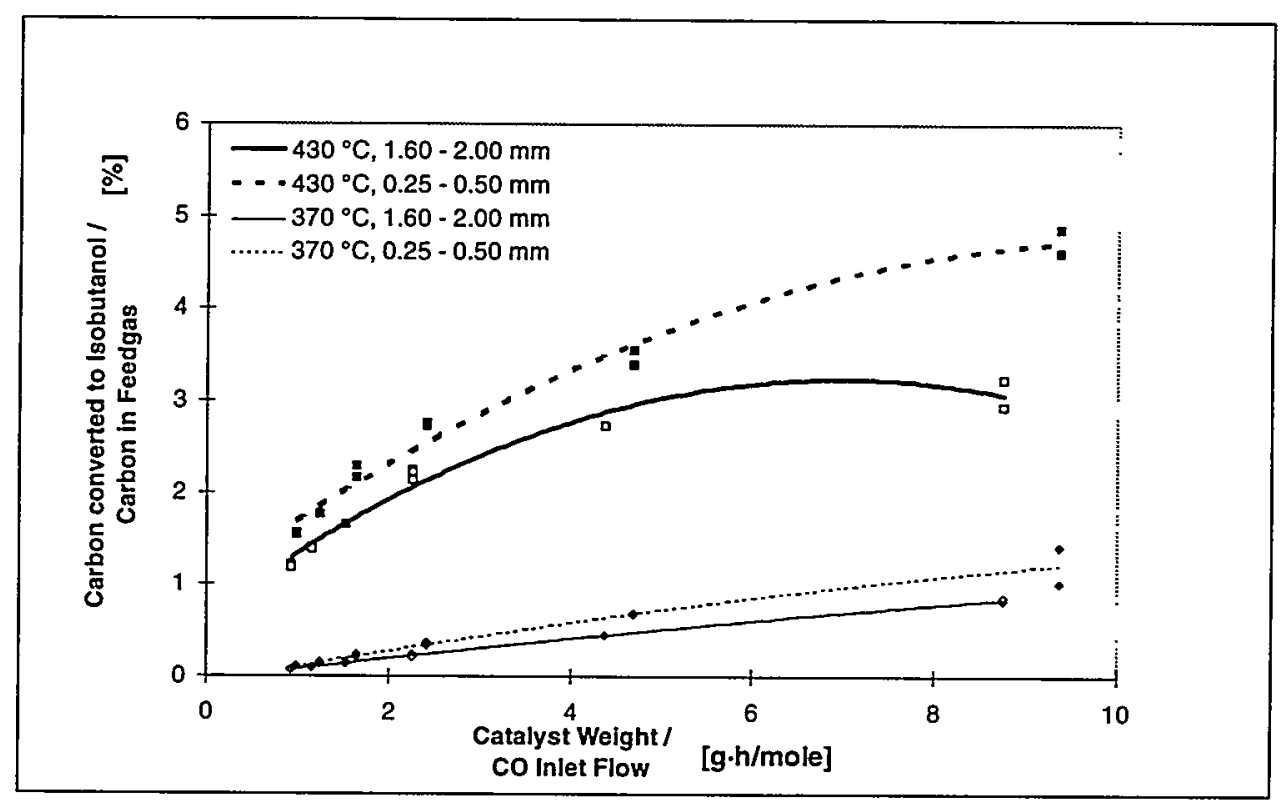

The opposite behavior can be observed for CO conversion to methanol (Figure 3.3.6). The activity decreases with temperature, which can be explained by an approach to chemical equilibrium. At higher temperatures the values are close to equilibrium, and no dependence on residence time can be seen. The measurement at $370^{\circ} \mathrm{C}$ shows the characteristics discussed above, reaching a steady state value at long residence times in the catalyst bed. 
Figure 3.3.6 Effect of Particle Size on CO Conversion to Methanol (VCat $=4 \mathrm{ml})$

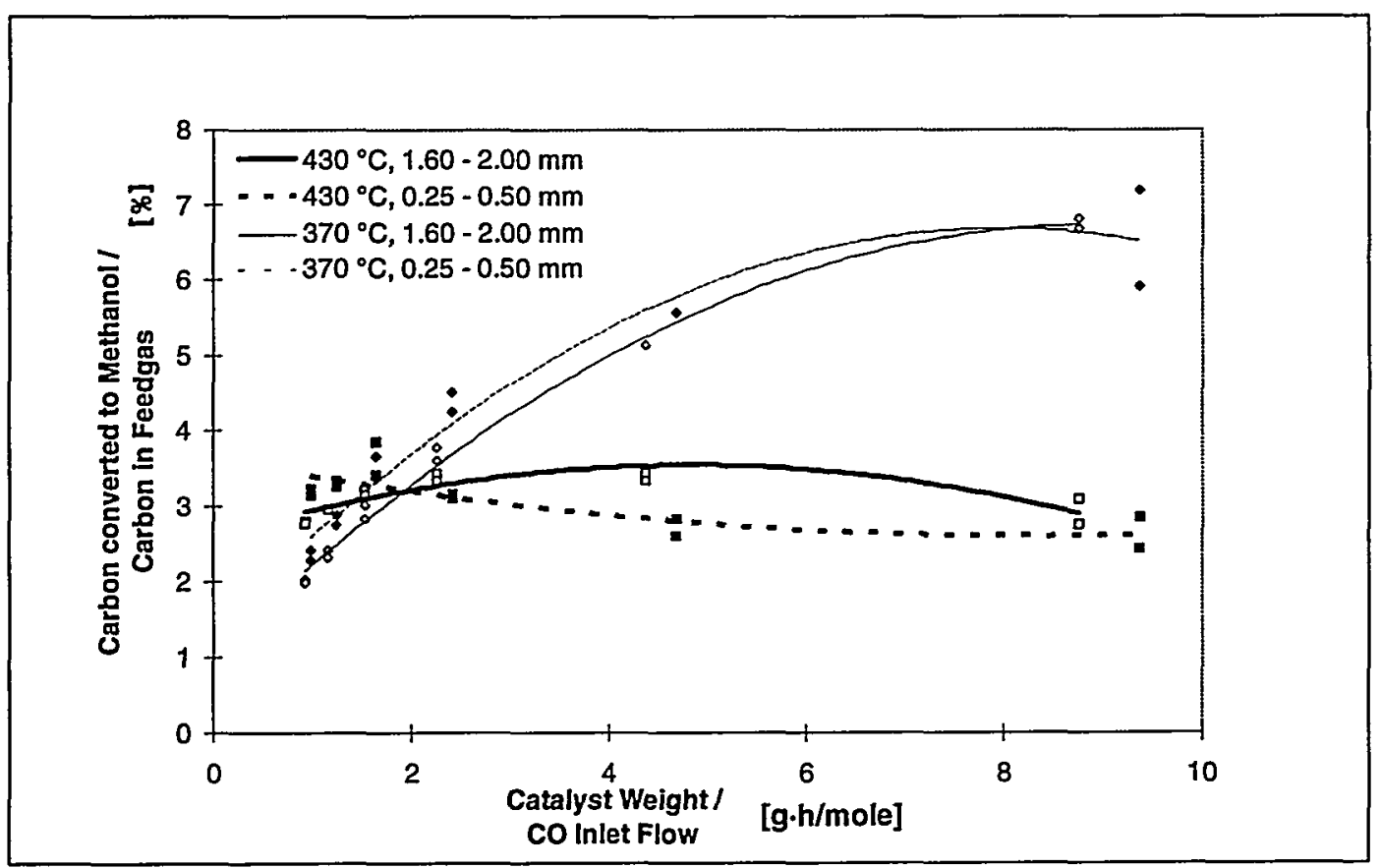

Film diffusion might be an additional limiting step in heterogeneously catalyzed reactions. The influence of film diffusion increases with temperature in the same way as porous diffusion and decreases with linear velocity by reducing laminar films covering the catalyst pellets. Film diffusion was tested for by varying the bed length. Figure 3.3.7 demonstrates that film diffusion has no influence on $\mathrm{CO}$ conversion to isobutanol at $370^{\circ} \mathrm{C}$ and only a little effect at $430^{\circ} \mathrm{C}$. 


\section{Figure 3.3.7 Influence of Catalyst Bed Length on CO Conversion to Isobutanol (Particle Size: $1.60-2.00 \mathrm{~mm}$ )}

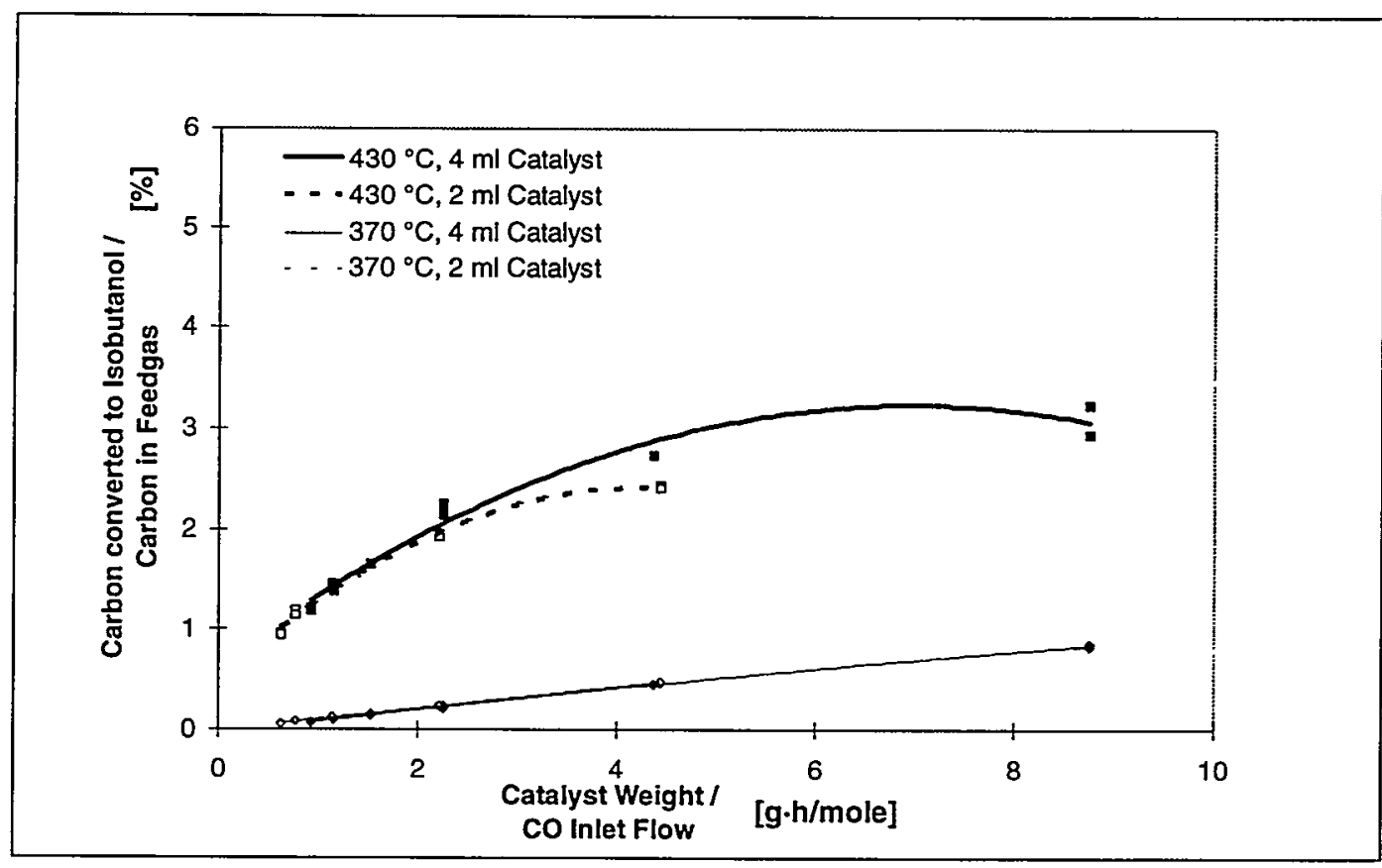

The most accepted reaction network for higher alcohol synthesis describes the mechanistic differences between the reaction paths to methanol and isobutanol. The first step in higher alcohol synthesis is hydrogenation of $\mathrm{CO}$ to a surface intermediate that is very similar to methanol. Linear primary alcohols are built by linear chain growth, including $\mathrm{CO}$ insertion steps. Isobutanol and 2-methylbutanol-1 originate from $\beta$-addition, including aldolic condensation. Formation of 1-propanol can be reached via both pathways (Scheme 1).

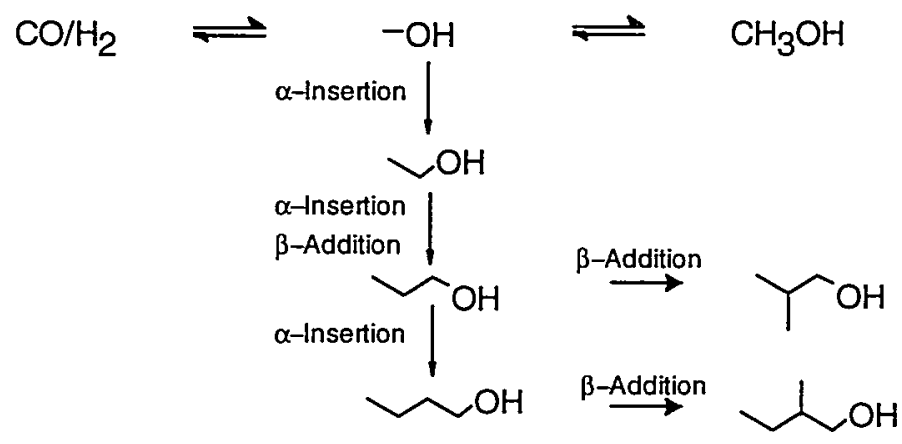

\section{Scheme 1 - Reaction Network for Alcohol Synthesis from $\mathrm{CO} / \mathrm{H}_{2}$}

Isobutanol and 2-methylbutanol-1 do not undergo consecutive reactions following this network. They cannot react further in aldolic condensations, and the probability of linear chain growth is low. On the other hand, the linear alcohols are able to undergo linear chain growth as well as $\beta$ addition. 
The CO conversions to the aforementioned alcohols ethanol, 1-propanol and 2-methylbutanol-1 are plotted in Figures 3.3.8, 3.3.9 and 3.3.10, respectively. The branched alcohol 2methylbutanol-1 shows similarities to the conversion to isobutanol, with an increasing activity with temperature (Figure 3.3.8).

Figure 3.3.8 CO Conversion to 2-Methylbutanol-1 (vCat $=4 \mathrm{ml}$, Particle Size: 0.25-0.50 mm)

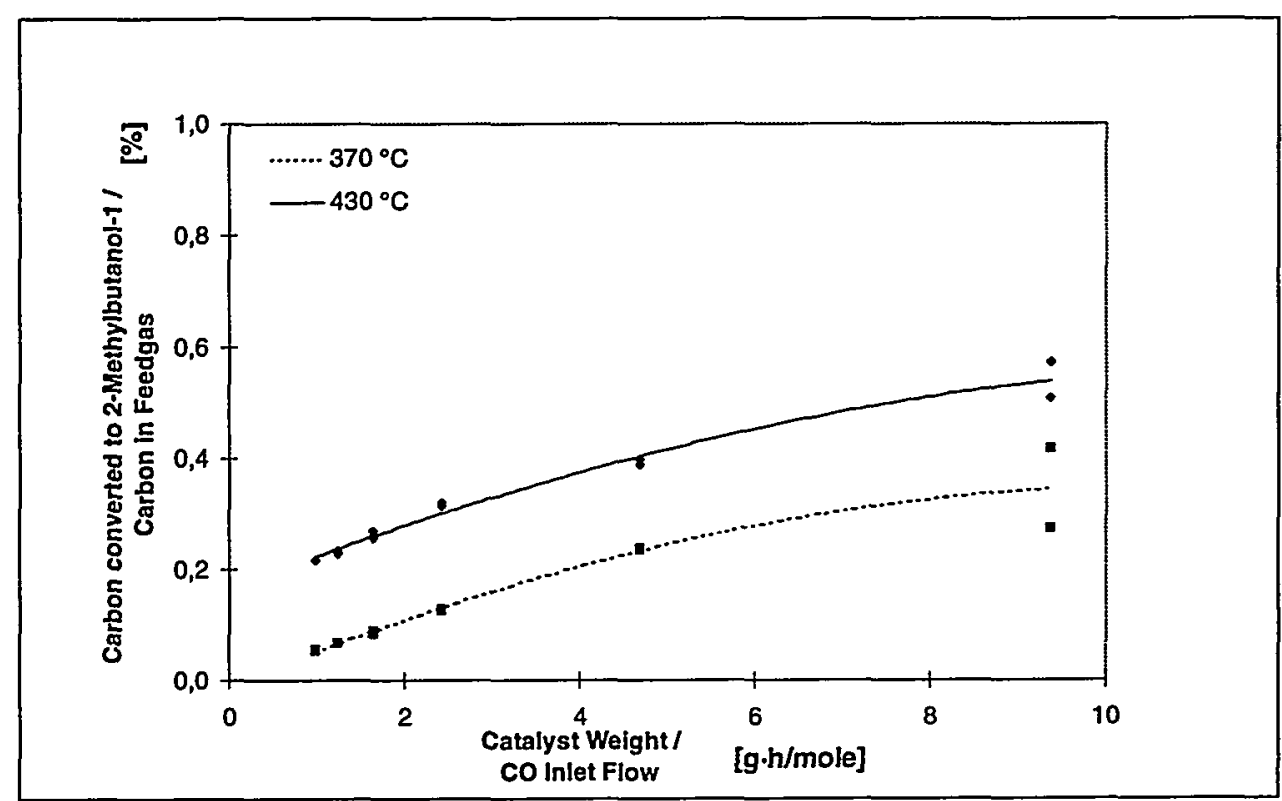

The conversions to ethanol (Figure 3.3.9) and 1-propanol (Figure 3.3.10) show behavior similar to that described for methanol. They exhibit a lower activity at higher temperature and seem to be independent of linear gas velocity at $430^{\circ} \mathrm{C}$. 
Figure 3.3.9 CO Conversion to Ethanol (VCat $=4 \mathrm{ml}$, Particle Size: $\mathbf{0 . 2 5 - 0 . 5 0 ~ m m}$ )

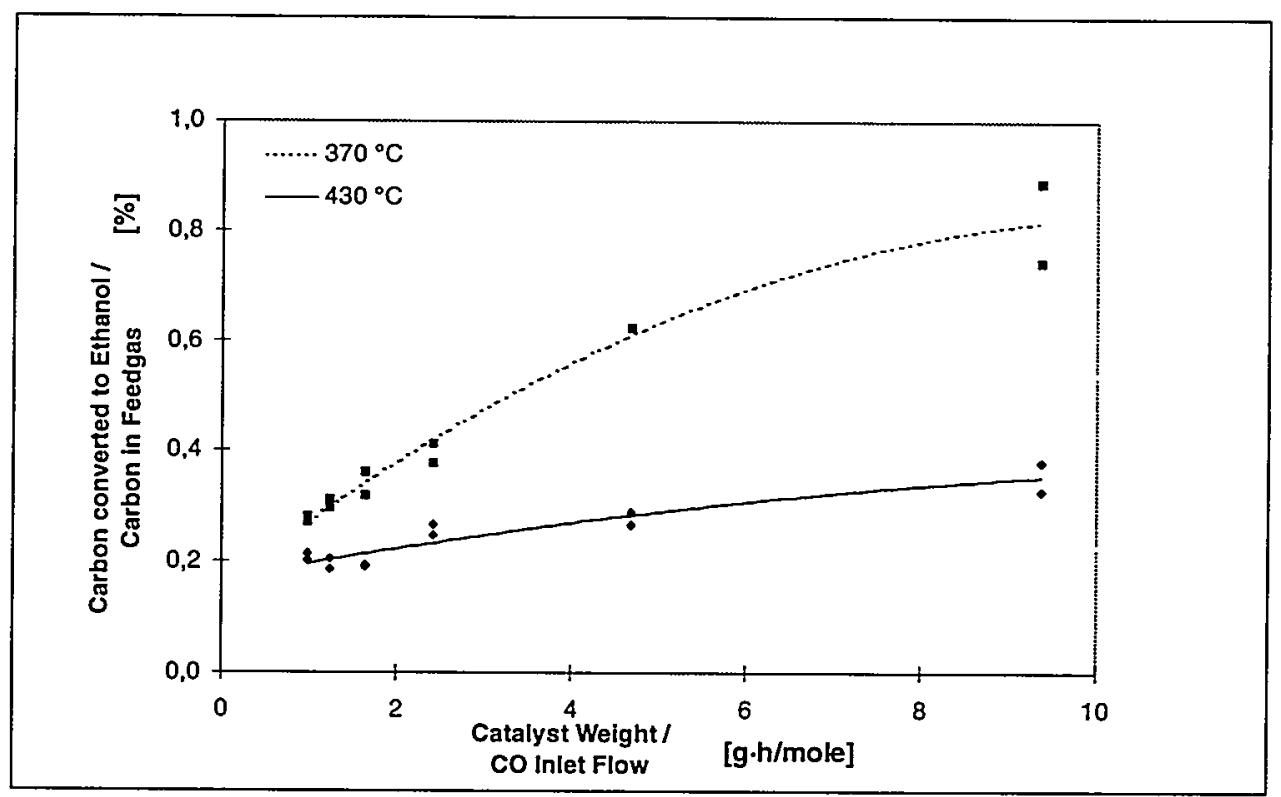

Figure 3.3.10 CO Conversion to 1-Propanol (VCat $=4 \mathrm{ml}$, Particle Size: 0.25-0.50 mm)

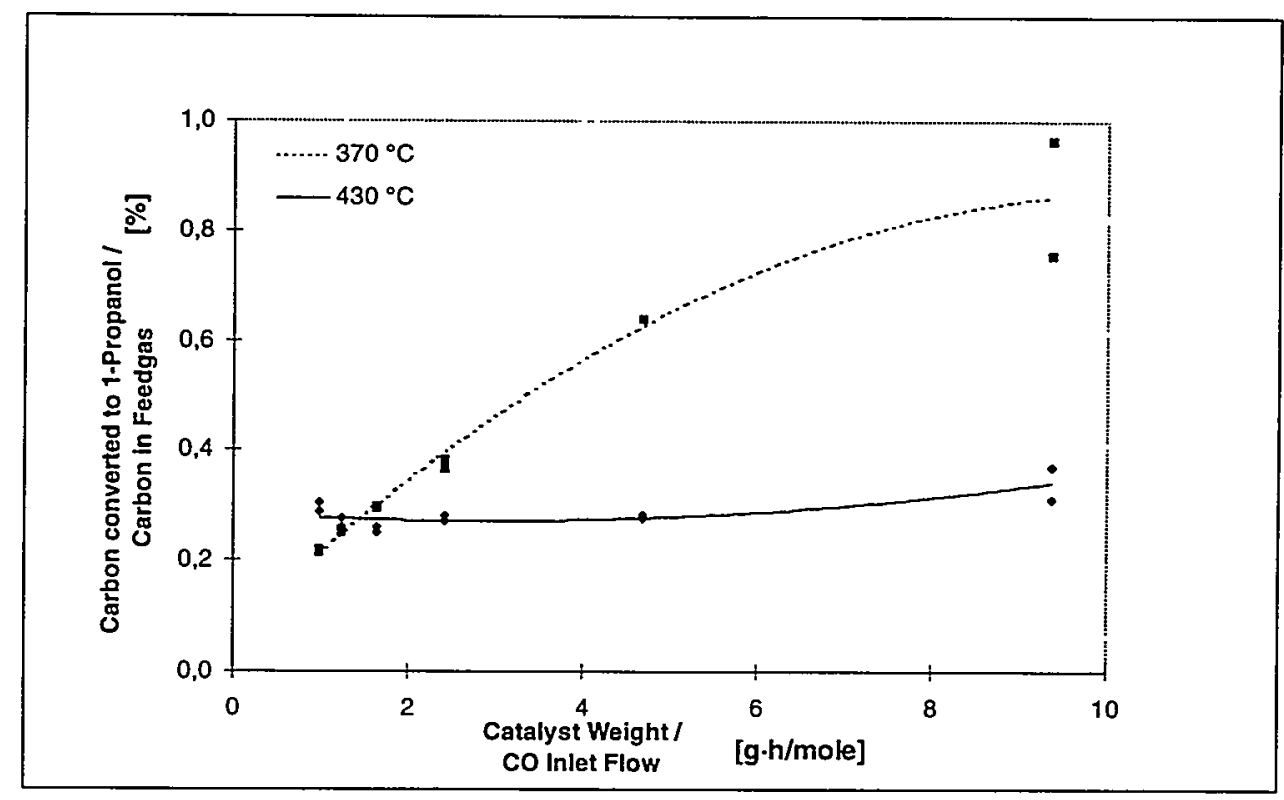

\section{Slurry Reactor Design and Runs}

In the last quarter, work dealt with mass transfer and the influence of pressure. Mass transfer was examined in the three-phase system, and the influence of reaction pressure on the yield was tested in two- and three-phase systems. 


\section{Mass Transfer}

Tests studying the mass transfer in a slurry reactor under isobutanol synthesis conditions were performed. Under such conditions, no mass transfer limitation could be proven. This result agrees with former theoretical conclusions (see quarterly report for Oct.-Dec. 1995). The maximum amount of catalyst suspended in decalin was $25 \mathrm{wt} \%$.

The procedure for these tests was as follows. Six runs were executed, including reduction and reaction. Between two runs, catalyst loading was increased and suspension level in the reactor was checked (Table 3.3.3). This procedure was followed by the three steps listed in Table 3.3.4, which were performed with the GHSV at a constant level. The reaction temperature was kept constant at $400^{\circ} \mathrm{C}$. All measurements listed below were carried out during step three.

Table 3.3.3 Catalyst Content in Slurry Runs Testing Mass Transfer

\begin{tabular}{lllllll}
\hline Run & 1 & 2 & 3 & 4 & 5 & 6 \\
\hline Catalyst volume $^{\mathrm{a}}[\mathrm{ml}]$ & 6 & 11.9 & 17.9 & 23.9 & 29.9 & 32.8 \\
Catalyst weight [g] $_{\text {Catalyst ratio [wt\%] }}[8$ & 16 & 24 & 32 & 40 & 44 \\
\hline C & 5.8 & 11 & 15.7 & 19.9 & 13.7 & 25.4 \\
\hline
\end{tabular}

${ }^{a}$ corresponding to the catalyst volume of the fixed-be $d$ reactor

Table 3.3.4 Reaction Conditions in Slurry Runs Testing Mass Transfer

\begin{tabular}{|c|c|c|}
\hline \multicolumn{2}{|l|}{ Step } & Conditions \\
\hline $\bar{I}$ & reduction & $\begin{array}{ll}\text { gas } & \mathrm{H}_{2} \\
\text { pressure }= & 3 \mathrm{MPa} \\
\text { mass flow }= & 30 \mathrm{Nl} / \mathrm{h} \\
\text { temperature }= & 225^{\circ} \mathrm{C} \text { for } 120 \mathrm{~min} \\
\end{array}$ \\
\hline II & reaction & $\begin{array}{ll}\text { feedstock } & \mathrm{CO} / \mathrm{H}_{2} \\
\text { pressure }= & 25 \mathrm{MPa} \\
\text { mass flow }= & 115 \mathrm{NV} / \mathrm{h} \text { over night } \\
\text { temperature } & 400^{\circ} \mathrm{C} \\
\end{array}$ \\
\hline III & reaction & $\begin{array}{ll}\text { feedstock } & \mathrm{CO} / \mathrm{H}_{2} \\
\text { pressure }= & 25 \mathrm{MPa} \\
\text { GHSV }= & 8700 \mathrm{~h}-1 \\
\text { temperature } & 400^{\circ} \mathrm{C} \\
\end{array}$ \\
\hline constant: & $\begin{array}{l}\text { catalyst } \mathrm{ZnO} / \mathrm{Cr} 2 \mathrm{O} / \mathrm{K} 2 \mathrm{O}(\mathrm{BASF}) \\
\text { heating rate } \\
\text { temperature of the preheater } \\
\text { temperature of the reflux condenser } \\
\text { slurry volume } \\
\text { stirrer speed }\end{array}$ & $\begin{array}{l}\text { particle size } 63-160 \mu \mathrm{m} \\
4^{\circ} \mathrm{C} / \mathrm{min} \\
385^{\circ} \mathrm{C} \\
160^{\circ} \mathrm{C} \\
150 \mathrm{cc} \\
2500 \mathrm{rpm}\end{array}$ \\
\hline
\end{tabular}

Each measurement was repeated three times. The results of the different runs were linked by a polynomial regression of the 2 nd order.

As mentioned above, mass transfer limitation has to be excluded (Figure 3.3.11). The mass of $\mathrm{CO}$ converted per unit of time increases slightly more than linearly. The identical effect is shown in Figure 3.3.12. CO conversion is not absolutely equal over the whole range, but increases from 
to $25 \%$. An explanation could be the diminution of surface effects at higher catalyst loadings; the relative amount of catalyst hidden at the reactor walls, at the housing of the stirrer head and in tubing system becomes smaller. This possibility also explains the increase in STY towards isobutanol and methanol. Concurrently the selectivity to $\mathrm{CO}_{2}$ decreases. A further explanation of the decrease in selectivity to $\mathrm{CO}_{2}$ could be given by the shortened residence time at higher catalyst loadings.

Figure 3.3.11 Converted CO vs Catalyst Volume Testing Mass Transfer

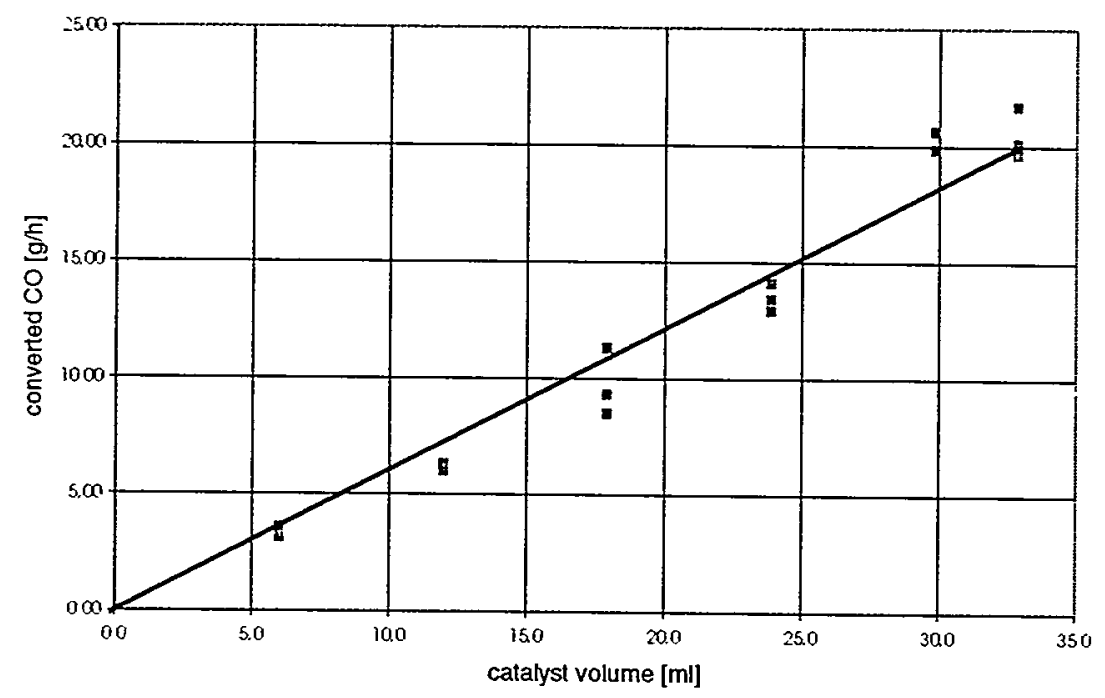

Figure 3.3.12 Yields by Runs Testing Mass Transfer Given in Relative Quantities

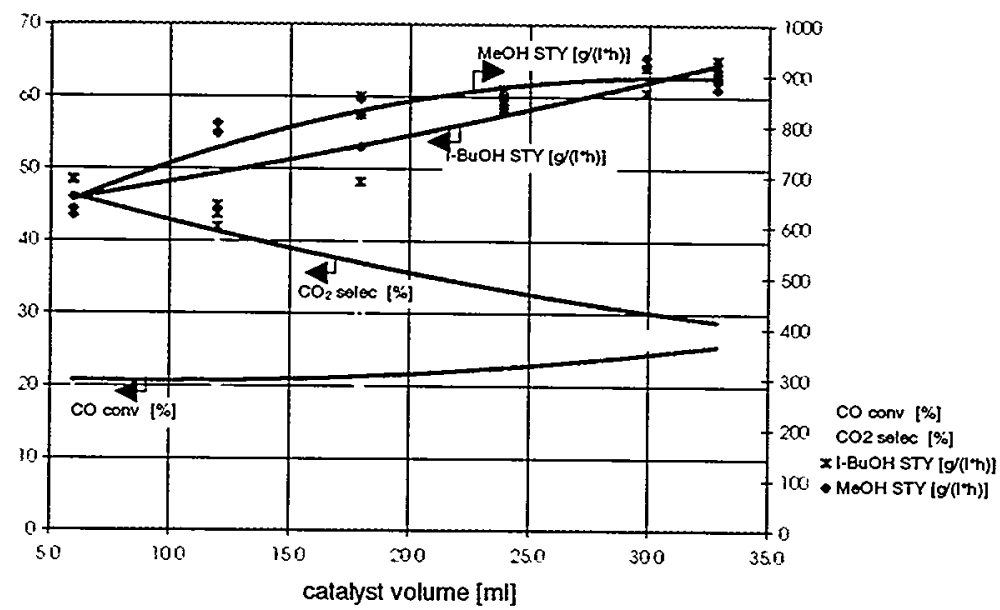

The results mentioned above were confirmed by experiments using the CSTR without decalin as a two-phase system. With similar residence time and gas hourly space velocity, the yield from a two- and a three- phase system is comparable (each CSTR). This gives a further hint that isobutanol synthesis under the reaction conditions mentioned above is limited by its intrinsic reaction rate. 


\section{Influence of Pressure}

An increase in reaction pressure causes a rise in the residence time and an increase in concentration in the gas phase. It is not possible to distinguish between the influence of residence time and concentration as long as a kinetic rate expression is not available.

However, the relative increase in yield is higher as the relative increase in reaction pressure. This was experimentally shown in the pressure range from $17 \mathrm{MPa}$ up to $33 \mathrm{MPa}$. The experiments were made using the fixed-bed reactor as well as the CSTR. The increase in yield to isobutanol depends on reaction temperature and reactor type (Figures 3.3.13-3.3.15). The yield to methanol rises to the new value of the thermodynamic equilibrium (Figures 3.3.16-3.3.18). The relative increase in methanol is therefore similar for both reactors. Ignoring the results from three-phase CSTR runs, which have a higher systematic error in measurement, the STY towards methanol increases by a factor in the range of 2.4 up to 2.8 , while the pressure is nearly doubled from 17 MPa up to $33 \mathrm{MPa}$ (Table 3.3.5). The same pressure rise causes an increase in STY towards isobutanol by a factor in the range of 2.0 to 3.3. Remarkable is the contrasting behavior of the fixed bed reactor and the two-phase CSTR. The relative amount of isobutanol made in the fixedbed reactor increases with decreasing temperature. The formation of by-products in the fixedbed reactor seems to be so strong at high temperatures that the advantage obtained by an increase in concentration and residence time is not realized entirely anymore.

The shape of the curves for the CSTR as two- or three- phase system is similar.

Table 3.3.5 Relative Increase in Isobutanol and Methanol by Increasing Pressure from 17 up to $33 \mathrm{MPa}$ for Various Temperatures and Reactors (ZnO/Cr2O3/K-Catalyst)

\begin{tabular}{|c|c|c|c|c|c|c|}
\hline $\begin{array}{l}\text { reaction conditions } \\
\text { reactor } \\
\text { GHSV [h-1] } \\
\text { corresponding to Figure }\end{array}$ & $\begin{array}{l}\text { fixed bed } \\
23000 \\
3\end{array}$ & $\begin{array}{l}\text { isobutanol } \\
\text { two phase } \\
\text { CSTR } \\
9500 \\
4 \\
\end{array}$ & $\begin{array}{l}\text { three phase } \\
\text { CSTR } \\
19000 \\
5\end{array}$ & $\begin{array}{l}\text { fixed bed } \\
23000 \\
6 \\
\end{array}$ & $\begin{array}{l}\text { methanol } \\
\text { two phase } \\
\text { CSTR } \\
9500 \\
7 \\
\end{array}$ & $\begin{array}{l}\text { three phase } \\
\text { CSTR } \\
19000 \\
8 \\
\end{array}$ \\
\hline $385^{\circ} \mathrm{C}$ & 3.3 & 2.0 & 2.3 & 2.5 & 2.6 & 2.0 \\
\hline $400^{\circ} \mathrm{C}$ & 2.8 & 2.3 & 2.3 & 2.4 & 2.6 & 2.5 \\
\hline $415^{\circ} \mathrm{C}$ & 2.4 & 2.5 & 2.1 & 2.5 & 2.8 & 3.1 \\
\hline
\end{tabular}


Figure 3.3.13 STY Isobutanol vs Reaction Pressure (Fixed-Bed Reactor, $\mathrm{ZnO} / \mathrm{Cr} 2 \mathrm{O}$ / K-Catalyst, Vcat $=5 \mathrm{ml}$, GHSV $=23000 \mathrm{~h}-1$ )

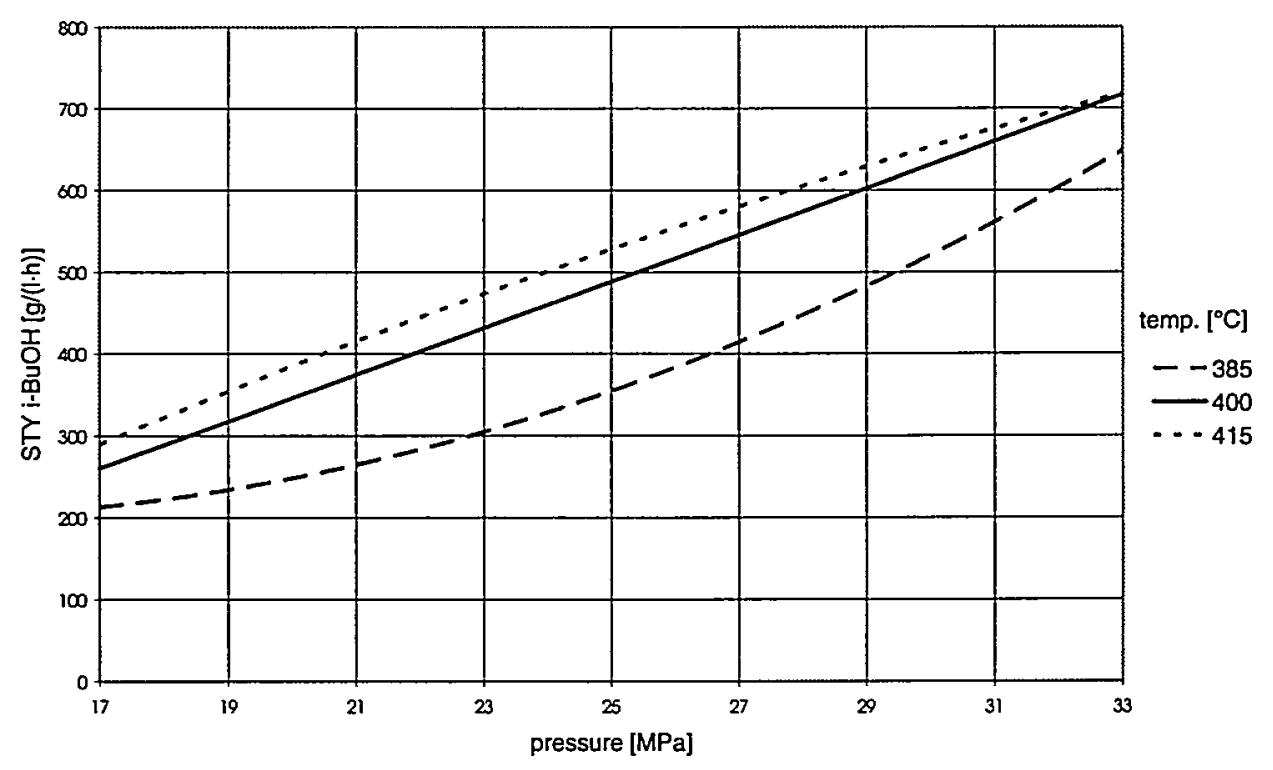

Figure 3.3.14 STY Isobutanol vs Reaction Pressure (Two-Phase CSTR, ZnO/Cr2O3/ K-Catalyst, Veat $=17.9 \mathrm{ml}, \mathrm{GHSV}=9500 \mathrm{~h}-1$ )

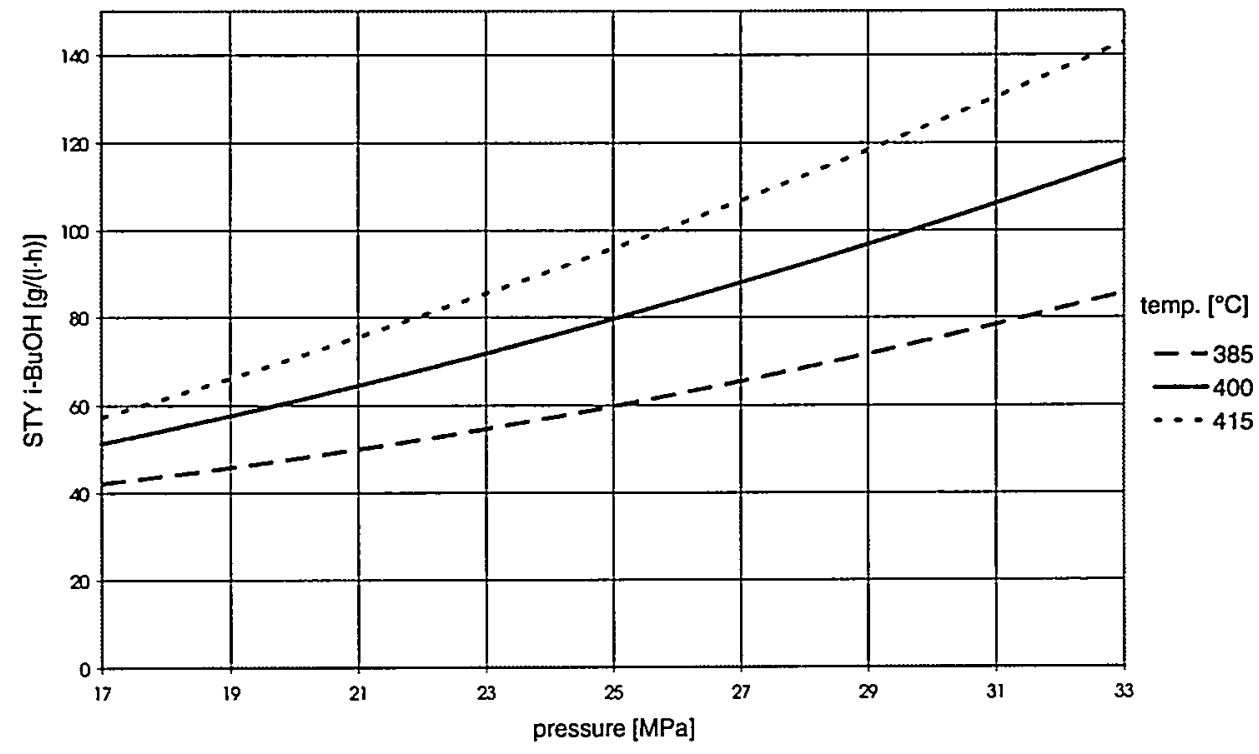


Figure 3.3.15 STY Isobutanol vs Reaction Pressure (Three-Phase CSTR, ZnO/Cr203/KCatalyst, Vcat $=6 \mathrm{ml}, \mathrm{GHSV}=19000 \mathrm{~h}-1$ )

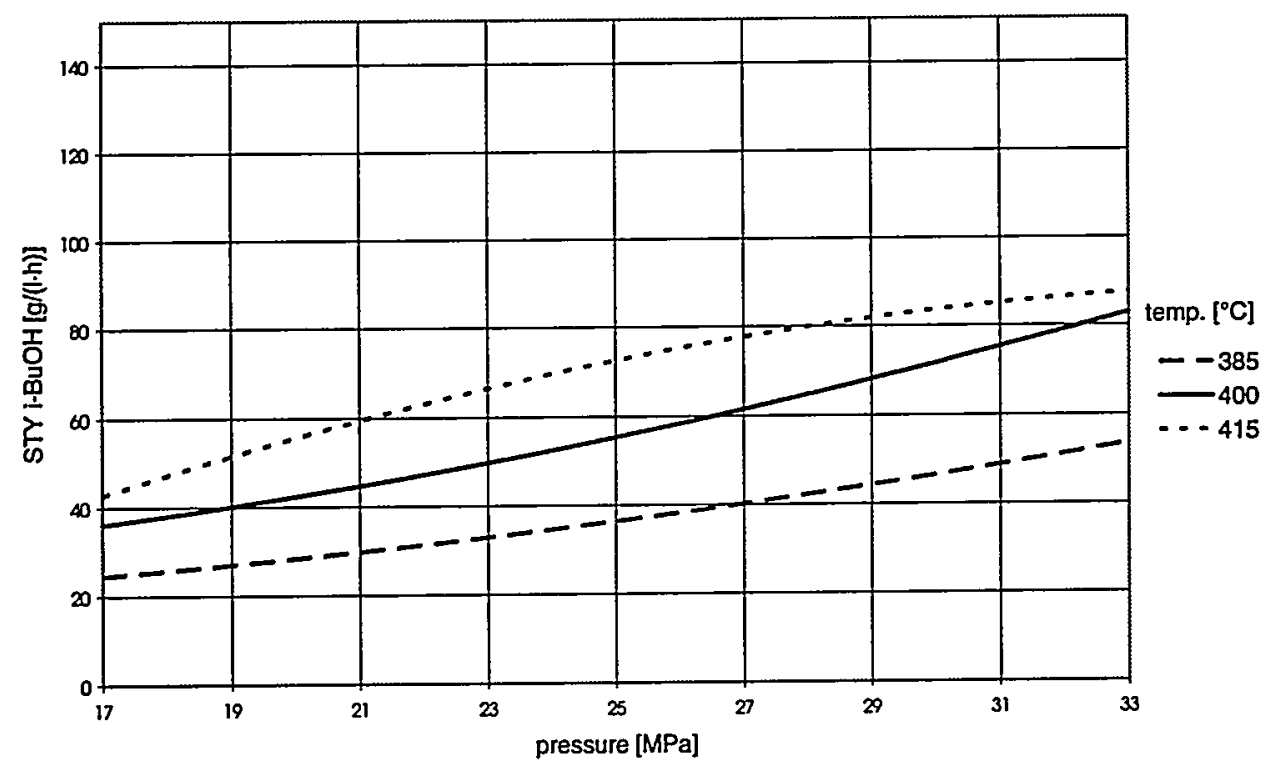

Figure 3.3.16 STY Methanol vs Reaction Pressure (Fixed-Bed Reactor, ZnO/Cr2O3/ K-Catalyst, Vcat $=5 \mathrm{ml}$, GHSV $=23000$ h-1)

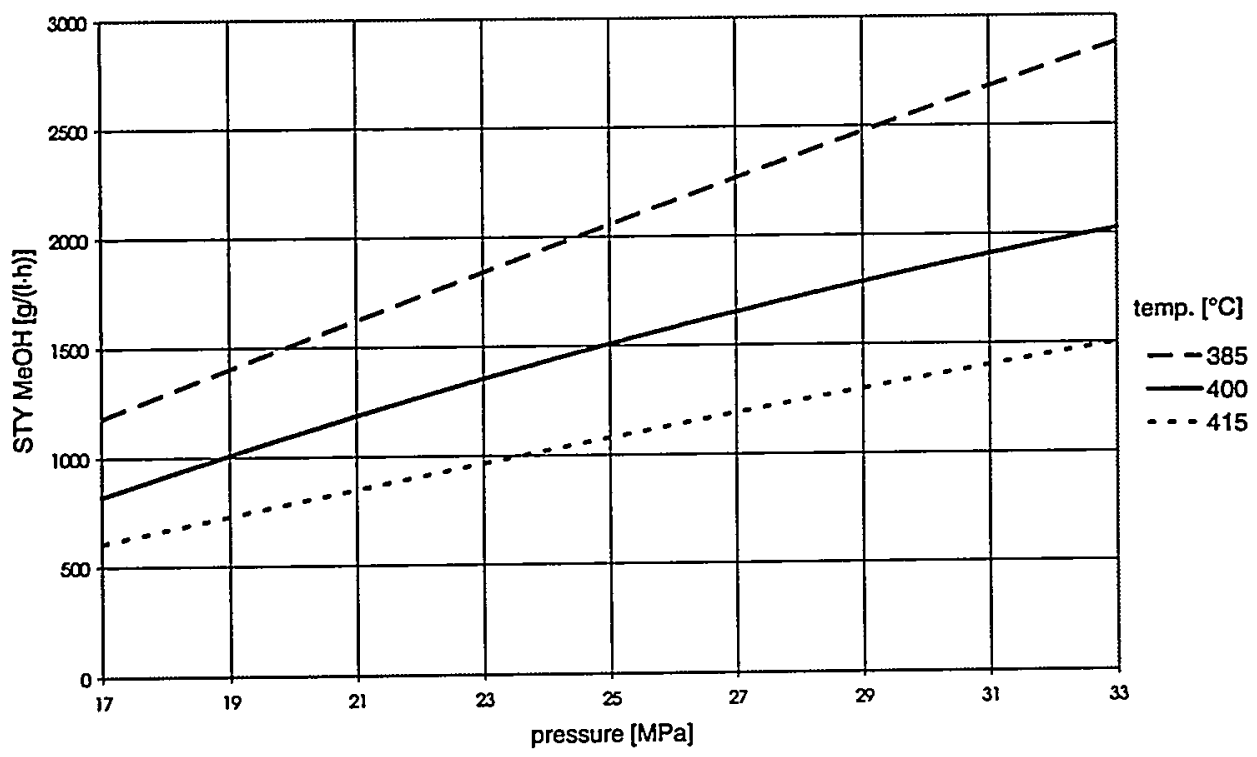


Figure 3.3.17 STY Methanol vs Reaction Pressure (Two-Phase CSTR, ZnO/Cr2O3/ K-Catalyst, Vcat $=17.9 \mathrm{ml}, \mathrm{GHSV}=9500 \mathrm{~h}-1$ )

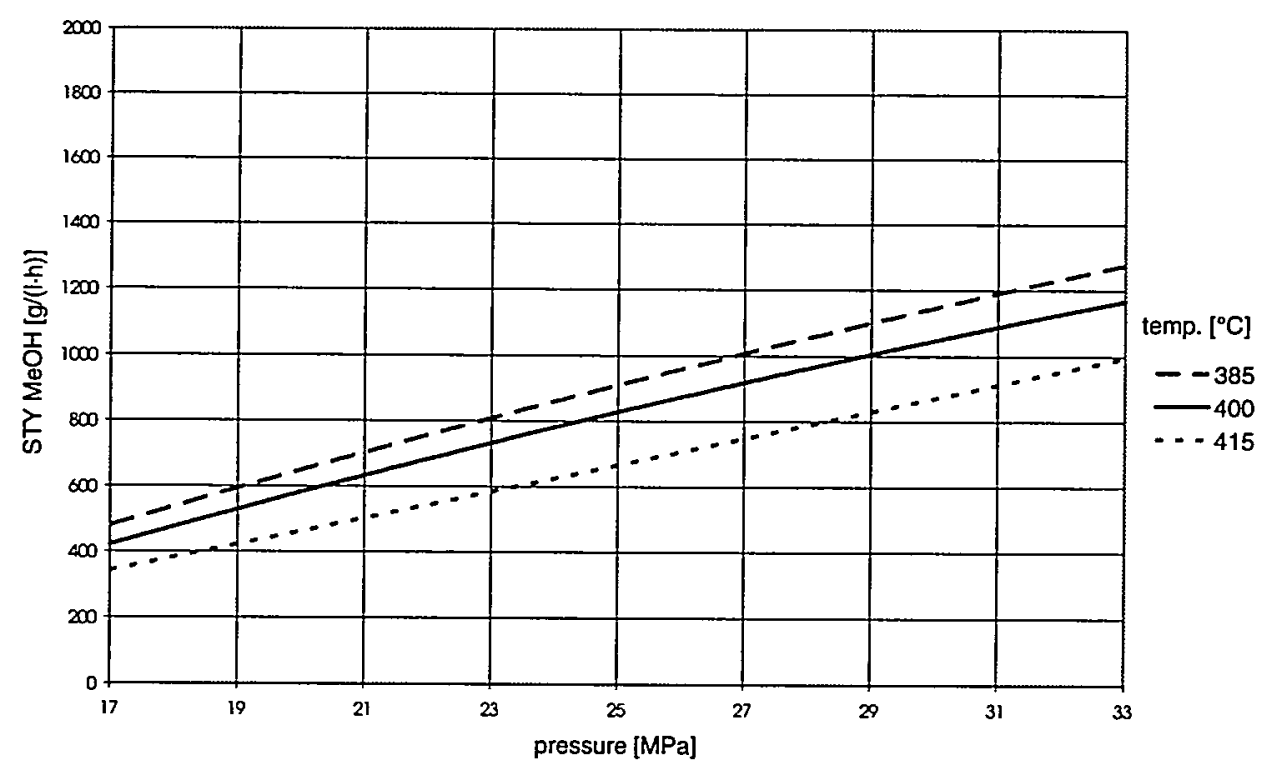

Figure 3.3.18 STY Methanol vs Reaction Pressure (Three-Phase CSTR, ZnO/Cr2O3/ K-Catalyst, Vcat $=6 \mathrm{ml}$, GHSV $=19000 \mathrm{~h}-1$ )

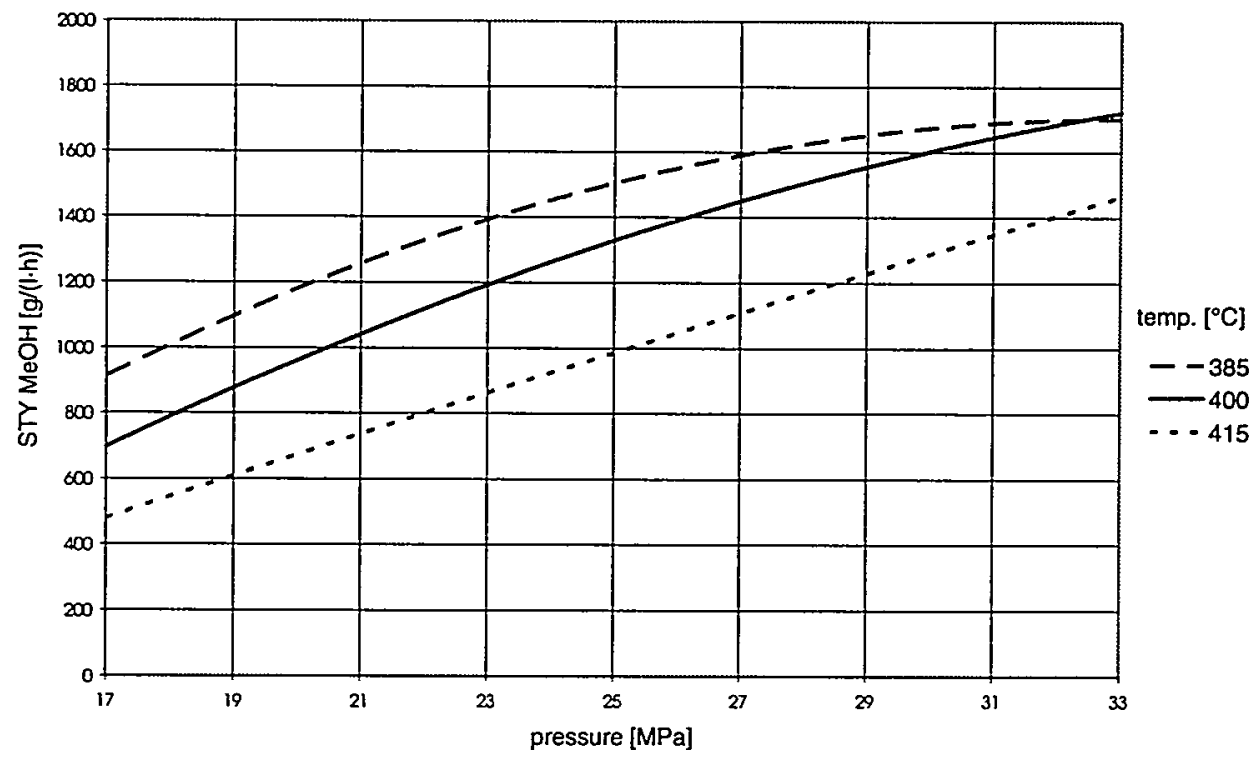




\subsubsection{Oxygenates via Synthesis Gas (Lehigh University)}

\section{Overall 2QFY96 Objectives}

(i) Continue studies of increasing the conversion of $\mathrm{H}_{2} / \mathrm{CO}$ to higher alcohols by promotion of the $\mathrm{C}_{1} \rightarrow \mathrm{C}_{2}$ carbon chain growth step over Cs-promoted $\mathrm{Cu} / \mathrm{ZnO} / \mathrm{Cr}_{2} \mathrm{O}_{3}$ catalysts,

(ii) Significantly enhance the $\mathrm{C}_{2} \rightarrow \mathrm{C}_{3} \rightarrow \mathrm{C}_{4}$ carbon chain growth steps over $\mathrm{Cs} / \mathrm{Cu} / \mathrm{ZnO} / \mathrm{Cr}_{2} \mathrm{O}_{3}$ catalysts, and

(iii) Prepare and test high surface area $\mathrm{Cu} / \mathrm{ZrO}_{2}$ catalysts, both Cs-doped and undoped, that are candidates for the synthesis of $\mathrm{C}_{1}-\mathrm{C}_{5}$ alcohols, in particular branched products such as isobutanol.

\section{Results and Discussion}

\section{$\mathrm{Cu} / \mathrm{ZnO} \mathrm{O}_{2}$ and $\mathrm{Cs} / \mathrm{Cu} / \mathrm{ZnO} \mathrm{O}_{2}$ Catalysts for Alcohol Synthesis}

During this quarter, experimental research with the $\mathrm{Cu} / \mathrm{ZrO}_{2}$ catalysts was completed. The $\mathrm{Cu} / \mathrm{ZrO}{ }_{2}$ and $\mathrm{Cs} / \mathrm{Cu} / \mathrm{ZrO}_{2}$ catalysts were previously tested, and most of the data analyses and catalyst characterization in terms of BET surface areas, X-ray photoelectron spectroscopy (XPS), and X-ray powder diffraction (XRD) have now been completed. In selected cases, electron microscopy (mainly TEM) is also being carried out.

Surface areas were obtained with a Micromeritics Gemini 2360 instrument using nitrogen as the adsorbate. A comparison of the surface areas, some of which were reported previously, is shown in Table 3.3.6 for $\mathrm{Cu} / \mathrm{ZrO}_{2}=10 / 90$ and $30 / 70 \mathrm{~mol} \%$ catalysts.

Table 3.3.6 BET Surface Areas for the $\mathrm{Cu} / \mathrm{ZrO}_{2}=10 / 90$ and $30 / 70 \mathrm{~mol} \%$ Catalysts, Where Each Calcination Treatment was Maintained for $3 \mathbf{~ h r}$

\begin{tabular}{|l|l|l|}
\hline \hline $\mathrm{Cu} / \mathrm{ZrO}_{2}$ Catalyst & $\begin{array}{l}\text { Calcination Temp. } \\
\left({ }^{\circ} \mathrm{C}\right)\end{array}$ & $\begin{array}{l}\text { BET Surface Area } \\
\left(\mathrm{m}^{2} / \mathrm{g}\right)\end{array}$ \\
\hline \hline $10 / 90$ & 500 & 63 \\
\hline $10 / 90$ & 400 & 112 \\
\hline $10 / 90$ & 350 & 148 \\
\hline $10 / 90$ & 350, after testing & 72 \\
\hline $3 \% \mathrm{Cs} / 10 / 90$ & 350, after testing & 73 \\
\hline $30 / 70$ & 500 & 25 \\
\hline $30 / 70$ & 400 & 73 \\
\hline $30 / 70$ & 350 & 78 \\
\hline $30 / 70$ & 350, after testing & 55 \\
\hline
\end{tabular}

It is evident that utilizing higher calcination temperatures resulted in less surface area for the catalysts. In addition, catalytic testing resulted in the loss of surface area. These observations were also reflected by the XRD results obtained with these catalysts, in which an increase in crystallinity was directly correlated with a decrease in surface. The data in Table 3.3.6 also indicate that doping of the 10/90 catalysts with Cs did not affect the surface area of the catalyst as 
observed after catalytic testing, since both the undoped and Cs-doped catalysts exhibited surface areas slightly above $70 \mathrm{~m}^{2} / \mathrm{g}$ after testing. This was approximately $50 \%$ of the surface area of the catalyst after calcination at $350^{\circ} \mathrm{C}$. It is noted that the temperature of catalytic testing did not exceed $330^{\circ} \mathrm{C}$.

Transmission electron micrographs and corresponding selected area diffraction patterns of the $\mathrm{Cu} / \mathrm{ZrO}_{2}=10 / 90$ and 30/70 catalysts after testing showed the presence of two distinct phases having different contrast properties. These phases corresponded to crystalline $\mathrm{ZrO}_{2}$ and metallic copper. The $\mathrm{Cu}^{\circ}$ particle sizes corresponded to $\approx 4.0 \mathrm{~nm}$ and $\approx 5.5 \mathrm{~nm}$ for the $10 / 90$ and $30 / 70$ catalysts, respectively.

X-ray photoelectron spectra of some of the samples were obtained with a SCIENTA ESCA-300 spectrometer with a monochromatic AI K $\alpha(1486.7 \mathrm{eV}) \mathrm{X}$-ray source. Samples for analysis were pressed onto a sample stub, inserted into the analysis chamber, and evacuated to $10^{-9}$ torr or lower. The surface charging problem caused by the liberation of photoelectrons was minimized by flooding the sample surface with a beam of low-energy electrons $(5-10 \mathrm{eV})$. For all spectra, Shirley background was subtracted, and a Voigt function was used to analyze the peaks. XPS analysis was centered on the tested $3 \mathrm{~mol} \% \mathrm{Cs} / \mathrm{Cu} / \mathrm{ZrO}_{2}$ catalyst. The $\mathrm{Zr} 3 \mathrm{~d}_{5 / 2}$ peak $(182.5 \mathrm{eV}$ ) was used as a reference, and was considered a better reference than the $\mathrm{C} 1 \mathrm{~s}$ line $(284.6 \mathrm{eV})$. The NTS survey spectrum of the sample is shown in Figure 3.3.19. The Cs component was readily detected, with the $\mathrm{Cs} 3 \mathrm{~d}$ core level peak located at $724.8 \mathrm{eV}$.

XPS spectra of regions of particular interest are shown in Figure 3.3.20. The Cu 2p peak in Figure $3.3 .20 \mathrm{a}$ is located at $932.8 \mathrm{eV}$, while the $\mathrm{Zr} 3 \mathrm{~d}_{5 / 2}$ and $3 \mathrm{~d}_{3 / 2}$ peaks, separated by $238 \mathrm{eV}$, are shown in Figure 3.3.20b. The position of the Cs $3 \mathrm{~d}$ peak shown in Figure 3.3.20c indicates that Cs was present as Cst. The O Is spectra shown in Figure 3.3.20d contains a pronounced shoulder, indicating the presence of two different states of oxygen in the catalyst. The surface composition of the catalyst was estimated by normalizing the peak areas with Scofield cross sections of the individual elements. The surface metal ratio was found to be $11 / 16 / 73 \mathrm{~mol} \%$ $\mathrm{Cs} / \mathrm{Cu} / \mathrm{Zr}$. The finding that the Cs content was higher than $3 \mathrm{~mol} \%$ shows that the $\mathrm{Cs}$ remained as a surface dopant and that it was uniformly dispersed over the surface.

\section{Isobutanol Synthesis Over Double Bed Catalysts}

The research this quarter has been a continuation of our higher alcohol synthesis research over double-bed catalysts in a single reactor that are operated at different reaction temperatures (see quarterly reports for July-September and October-December 1995). In our previous research, the two catalysts consisted of $3 \% \mathrm{Cs} / \mathrm{Cu} / \mathrm{ZnO} / \mathrm{Cr}_{2} \mathrm{O}_{3} / \mathrm{ZnO} / 14 \% \mathrm{Cs} / \mathrm{ZnO} / \mathrm{Cr}_{2} \mathrm{O}_{3}$. We have now shown that much higher productivity of isobutanol was obtained when both beds consisted of 3 mol\% $\mathrm{Cs} / \mathrm{Cu} / \mathrm{ZnO} / \mathrm{Cr}_{2} \mathrm{O}_{3}$ (at different temperatures of 325 and $340^{\circ} \mathrm{C}$ ) than when the lower catalyst bed consisted of copper-free $4 \% \mathrm{Cs} / \mathrm{ZnO} / \mathrm{Cr}_{2} \mathrm{O}_{3}$ catalyst at $405^{\circ} \mathrm{C}$.

Before further testing in the dual-bed configuration, the $3 \mathrm{~mol} \% \mathrm{Cs} / \mathrm{Cu} / \mathrm{ZnO} / \mathrm{Cr}_{2} \mathrm{O}_{3}$ catalyst $(2 \mathrm{~g}$; prepared as described in the quarterly report for October-December 1995) was first tested for alcohol synthesis by itself at 7.6 MPa using $\mathrm{H}_{2} / \mathrm{CO}=0.45$ synthesis gas at a gas hourly space 
Figure 3.3.19 X-Ray Photoelectron Spectroscopy Survey Spectrum of the $3 \mathrm{~mol} \%$ $\mathrm{Cs} / \mathrm{Cu} / \mathrm{ZrO}_{2}$ Catalyst After Catalytic Testing

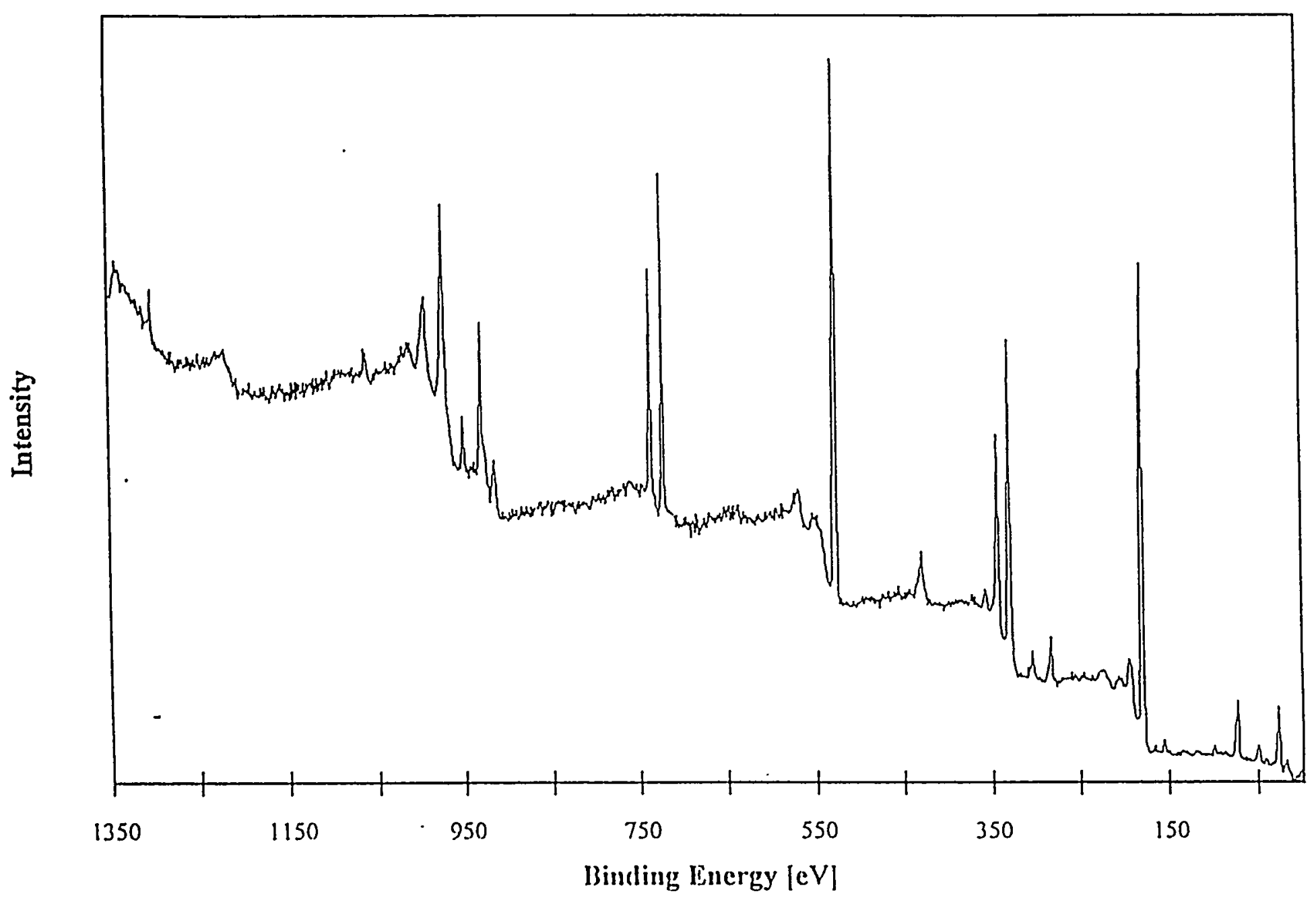


Figure 3.3.20 Photoelectron Al K $\alpha$ Spectra of the (a) $\mathrm{Cu} 2 \mathrm{p}$, (b) $\mathrm{Zr} 3 \mathrm{~d}$, (c) Cs 3d, and

(d) $\mathrm{O}$ Is Regions of the $3 \mathrm{~mol} \% \mathrm{Cs} / \mathrm{Cu} / \mathrm{ZrO}_{2}$ Catalyst after Catalytic Testing
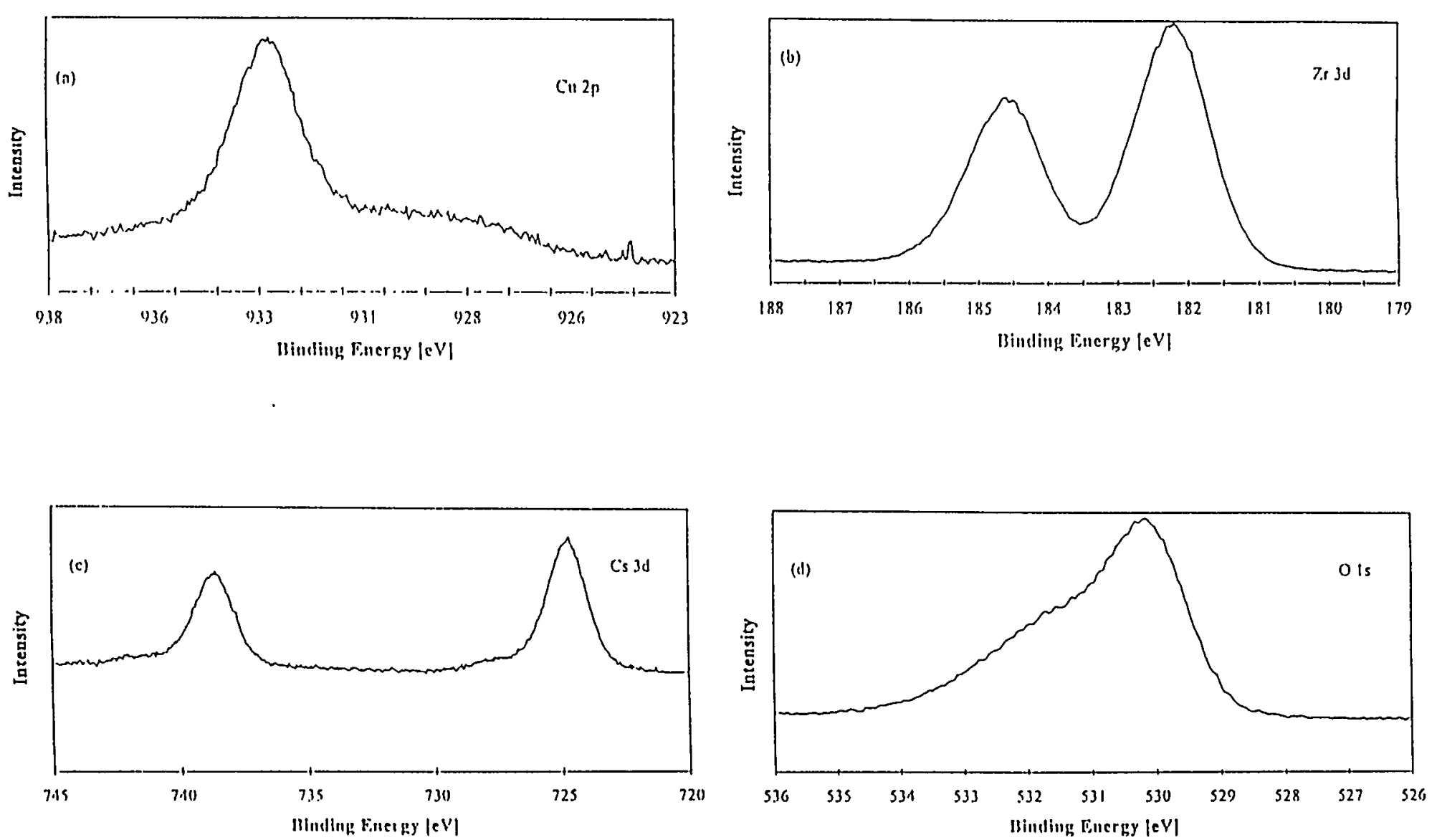
velocity (GHSV) of 5450 liter (STP)/kg cat/hr at temperatures higher than previously employed for this copper-containing catalyst. The results of this catalytic testing, where steady-state conversions and selectivities were observed, are shown in Table 3.3.7.

By systematic testing at $340,370,405$, and $430^{\circ} \mathrm{C}$, it was shown that $\mathrm{CO}$ conversion decreased from 9.6 to 7.5 to 5.3 to $4.2 \mathrm{~mol} \%$ as the temperature was sequentially increased from 340 to $430^{\circ} \mathrm{C}$. Methanol productivity steadily decreased as well in the sequence of $122,77,29$, and $19 \mathrm{~g} / \mathrm{kg} \mathrm{cat} / \mathrm{hr}$. At the same time, isobutanol productivity decreased from 73 to 67 to 53 to $40 \mathrm{~g} / \mathrm{kg} \mathrm{cat} / \mathrm{hr}$, with the decline more gradual than that for methanol. This resulted in higher isobutanol productivity than for methanol at 405 and $430^{\circ} \mathrm{C}$. With methanol as a precursor to the higher alcohols, this range of high reaction temperatures under these reaction conditions is not conducive to the enhancement of isobutanol synthesis.

Catalytic testing of the dual catalysts was carried out as described in previous quarterly reports, and the double-bed experiment used $1 \mathrm{~g}$ of catalyst in each bed. In this experiment, two portions of the $3 \mathrm{~mol} \% \mathrm{Cs} / \mathrm{Cu} / \mathrm{ZnO} \mathrm{Cr}_{2} \mathrm{O}_{3}$ catalyst were utilized in a double-bed configuration, both in the lower temperature first bed and in the higher temperature second bed. $\mathrm{A}_{2} / \mathrm{CO}=0.75$ synthesis gas at GHSV $=18,375 \mathrm{liter}(\mathrm{STP}) / \mathrm{kg}$ cat $/ \mathrm{hr}$ and $7.6 \mathrm{MPa}$ was utilized; the temperature of the first (top) catalyst bed was $325^{\circ} \mathrm{C}$, while the second (bottom) bed was maintained at 340 or $370^{\circ} \mathrm{C}$. The productivities and $\mathrm{CO}$ conversion levels are given in Table 3.3.8.

As shown in the quarterly technical progress report for October-December 1995, using the 4 $\mathrm{mol} \% \mathrm{Cs} / \mathrm{ZnO} / \mathrm{Cr}_{2} \mathrm{O}_{3}$ catalyst in the second bed (at $405^{\circ} \mathrm{C}$, but under similar reaction conditions) resulted in a CO conversion of $6.1 \mathrm{~mol} \%$ and an isobutanol (2m-PrOH) productivity of $125 \mathrm{~g} / \mathrm{kg}$

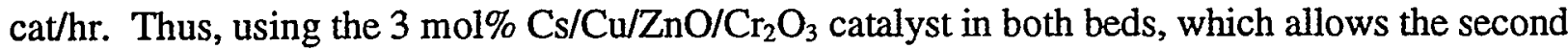
bed to be operated at lower temperature, resulted in a significant increase in the productivity of isobutanol, with high selectivity to methanol + isobutanol. The $202 \mathrm{~g}$ of isobutanol $/ \mathrm{kg} \mathrm{cat} / \mathrm{hr}$ reported in Table 3.3.8 for a second catalyst bed temperature of $340^{\circ} \mathrm{C}$ is a significant enhancement of isobutanol productivity over the space time yields previously observed over this type of catalyst.

The selectivities shown in Table 3.3.8 are especially notable. The isobutanol $/ \mathrm{methanol} \mathrm{mass}$ ratios are about 0.35 and 0.5 for the lower bed temperatures of 340 and $370^{\circ} \mathrm{C}$, respectively. At the lower bed temperature of $340^{\circ} \mathrm{C}, 67 \%$ of the carbon in the products shown in Table 3.3 .8 is in the isobutanol and methanol. If n-propanol is included, then $80 \%$ of the carbon in alcohol and hydrocarbon products is found in these three alcohols. This is a remarkable product distribution.

\section{Overall 3QFY96 Objectives}

Future research for Task 3 will focus on the following areas:

(i) Complete revision of the manuscript detailing our experimental progress on the preparation of $\mathrm{Cu} / \mathrm{ZrO}_{2}$ catalysts, both Cs-doped and undoped, and the synthesis of methanol and dimethyl ether over these catalysts from $\mathrm{H}_{2} / \mathrm{CO}$ synthesis gas mixtures, in which the effects of $\mathrm{CO}_{2}$ and $\mathrm{H}_{2} \mathrm{O}$ were determined. 
Table 3.3.7 Productivities and Distribution of Products Formed Over the $3 \mathrm{~mol} \%$ $\mathrm{Cs} / \mathrm{Cu} / \mathrm{ZnO} / \mathrm{Cr}_{2} \mathrm{O}_{3}$ Catalyst $(2 \mathrm{~g})$ with $\mathrm{H}_{2} / \mathrm{CO}=0.45$ Synthesis Gas at $7.6 \mathrm{MPa}$ with GHSV $=\mathbf{5 , 4 5 0 ~ l i t e r ( S T P ) / k g ~ c a t ~} / \mathrm{hr}$ as the Temperature (T) was Increased from 340 to $430^{\circ} \mathrm{C}$. The productivities of aldehydes and ketones have been added to those of the corresponding primary and secondary alcohols. Abbreviations used are $\mathrm{Me}=$ methyl, Et $=$ ethyl, $\mathrm{Pr}=$ propyl, $\mathrm{Bu}=$ butyl, Pent $=$ pentyl, $2 \mathrm{~m}=2$-methyl, $3 \mathrm{~m}=3$-methyl, $\mathrm{MF}=$ methylformate, $\mathrm{MAC}=$ methylacetate, $\mathrm{DME}=$ dimethylether, and $\mathrm{HC}=$ hydrocarbon.

\begin{tabular}{|c|c|c|c|c|}
\hline & $\begin{array}{l}\mathrm{T}=340^{\circ} \mathrm{C} \\
(\mathrm{g} / \mathrm{kg} \mathrm{cat} / \mathrm{hr})\end{array}$ & $\begin{array}{l}\mathrm{T}=370^{\circ} \mathrm{C} \\
\text { (g/kg cat } / \mathrm{hr})\end{array}$ & $\begin{array}{l}\mathrm{T}=405^{\circ} \mathrm{C} \\
(\mathrm{g} / \mathrm{kg} \mathrm{cat} / \mathrm{hr})\end{array}$ & $\begin{array}{l}\mathrm{T}=430^{\circ} \mathrm{C} \\
\text { (g/kg cat } / \mathrm{hr})\end{array}$ \\
\hline $\begin{array}{l}\mathrm{MeOH} \\
\mathrm{EtOH} \\
\mathrm{PrOH} \\
\mathrm{BuOH} \\
\text { PentOH }\end{array}$ & $\begin{array}{l}122 \\
4 \\
22 \\
3 \\
3\end{array}$ & $\begin{array}{l}77 \\
1 \\
13 \\
0 \\
0\end{array}$ & $\begin{array}{l}29 \\
1 \\
4 \\
0 \\
1\end{array}$ & $\begin{array}{l}19 \\
1 \\
3 \\
1 \\
1\end{array}$ \\
\hline $\begin{array}{l}2 \mathrm{~m}-\mathrm{PrOH} \\
2 \mathrm{~m}-\mathrm{BuOH} \\
2 \mathrm{~m}-\mathrm{PentOH}\end{array}$ & $\begin{array}{l}73 \\
20 \\
12\end{array}$ & $\begin{array}{l}67 \\
13 \\
10\end{array}$ & $\begin{array}{l}53 \\
8 \\
4\end{array}$ & $\begin{array}{l}40 \\
4 \\
2\end{array}$ \\
\hline $\begin{array}{l}\text { 2-BuOH } \\
3 \mathrm{~m}-2-\mathrm{BuOH} \\
\text { 3-PentOH } \\
\text { 2m-3-PentOH }\end{array}$ & $\begin{array}{l}5 \\
3 \\
5 \\
12\end{array}$ & $\begin{array}{l}6 \\
4 \\
6 \\
10\end{array}$ & $\begin{array}{l}5 \\
1 \\
4 \\
7\end{array}$ & $\begin{array}{l}2 \\
1 \\
3 \\
6\end{array}$ \\
\hline $\begin{array}{l}\text { MF } \\
\text { MAC } \\
\text { DME } \\
\mathrm{C}_{7}^{+}- \\
\text {Oxygenates }\end{array}$ & $\begin{array}{l}1 \\
1 \\
2 \\
9\end{array}$ & $\begin{array}{l}4 \\
2 \\
3 \\
9\end{array}$ & $\begin{array}{l}6 \\
1 \\
3 \\
\\
11\end{array}$ & $\begin{array}{l}9 \\
3 \\
1 \\
10\end{array}$ \\
\hline $\begin{array}{l}\mathrm{CH}_{4} \\
\mathrm{C}_{2}-\mathrm{C}_{4} \mathrm{HC}\end{array}$ & $\begin{array}{l}7 \\
11\end{array}$ & $\begin{array}{l}10 \\
10\end{array}$ & $\begin{array}{l}14 \\
15\end{array}$ & $\begin{array}{l}18 \\
15\end{array}$ \\
\hline $\begin{array}{l}\text { \%CO Conv. } \\
\left(\mathrm{CO}_{2} \text {-free }\right)\end{array}$ & 9.6 & 7.5 & 5.3 & 4.2 \\
\hline
\end{tabular}


Table 3.3.8 Higher Alcohol Synthesis Over Two Portions of the $3 \mathrm{~mol} \% \mathrm{Cs} / \mathrm{Cu} / \mathrm{ZnO} / \mathrm{Cr}_{2} \mathrm{O}_{3}$ Catalyst Held in a Double-Bed Configuration, Where the Top Bed $(1 \mathrm{~g})$ was Held at $325^{\circ} \mathrm{C}$ and the Lower Bed $(1 \mathrm{~g})$ was Maintained at 340 or $370^{\circ} \mathrm{C}$. The synthesis gas consisted of $\mathrm{H}_{2} / \mathrm{CO}=0.75$ at $7.6 \mathrm{MPa}$ with GHSV $=18,375 \mathrm{liter}(\mathrm{STP}) / \mathrm{kg}$ cat $/ \mathrm{hr}$. The productivities of aldehydes and ketones have been added to those of the corresponding primary and secondary alcohols. Abbreviations used are $\mathrm{Me}=$ methyl $\mathrm{Et}=$ ethyl $\mathrm{Pr}=$ propyl, $\mathrm{Bu}=$ butyl, Pent $=$ pentyl, $2 \mathrm{~m}=2$-methyl, $3 \mathrm{~m}=3$-methyl, and $\mathrm{HC}=$ hydrocarbon.

\begin{tabular}{|c|c|c|}
\hline & $\begin{array}{l}\text { Top }=325^{\circ} \mathrm{C} \\
\text { Bottom }=340^{\circ} \mathrm{C} \\
(\mathrm{g} / \mathrm{kg} \mathrm{cat} / \mathrm{hr})\end{array}$ & $\begin{array}{l}\text { Top }=325^{\circ} \mathrm{C} \\
\text { Bottom }=370^{\circ} \mathrm{C} \\
(\mathrm{g} / \mathrm{kg} \mathrm{cat} / \mathrm{hr})\end{array}$ \\
\hline $\begin{array}{l}\mathrm{MeOH} \\
\text { EtOH } \\
\mathrm{PrOH} \\
\mathrm{BuOH} \\
\text { PentOH }\end{array}$ & $\begin{array}{l}574 \\
15 \\
93 \\
0 \\
0 \\
\end{array}$ & $\begin{array}{l}369 \\
5 \\
47 \\
1 \\
1 \\
\end{array}$ \\
\hline $\begin{array}{l}2 \mathrm{~m}-\mathrm{PrOH} \\
2 \mathrm{~m}-\mathrm{BuOH} \\
2 \mathrm{~m}-\mathrm{PentOH}\end{array}$ & $\begin{array}{l}202 \\
7 \\
5\end{array}$ & $\begin{array}{l}180 \\
6 \\
5 \\
\end{array}$ \\
\hline $\begin{array}{l}\text { 2-BuOH } \\
3 \mathrm{~m}-2-\mathrm{BuOH} \\
\text { 3-PentOH } \\
\text { 2m-3-PentOH }\end{array}$ & $\begin{array}{l}26 \\
1 \\
11 \\
13 \\
\end{array}$ & $\begin{array}{l}20 \\
0 \\
9 \\
2 \\
\end{array}$ \\
\hline $\begin{array}{l}\mathrm{CH}_{4} \\
\mathrm{C}_{2}-\mathrm{C}_{4} \mathrm{HC}\end{array}$ & $\begin{array}{l}14 \\
24 \\
\end{array}$ & $\begin{array}{l}22 \\
22 \\
\end{array}$ \\
\hline $\begin{array}{l}\% \mathrm{CO} \text { Conv. } \\
\left(\mathrm{CO}_{2} \text {-free }\right)\end{array}$ & 8.5 & 6.2 \\
\hline
\end{tabular}


(ii) Finish data analysis for the catalytic testing and characterization carried out with $\mathrm{Cs} / \mathrm{Cu} / \mathrm{ZnO} / \mathrm{Cr}_{2} \mathrm{O}_{3}$ catalyst, both by itself and in the configuration of $\mathrm{Cs} / \mathrm{Cu} / \mathrm{ZnO} / \mathrm{Cr}_{2} \mathrm{O}_{3} \| \mathrm{Cs} / \mathrm{Cu} / \mathrm{ZnO} / \mathrm{Cr}_{2} \mathrm{O}_{3}$ dual-bed catalysts at different reaction temperatures; these catalysts were systematically tested for the synthesis of methanol and isobutanol. In addition, complete the revision of a full manuscript describing this research.

3.4 Chemicals from Synthesis Gas - No progress to report this quarter.

\subsection{Poison Resistant Catalyst Development and Testing}

\subsubsection{Alternate Fuels Field Test Unit (AFFTU)}

Construction of the AFFTU, which began in June 1995, was completed, and the equipment will be ready for a shakedown run in mid April. The project has remained basically on schedule and on budget, in spite of a significant cost and time overrun in the electrical installation work.

The Air Products Hazards Review process was completed in March. The results of this review were forwarded to Eastman Chemicals for their review, in preparation for the feed tests to be performed on-site at Eastman (Kingsport, Tenn.) in May/June of this year. The safety strategy and controls have been approved by both parties, with only minor changes recommended. These have been adopted and implemented. We have had ongoing dialogue with Eastman to verify such elements as schedule, site preparation, utility tie-ins, and emergency response procedures.

Two key technical hurdles were surmounted in our analytical methods: (a) analysis of trace hydrogen sulfide, which readily reacts with tubing, valves, and other process equipment before reaching the point of analysis and (b) analysis of both DME and methanol using the GC configuration that was originally specified and supplied. The former problem was minimized by using specially passivated tubing and regulators; however this is no guarantee that temporary pulses of trace $\mathrm{H}_{2} \mathrm{~S}$ in the Eastman gas might not disappear in tie-in piping long before they reach the AFFTU. The latter problem was eventually solved by switching the methanol and DME analysis from the TCD to the FID and using a different column for the FID separation. While DME analysis is only a minor issue for the Kingsport work, it will become important for future experimentation.

In the shakedown run, stable methanol activity was observed over a 250 -hour test period (Figure 3.5.1). The observed methanol productivity of $18-19 \mathrm{gmol} / \mathrm{hr} \mathrm{kg}$ was consistent with past runs using Texaco feed gas under similar conditions $\left(250^{\circ} \mathrm{C}, 750 \mathrm{psig}, \mathrm{GHSV}=6000 \mathrm{~L} / \mathrm{hr} \mathrm{kg}\right)$. Additionally, the ability of the analytical system to detect and identify key catalyst poisons and the ability of the four-bed adsorption system to selectively remove these poisons from the feed stream were demonstrated (Table 3.5.1). Several critical problems with process control and data acquisition surfaced during this testing; while they were eventually solved, the schedule of the Eastman testing had to be pushed back one week. Transport of the AFFTU to Kingsport is now scheduled for 6 May; details of the workplan are given in Table 3.5.2. 
Figure 3.5.1 Stability of Methanol Synthesis Over the 250 Hours Shakedown Run

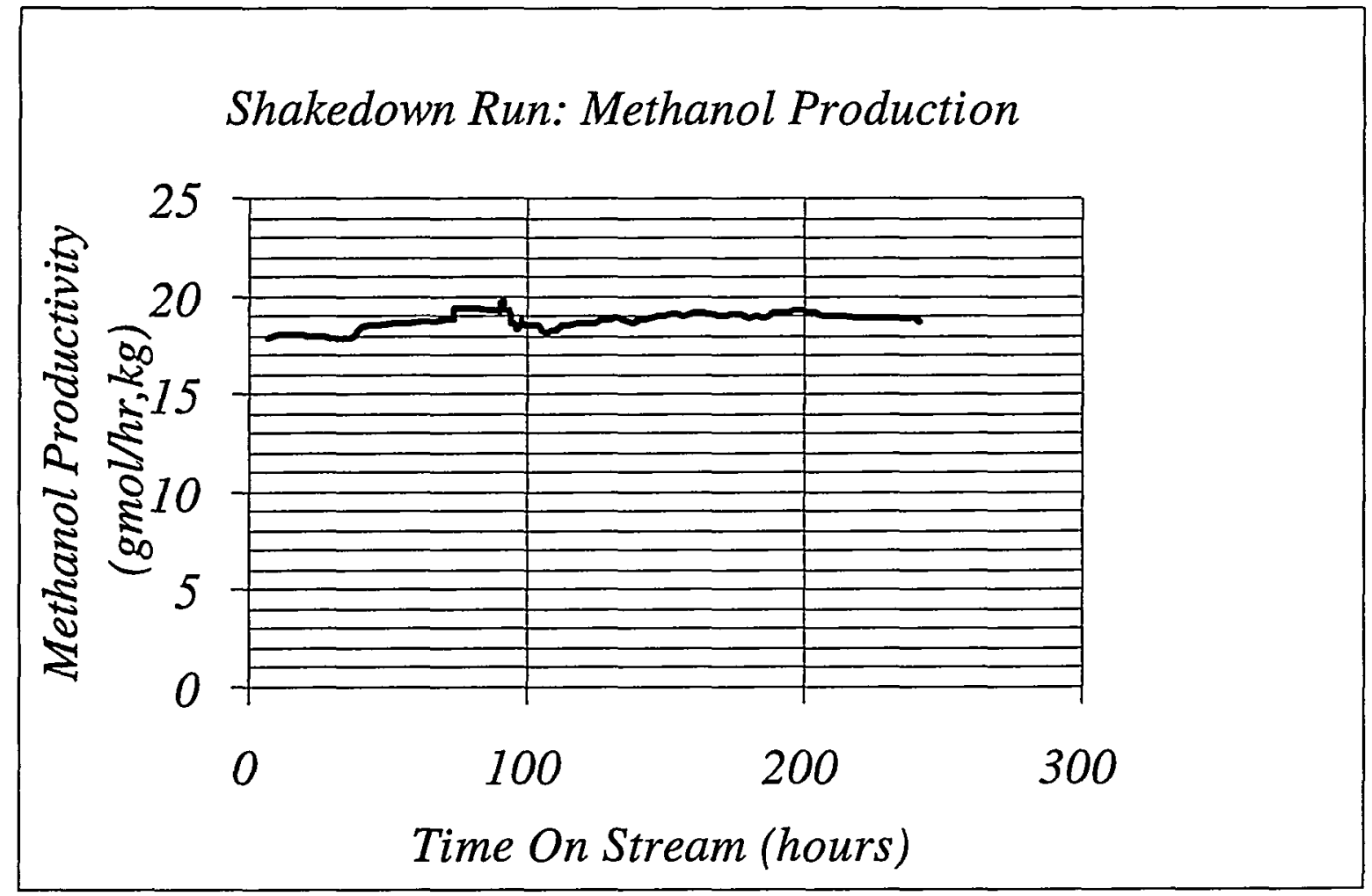

Table 3.5.1 Shakedown Run Poisons/Adsorption History

\begin{tabular}{|l|l|l|l|l|l|}
\hline $\begin{array}{l}\text { Time On } \\
\text { Feed }\end{array}$ & $0-71$ hrs. & $71-100$ hrs. & $100-180$ hrs. & $180-192$ hrs. & $192-240$ hrs. \\
\hline $\begin{array}{l}\text { Nickel } \\
\text { Carbonyl } \\
\text { (1.45 ppm in } \\
\text { Feed })\end{array}$ & $\begin{array}{l}\text { Removed on } \\
\text { Bed\#1 }\end{array}$ & $\begin{array}{l}\text { Breakthru } \\
\text { Beds \#1 \& } \\
\# 2 ; \text { Removed } \\
\text { on Bed \#3 }\end{array}$ & $\begin{array}{l}\text { Removed on } \\
\text { Bed \#3 }\end{array}$ & $\begin{array}{l}\text { Removed on } \\
\text { Bed \#3 }\end{array}$ & $\begin{array}{l}\text { Removed on } \\
\text { Bed \#3 }\end{array}$ \\
\hline $\begin{array}{l}\text { Iron Carbonyl } \\
(2.73 \text { ppm in } \\
\text { Feed })\end{array}$ & $\begin{array}{l}\text { Removed on } \\
\text { Bed\#1 }\end{array}$ & $\begin{array}{l}\text { Removed on } \\
\text { Bed\#1 }\end{array}$ & $\begin{array}{l}\text { Removed on } \\
\text { Bed\#1 }\end{array}$ & $\begin{array}{l}\text { Removed on } \\
\text { Bed\#2 }\end{array}$ & $\begin{array}{l}\text { Breakthrough } \\
\text { Bed \#2; } \\
\text { Removed on } \\
\text { Bed\#3 }\end{array}$ \\
\hline
\end{tabular}


Table 3.5.2 AFFTU Schedule for Kingsport Tests

\begin{tabular}{|c|c|c|}
\hline Now $-4 / 29$ & & \begin{tabular}{|l|} 
Final Testing of Control and Data Acquisition System \\
\end{tabular} \\
\hline $\mathrm{M} 4 / 29-\mathrm{F} 5 / 3$ & & Disassembly and Packing \\
\hline $\mathrm{M} 5 / 6-\mathrm{W} 5 / 8$ & & Trailer transport from Iron Run to Kingsport \\
\hline $\mathrm{W} 5 / 7,8$ & & $\begin{array}{l}\text { Arrival of Tom Dahl and Andrew Wang, Dean Chin-Fatt (GC expert) } \\
\text { and Kevin Snyder (Electronics/IEAS) at Kingsport }\end{array}$ \\
\hline $\mathrm{W} 5 / 8-\mathrm{F} 5 / 10$ & & $\begin{array}{l}\text { Kingsport safety indoctrination (AW \& TD), setup and testing of } \\
\text { equipment, alarm calibration (KS), shakedown of GC system, reactor } \\
\text { loaded and pressure checking. }\end{array}$ \\
\hline$\sim \mathrm{F} 5 / 10$ & $\begin{array}{l}\text { Day } \\
\#\end{array}$ & ORI with Eastman representatives \\
\hline $\mathrm{F} 5 / 10-\mathrm{Su} 5 / 12$ & 1,2 & $\begin{array}{l}\text { Reduction of Bed \#1 and reactor catalyst. Dean and Kevin depart } \\
\text { once systems are functioning satisfactorily (Friday, Saturday or } \\
\text { Sunday). }\end{array}$ \\
\hline M5/13 & 3 & $\begin{array}{l}\text { Syngas feed through full adsorption system -- complete GC analysis } \\
\text { of feed, product and intermediate flows. Start with syngas alone, } \\
\text { then add makeup CO. }\end{array}$ \\
\hline $\mathrm{T} 5 / 14$ & 4 & Begin feed to reactor with ramping to $250^{\circ} \mathrm{C}$ and $750 \mathrm{psig}$. \\
\hline T5/14 - Th5/16 & 5,6 & $\begin{array}{l}\text { Reaction run using all four adsorption beds -- confirm stability of } \\
\text { methanol production. }\end{array}$ \\
\hline $\mathrm{F} 5 / 17$ & 7 & $\begin{array}{l}\text { Remove Bed \#4 from feed pretreatment -- confirm stability and } \\
\text { poison-free flows. }\end{array}$ \\
\hline S5/18 & 8 & $\begin{array}{l}\text { Remove Bed \#1 from feed pretreatment -- confirm stability and } \\
\text { poison-free flows. }\end{array}$ \\
\hline Su5/19 & 9 & $\begin{array}{l}\text { Remove Bed \#2 from feed pretreatment -- confirm stability and } \\
\text { poison-free flows. }\end{array}$ \\
\hline M5/20 & 10 & $\begin{array}{l}\text { Remove Bed \#3 from feed pretreatment -- begin long-term stability } \\
\text { tests with no guard beds in place. }\end{array}$ \\
\hline $\mathrm{M} 6 / 10$ & 31 & $\begin{array}{l}\text { Long-term stability test ends. Criteria for success are three weeks on } \\
\text { stream with no guard beds and a final methanol productivity greater } \\
\text { than } 90 \% \text { of the original "steady-state" value achieved during the } \\
\text { guard bed phase of the run. }\end{array}$ \\
\hline $\mathrm{T} 6 / 11$ & & System shutdown and depressurization \\
\hline W6/12 & & Regeneration of the adsorption beds; purging of reactor. \\
\hline Th6/13 & & $\begin{array}{l}\text { Passivation of Bed \#1 in } 2 \% \text { oxygen; emptying of Beds \#2-4 with } \\
\text { sample collection for analysis. }\end{array}$ \\
\hline $\mathrm{F} 6 / 14$ & & Emptying of Bed \#1 and reactor with sample collection. \\
\hline $\mathrm{S} 6 / 15-\mathrm{R} 6 / 20$ & & Disassembly and packing. \\
\hline $\mathrm{F} 6 / 21$ & & Target date for trailer to leave Eastman/Kingsport \\
\hline
\end{tabular}


Composition and Flow Rate Information

\begin{tabular}{|l|ccc|}
\hline & $1^{\circ}$ Feed (Str. 30) & $2^{\circ}$ Feed (Str. 10) & Autoclave Feed \\
\hline Flow Rate & $2475 \mathrm{sccm}$ & $825 \mathrm{sccm}$ & $3000 \mathrm{sccm}$ \\
Hydrogen & $67.8 \%$ & $2.0 \%$ & $51.35 \%$ \\
Carbon & $27.7 \%$ & $97.0 \%$ & $45.02 \%$ \\
Monoxide & & & \\
Nitrogen & $0.5 \%$ & $1.0 \%$ & $0.63 \%$ \\
Carbon Dioxide & $4.0 \%$ & $0.0 \%$ & $3.00 \%$ \\
\hline
\end{tabular}

\subsubsection{Contingency Plans if Poisons Are Detected}

Contingency Plan \#1 -- Poisons observed via GC prior to putting reactor on line (Test Day 3) Determine whether poison is due to primary feed, secondary feed or in-situ generation on one of the beds. Assuming that poison is in one of the feeds, work with Eastman to identify the cause and decide whether test should be continued. If poison is identified by GC (metal carbonyl or sulphide), verify that it is removed by the appropriate beds. Proceed with Test Days 4-9, but modify order of adsorbent bed removal appropriately. Verify stable operation with minimum guard beds in place. After two weeks of stable operation (assuming concentration is low enough to permit two weeks' operation), remove the last guard bed and monitor methanol activity for two additional weeks.

If poison is produced in-situ on one of the beds, remove it from the system and verify that poison is no longer observed. Proceed with operating plan as originally designed.

Contingency Plan \#2 -- Poisons not observed via GC, but methanol synthesis catalyst displays deactivation.

Hopefully this problem will be detected during Test Days 5-9, so that it will be clear which adsorbent bed is needed to remove the unknown poison. The objective will become identification of this poison by collecting it either on an adsorbent bed or, if none of the beds is effective at removing it, on the catalyst itself. These materials will be brought back to Air Products for analysis using some sophisticated techniques. In this scenario, it will also be valuable to communicate with Eastman to determine whether any upsets have occurred or if they can provide any other insights into the nature of the poisoning.

During Test Days 5-9 we will need to carefully evaluate any potential signs of deactivation. Due to the occasional scatter in the data, it will be easy to have "false alarms." If we suspect deactivation after removing one of the adsorbent beds, we may follow the performance for longer than the allotted one day to confirm poisoning before making any other changes to the experiment.

\section{Contingency Plan \#3 -- Poisoning due to an upset condition}

Presumably this will be seen via GC. If no guard beds are in place at the time, it will provide some data regarding how well the catalyst will respond to these excursions. If the duration of the excursion is sufficiently long, we can protect the catalyst with the appropriate guard bed for the balance of the upset. 


\section{TASK 4: PROGRAM SUPPORT}

\subsection{Economics of MTBE via Mixed Alcohol Synthesis (Bechtel Corporation)}

\section{Introduction}

The primary objective of this DOE/PETC-funded study is to evaluate the use of a liquid phase mixed alcohol synthesis (LPMAS) plant to produce gasoline blending ethers. This evaluation will then be used to determine a target for catalyst development and reactor design.

The LPMAS plant was integrated into three utilization scenarios:

- Case 1 - A base-load, coal-fed integrated gasification combined cycle (IGCC) utility plant.

- Case 2 - A petroleum refinery. The syngas feed is derived from gasifying petroleum coke.

- Case 3 - A stand-alone LPMAS plant. The syngas feed is derived from the partial oxidation of natural gas.

This paper summarizes the basis and the results for each of the case studies, and identifies the required catalyst productivities for an economical utilization.

\section{Common Study Basis}

The following assumptions were common to all three cases.

\section{LPMAS Yield}

The starting point for developing the LPMAS reactor product selectivity was a paper by Heydorn, et al.,' which provided data on the coproduction of methanol and isobutanol.

The major nonalcohol organic by-products were hydrocarbons (light paraffins) and esters. It was assumed that the production of the hydrocarbon and ester by-products could be excluded in the present study because:

- The demonstrated by-product yields are low, and further catalyst development should lead to more selective production to alcohols.

\begin{tabular}{|l|c|}
\hline \multicolumn{2}{|l|}{$\begin{array}{l}\text { Table 4.1.1 Study Basis - Alcohol } \\
\text { Product Distribution }\end{array}$} \\
\hline Component & Alcohol (mol\%) \\
\hline Methanol & 48.83 \\
\hline Ethanol & 0.0 \\
\hline Propanol & 0.0 \\
\hline n-Butanol & 0.84 \\
\hline i-Butanol & 47.56 \\
\hline n-Pentanol & 0.28 \\
\hline i-Pentanol & 1.42 \\
\hline n-Hexanol & 0.25 \\
\hline i-Hexanol & $\underline{0.82}$ \\
\hline \multicolumn{1}{|c|}{ Total } & 100.00 \\
\hline
\end{tabular}


- If these by-products were part of the product mix, they would be utilized as fuel and would have the same value on a BTU basis as the unconverted syngas. In other words, having a small amount of hydrocarbons and esters in the product mix would have very little effect on the overall analysis.

It was also assumed that the production of ethanol and propanol could be eliminated by using a more selective catalyst and/or by fractionating the raw product and recycling the ethanol and propanol back to the LPMAS reactor.

\section{Alcohol Selectivity}

Since MTBE currently has a higher market price than methanol ( $\sim 85$ cents/gallon vs. 35 cents/gallon), it was decided to maximize revenues and analyze the LPMAS integration at the optimum methanol/isobutanol ratio to produce ethers. This ratio is 1.03 (there is small amount of methanol required to convert iso-amylene to TAME).

Based on the above assumptions, the alcohol product distribution is shown in Table 4.1.1.

\section{LPMAS Reactor Design Basis}

The design basis for the LPMAS reactor was based on Air Products' autoclave and pilot plant demonstration runs:

Gas hourly space velocity

Temperature

Pressure

Catalyst slurry concentration
$5000 \mathrm{sl} / \mathrm{kg}-\mathrm{hr}$

$315^{\circ} \mathrm{C}$

$1800 \mathrm{psig}$

$40 \mathrm{wt} \%$

\section{Case 1 - IGCC Power Plant}

The scenario for Case 1, a coal-fed IGCC power plant, was chosen for three reasons:

- Coal gasification produces a low $\mathrm{H}_{2} / \mathrm{CO}$ ratio syngas which has been shown to be favorable to higher alcohol production.

- The combined cycle power plant can easily consume low-BTU content, unconverted syngas. This allows for lower syngas conversions in the LPMAS plant.

- Higher power plant availability can be claimed, since the LPMAS plant can be bypassed if there is a partial shutdown of the coal gasification section of the plant. 
Figure 4.1.1 Case 1 - IGCC/LPMAS Block Flow Diagram

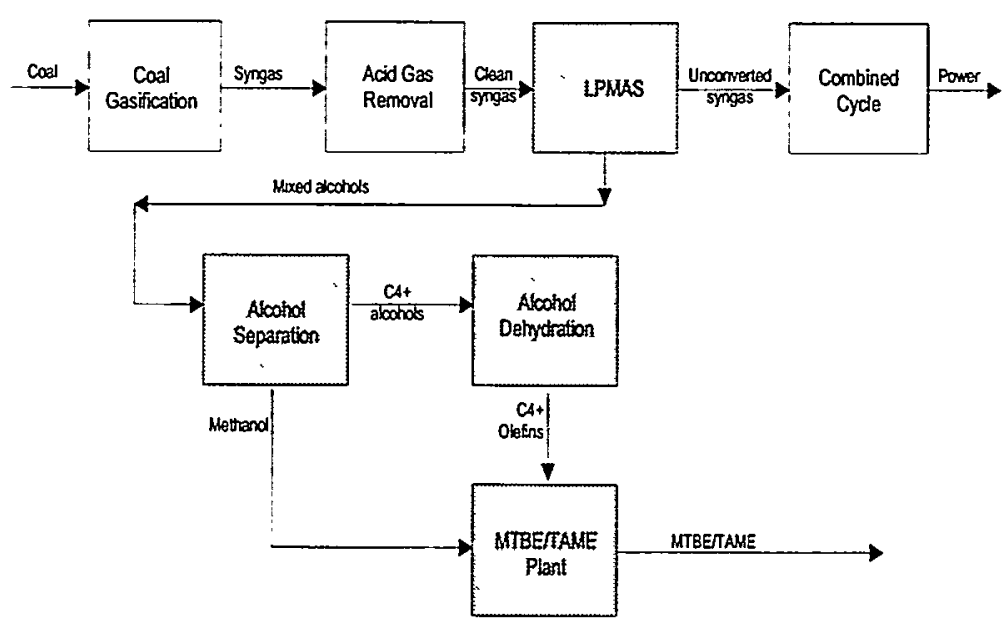

Figure 4.1.1 shows how the LPMAS plant was integrated into the IGCC power plant. The shaded blocks represent plants that need to be added for alcohol/ether production. Shell gasifiers are used to produce a syngas with a $\mathrm{H}_{2} / \mathrm{CO}$ ratio of 0.5 . After cleanup, the entire syngas production is fed to the LPMAS plant, where a portion of the syngas is converted into methanol and higher alcohols. The unconverted syngas is sent to the combined cycle section of the plant for power production. The mixed alcohol stream is separated into methanol and $\mathrm{C}_{4+}$ alcohols. The $\mathrm{C}_{4+}$ alcohols are dehydrated into olefins and are then sent to the ether plant. The isobutylene and iso-amylene portions of the $\mathrm{C}_{4+}$ olefins are converted into MTBE and TAME, respectively.

Power production from the IGCC plant, 385 net MW, was based on the production from a single 3000-stpd Shell gasifier without the addition of a LPMAS system. Since the LPMAS plant consumes a portion of the syngas, the coal feed rate is higher than 3000 stpd to maintain the 385 net MW production level.

In Case 1, overall syngas conversion levels ranging from 20 to $64 \%$ were studied. At conversion levels below $49 \%$, a once-through LPMAS system is utilized. Above $49 \%$, methanol equilibrium limitations require recycling unconverted syngas back to the LPMAS reactor. Figure 4.1.2 shows the effect of recycling on the feed rate to the LPMAS reactor. At overall conversion levels above $60 \%$, the costs of recycling (e.g., larger equipment, multiple trains, recycle compression) become prohibitive. 
Figure 4.1.2 Case 1 - IGCC/LPMAS Reactor Feed Rate

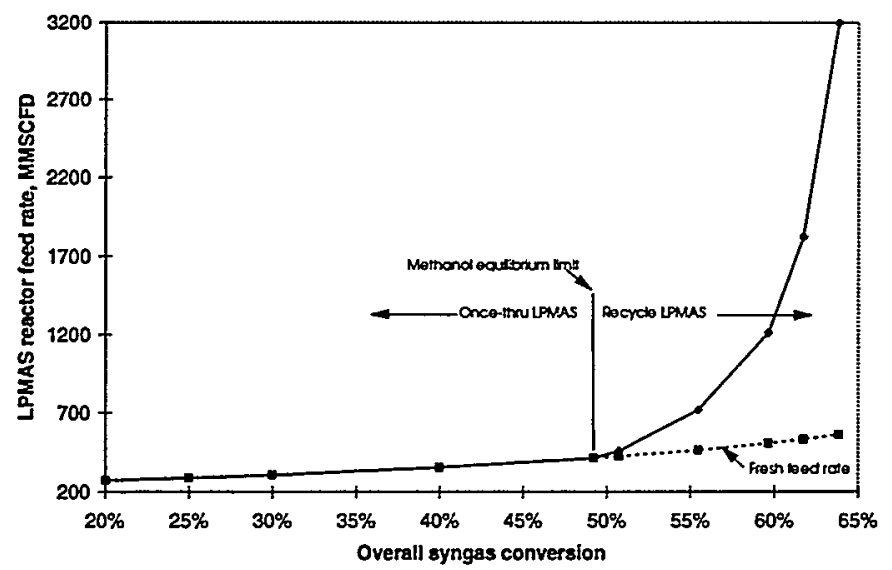

The effect of overall syngas conversion on economic feasibility was determined by calculating the required ether price to achieve a $13 \%$ internal rate of return. Figure 4.1 .3 shows the required price as a function of overall syngas conversion. From 20 to $49 \%$, the required price declines as the conversion of low-value syngas to high-value ethers increases. At $49 \%$ conversion, there is a very small increase in the required price because a recycle system is required at this point. At $51 \%$, there is discontinuity where the number of gasifier trains jumps from two to three. Above $51 \%$, the costs of recycle start to overwhelm the benefit of higher conversion levels. At $64 \%$ overall conversion, the recycle ratio (moles of recycle/moles fresh feed) is 4.7 , and the per pass conversion has declined to $14 \%$.

Also shown in Figure 4.1.3 is the required catalyst productivity. For once-through operation (up to $49 \%$ overall conversion), the required catalyst productivity rises steadily. Above $49 \%$, the productivity decreases as the recycle ratio increases.

\section{Figure 4.1.3 Case 1 - IGCC/LPMAS Required Ether Price and Catalyst Productivity}

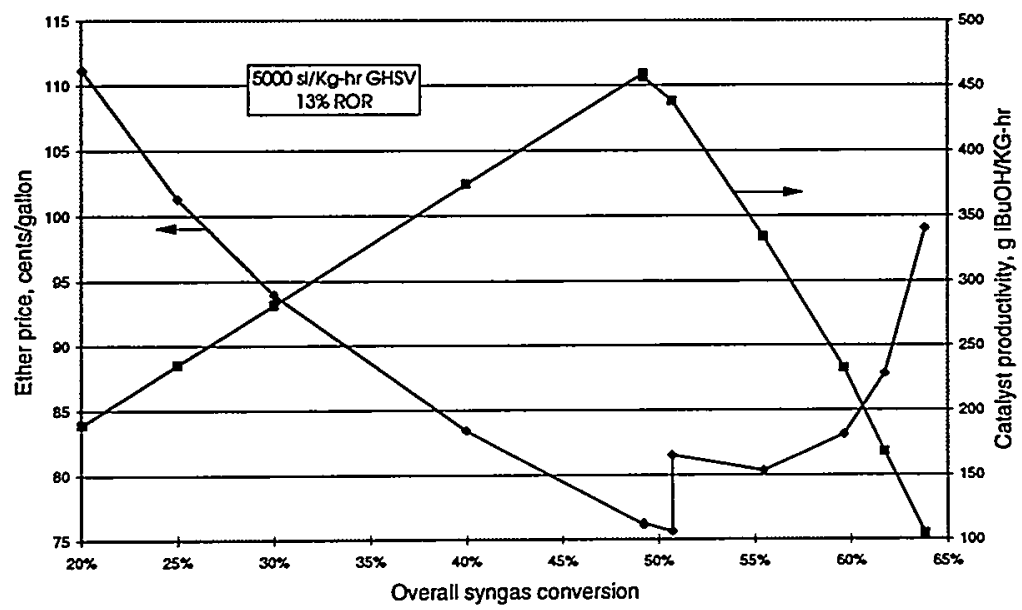




\section{Sensitivity Study - LPMAS Space Velocity}

The effect of the LPMAS reactor space velocity on the economics of an IGCC/LPMAS plant was also examined. Halving or doubling the space velocity (to 2500 or $10,000 \mathrm{sL} / \mathrm{kg}$-hr) results in a small change in the required ether price (2-3 cents/gallon). This occurs because the cost of the LPMAS reactor represents a small portion of the capital cost of the overall plant.

\section{Case 2 - Petroleum Refinery}

The scenario for Case 2, petroleum refinery, was chosen for four reasons:

- Coke gasification produces a low $\mathrm{H}_{2} / \mathrm{CO}$ ratio syngas which has been shown to be favorable to higher alcohol production.

- The feedstock for syngas production--petroleum coke--has a zero or negative value.

- The refinery consumes ethers for oxygenated or reformulated gasolines.

- The refinery can consume a limited amount of unconverted syngas.

Figure 4.1.4 shows how the LPMAS plant was integrated into an existing petroleum refinery. The shaded blocks represent the new plants that are required. Syngas from an 1800-stpd coke gasification plant is sent to acid gas removal, where $\mathrm{H}_{2} \mathrm{~S}$ and $\mathrm{CO}_{2}$ are removed. The clean syngas, having a $\mathrm{H}_{2} / \mathrm{CO}$ ratio of 0.4 , is sent to the LPMAS plant. The mixed alcohols from the LPMAS plant are separated and the $\mathrm{C} 4+$ alcohols are dehydrated. The primary products from the new plants are methanol, $\mathrm{C} 4+$ olefins and unconverted syngas. These products are consumed by the refinery to produce additional ethers and reduce the amount of purchased MTBE.

\section{Figure 4.1.4 Case 2 - Petroleum Refinery/LPMAS Block Flow Diagram}

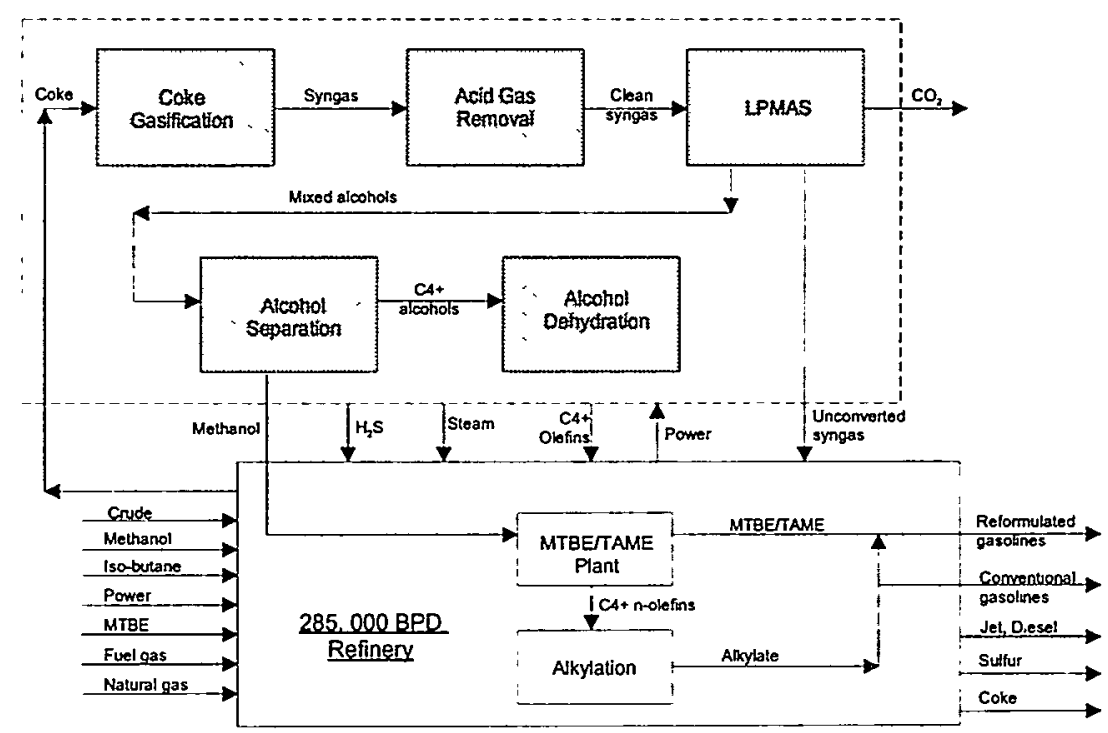

There are several key differences between Case 2 and Case 1:

- There is a single overall syngas conversion level, $95 \%$. This level was chosen so that the refinery fuel system would not be diluted with large volumes of low-BTU unconverted syngas. 
- To achieve the $95 \%$ conversion, a recycle LPMAS system is required.

- Steam is added to the LPMAS feed to provide hydrogen via internal water gas shift (WGS).

- $\mathrm{CO}_{2}$ (generated by WGS) is removed from the LPMAS recycle loop.

\section{Figure 4.1.5 Case 2 - Refinery/LPMAS - Rate of Return - Catalyst Productivity}

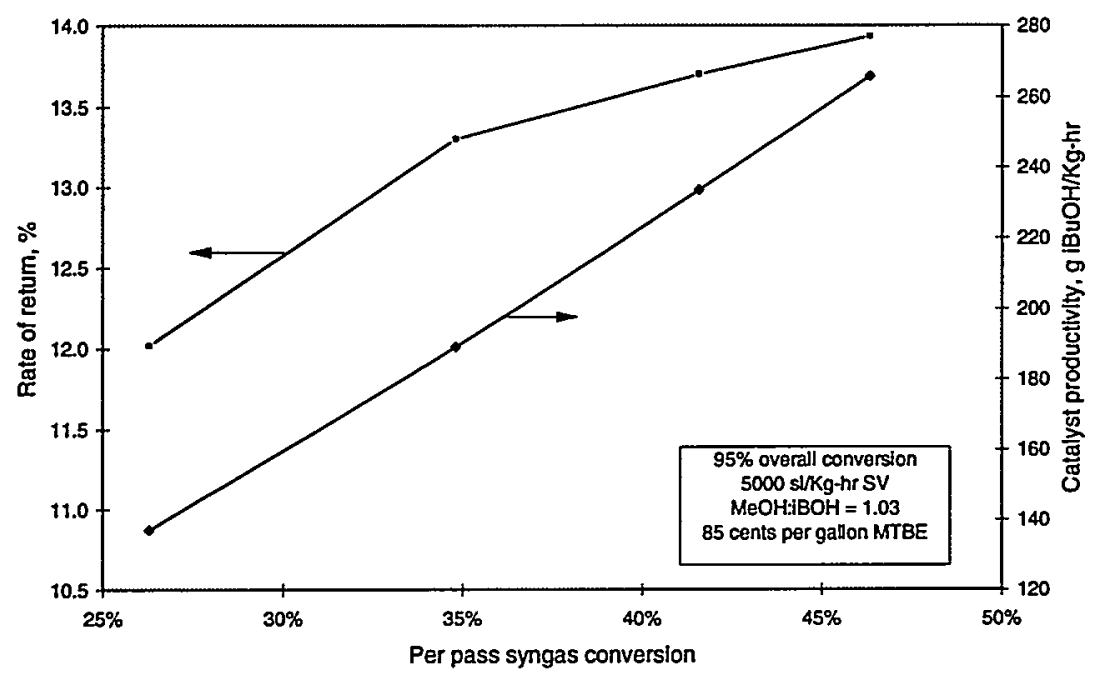

The Bechtel Process Industry Modeling System (PIMS) linear program was used to determine the rate of return at the current market MTBE price of 85 cents per gallon. Recycle ratios were varied between 2.1 and 4.7. Figure 4.1.5 shows the rate of return and the required catalyst productivity as a function of per pass conversion. Higher recycle rates are needed to achieve the $95 \%$ overall syngas conversion as the per pass conversion declines. The rate of return decreases because of the higher cost of recycling. The highest rate of return is at the methanol equilibrium limit (highest per pass conversion/lowest recycle ratio). However, higher recycle ratios do permit lower catalyst productivities. 
Figure 4.1.6 Case 3 - Standalone LPMAS Block Flow Diagram

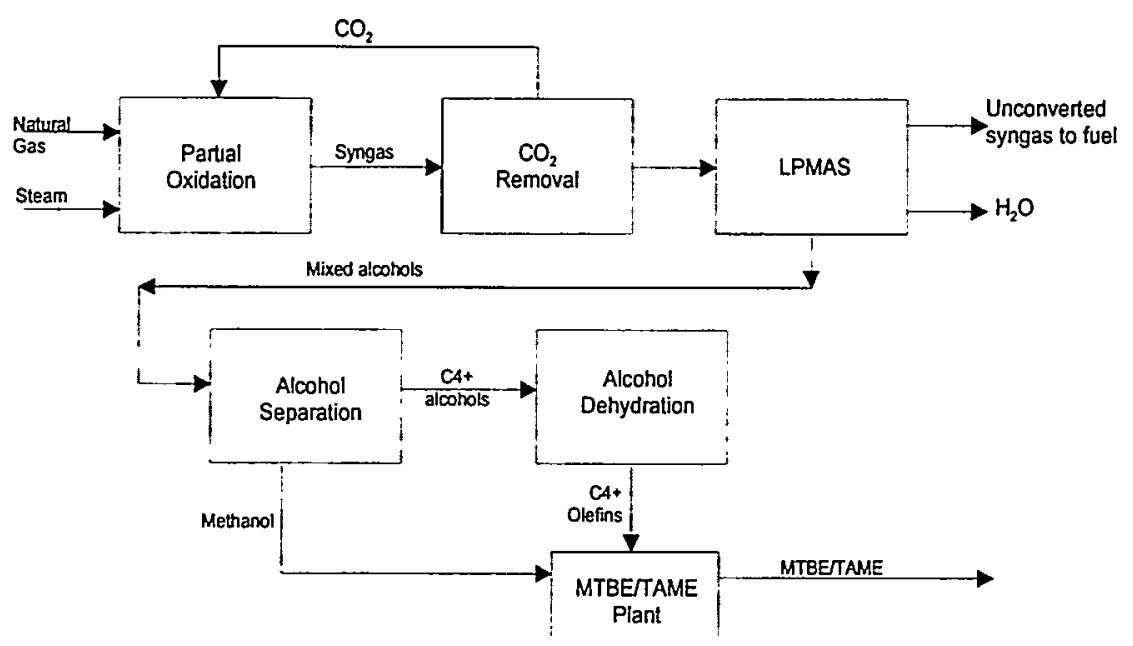

The scenario for Case 3, a stand-alone LPMAS plant, was chosen because of the potential for low cost natural gas feedstock in certain situations, and because it is less expensive to produce syngas from natural gas than from coal or coke.

Figure 4.1.6 shows the key components for the stand-alone plant. 230 MMSCFD of natural gas is partially oxidized with steam and oxygen. $\mathrm{CO}_{2}$ is recovered from the syngas and recycled back to the POX plant to reduce the $\mathrm{H}_{2} / \mathrm{CO}$ ratio. Syngas, having a $\mathrm{H}_{2} / \mathrm{CO}$ ratio of 1.54 , is sent to the LPMAS plant. The balance of the system is similar to Case 1 .

The key differences between Cases 2 and 3 are:

- To achieve a fuel balanced plant, a syngas conversion level of $98 \%$ is required.

- The natural gas feed price is $\$ 1 / \mathrm{MMBTU}$

Similar to Case 1, the required ether price to achieve a $13 \%$ rate of return was determined. As with Case 2, a recycle LPMAS system was required to achieve the $98 \%$ overall syngas conversion. Recycle ratios were varied between 2.3 and 5.7. Figure 4.1 .7 shows that the lowest required ether price is at the methanol equilibrium limit (highest per pass conversion/lowest recycle ratio).

Sensitivity Study - Elimination of $\mathrm{CO}_{2}$ Recovery System -

The $\mathrm{CO}_{2}$ recovery system shown in Figure 4.1 .6 represents about 25\% of the capital cost of producing the syngas. A sensitivity study was conducted from which the $\mathrm{CO}_{2}$ system was deleted. Aside from the cost savings, the key change is that the $\mathrm{H}_{2} / \mathrm{CO}$ ratio increases from 1.54 to 2.02 . With this syngas, it was immediately apparent that the methanol equilibrium limitation dictates a high recycle ratio (5.7) to achieve the $98 \%$ conversion requirement. Since this is a $\mathrm{H}_{2}$ - 
rich syngas, it was decided to investigate the effect of increasing the methanol/isobutanol selectivity ratios. At higher selectivity ratios, overall capital costs are lower because of lower recycle ratios. However, as the selectivity ratio increases, more methanol and less MTBE is produced. At the current market price of 35 cents/gallon, methanol has a much lower product value than MTBE, and the overall revenues decrease. Figure 4.1.8 shows the effect of selectivity ratio on the required ether price. A minimum is reached at a selectivity ratio of 4.0 when the capital savings from the decline in recycle requirements is just offset by decreases in revenues because of higher methanol (lower MTBE) production.

\section{Figure 4.1.7 Case 3 - Standalone LPMAS - Required Ether Price - Catalyst Productivity}

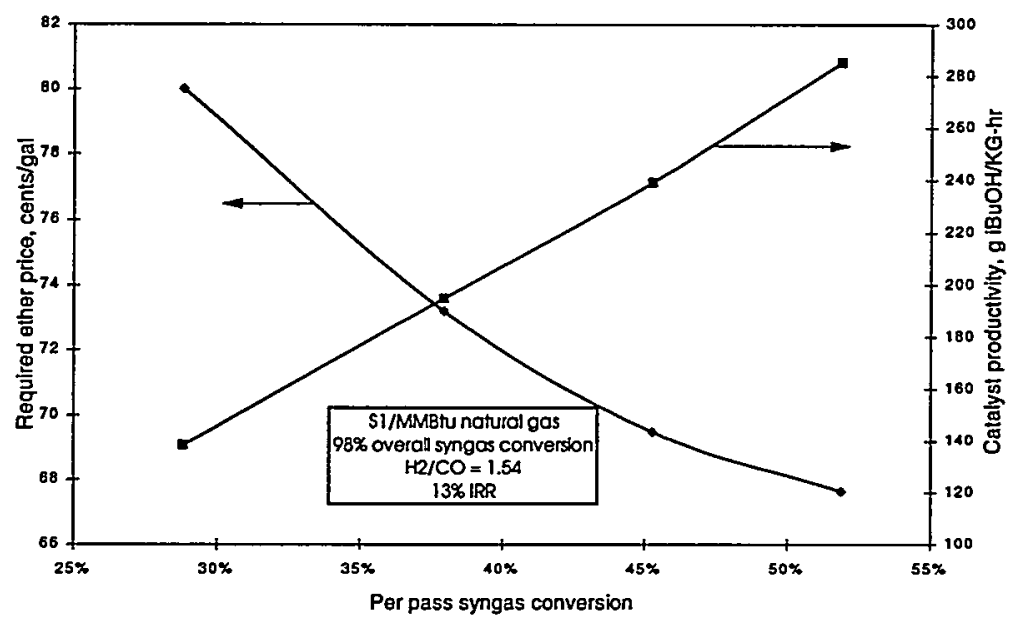

Figure 4.1.8 Case 3 - Standalone LPMAS - Sensitivity Study - Required Ether Price Recycle Ratio @ $\mathrm{H}_{2} / \mathrm{CO}=\mathbf{2 . 0 2}$

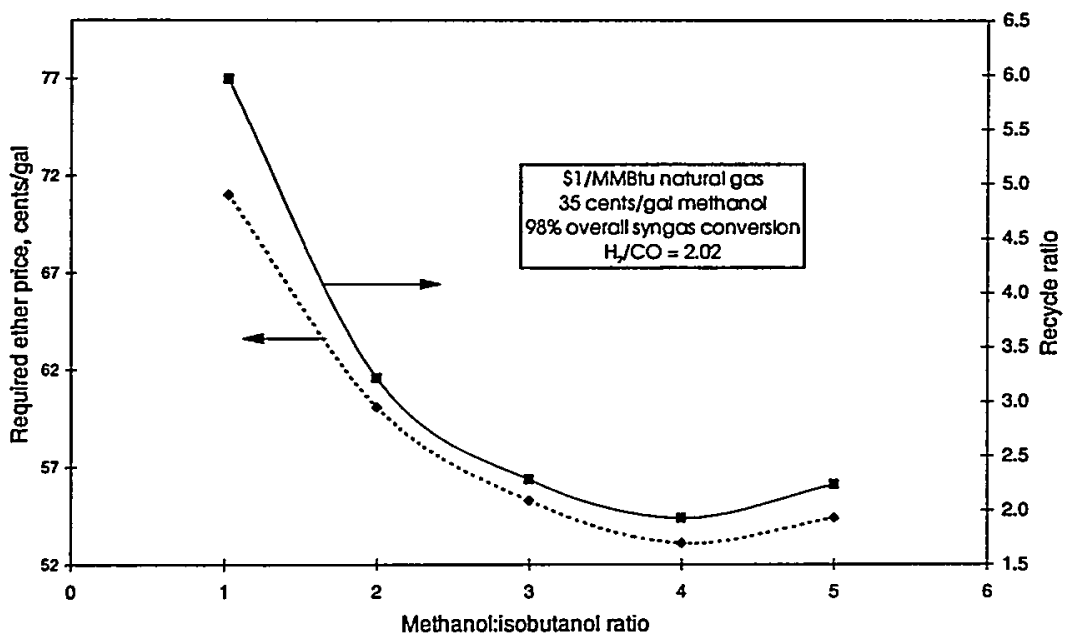

\section{Summary}

Although not all presented in this paper, this study has examined a number of factors that had significant bearing on the results of the study:

- Methanol/isobutanol selectivity

- Syngas $\mathrm{H}_{2} / \mathrm{CO}$ ratio 
- Syngas conversion/disposition of unconverted syngas

- Recycling of syngas to LPMAS reactor

- Methanol equilibrium limitation

- LPMAS reactor space velocity

- $\mathrm{CO}_{2}$ removal

- Steam addition

- Plant location

- Feedstock costs

In using this study, it is important to bear in mind that the results (e.g., catalyst productivity) are very specific to the selected conditions.

Table 4.1.2 summarizes the operating conditions for the most economic scenario for each case. Also included is the Case 3 sensitivity study in which the methanol/isobutanol selectivity ratio was raised from 1.03 to 4.0 .

For Case 1, to produce an ether product that is at or below the current MTBE market price of 85 cents per gallon with a once-through LPMAS system, the required catalyst productivity would need to be in the range of $370-460 \mathrm{~g}$ iBuOH $/ \mathrm{kg}-\mathrm{hr}$ (methanol/isobutanol ratio - 1.03). For Case 2 , the most economic case is that in which the LPMAS reaction is at methanol equilibrium. The internal rate of return is $13.9 \%$ and the required catalyst productivity is $265 \mathrm{~g} \mathrm{iBuOH} / \mathrm{Kg}-\mathrm{hr}$. For Case 3, the most economic case is also that in which the LPMAS reaction is at methanol equilibrium. For $\$ 1 / M M B T U$ natural gas feedstock, the required ether price is 68 cents/gallon. For $\$ 2 / M M B T U$ natural gas feedstock, the required ether price is 84 cents/gallon. Table 4.1.2 also shows that for higher $\mathrm{H}_{2} / \mathrm{CO}$ ratio syngas, there is potential for higher returns if coproduction of methanol and ethers is an option.

\begin{tabular}{|l|c|c|c|c|}
\hline \multicolumn{5}{|c}{ Table 4.1.2 Summary of Conditions } \\
\hline Case & 1 & 2 & 3 & $3 \mathrm{~S}$ \\
\hline Feed & Coal & Coke & NG @ \$1 & NG @ \$1 \\
\hline Syngas $\mathrm{H}_{2} / \mathrm{CO}$ ratio & 0.5 & 0.4 & 1.54 & 2.02 \\
\hline LPMAS reactor feed $\mathrm{H}_{2} / \mathrm{CO}$ ratio & 0.5 & 0.5 & 1.8 & 3.3 \\
\hline MeOH:iBuOH ratio & 1.03 & 1.03 & 1.03 & 4.0 \\
\hline LPMAS syngas recycle ratio & 0 & 2.0 & 2.3 & 1.9 \\
\hline Per pass conversion, \% & $38-49$ & 48 & 52 & 45 \\
\hline Overall conversion, \% & $38-49$ & 95 & 98 & 98 \\
\hline Productivity, g iBuOH/kg-hr & $370-460$ & 265 & 285 & 181 \\
\hline \multicolumn{1}{|c|}{ g MeOH/kg-hr } & $165-205$ & 118 & 126 & 314 \\
\hline Req'd ether price @ 13\% IRR, cents/gal & $85-76$ & & 68 & 53 \\
\hline IRR at 85 cents/gal ether, \% & & 13.9 & & \\
\hline
\end{tabular}




\section{Conclusions}

For all three scenarios, economical LPMAS plants are possible even at current ether market prices. However, large improvements in catalyst productivity and alcohol selectivity must be achieved prior to commercialization of this process. If inexpensive natural gas feedstock is available, because of less demanding catalyst productivity and selectivity requirements, coproduction of methanol and ethers looks attractive.

\section{References}

1. Heydorn, E.C., E.S. Schaub, V. E. Stein, R.P. Underwood, and F.J. Waller, "Recent Progress on Syngas Conversion to Isobutanol," 1994 Coal Liquefaction and Gas Conversion Contractors' Review Conference, September 7-8, 1994, Pittsburgh, Pennsylvania.

\subsection{Economic Incentive to Develop a Sulfur-Tolerant Methanol Synthesis Catalyst for Coal Gasification and Other High-Sulfur Feedstock Applications}

\section{Introduction}

By developing a more sulfur-tolerant synthesis catalyst, the costs associated with the production of methanol from coal can be reduced. This cost saving has to be evaluated by catalyst developers/suppliers to determine whether there is sufficient incentive, together with market opportunity, to warrant developing such a catalyst.

This report summarizes the study work performed and presents the results of the cost savings realized by relaxing the sulfur removal specification from $<0.1$ ppmv total sulfur in the treated syngas to 20-30 ppmv total sulfur, for four different syngases, each using a different sulfur removal technology.

The sulfur removal technologies selected for evaluation are all "regenerable solvents" - a class of commercially proven solvents and the main technology in use today for sulfur removal. In some cases, to achieve the required sulfur specification, pre- and post-solvent processing are necessary.

This work is part of the Alternative Fuels and Chemicals from Synthesis Gas subcontract (No. PT5781B) between Air Products and Bechtel.

\section{Need for a Sulfur-Tolerant Catalyst}

- Cost Savings - Lower capital and operating costs for sulfur removal are a result of relaxing the sulfur removal specification. For a high-sulfur coal, with $1.5 \mathrm{~mol} \%$ sulfur species in the raw syngas, treating to $20 \mathrm{ppmv}$ total sulfur is equivalent to a three-nines reduction (99.87\%), compared to the greater than five-nines reduction $(99.9996 \%)$ required for conventional methanol catalyst.

- Selective $\mathrm{H}_{2} \mathrm{~S}$ Removal - For applications in which the $\mathrm{CO}_{2}$ content of the syngas is high, coabsorption/removal of $\mathrm{CO}_{2}$ can be costly, and undesirable. Lowering the treated syngas specification can simplify the design of the sulfur removal plant for selective $\mathrm{H}_{2} \mathrm{~S}$ removal and increase the quality of the feed gas to the sulfur recovery unit.

- Expanded Technology Range - Certain preferred solvents, which are noncompetitive at deep removal efficiencies, can now be added to the list of potential processes. Emerging 
technologies, such as regenerable solid sorbents (hot-gas cleanup technology), can also be included on the list of potential processes for sulfur removal.

- Single Sulfur Specification - For a combined power generation/methanol production facility, relaxing the treated syngas sulfur specification to $20 \mathrm{ppmv}$ would simplify the sulfur removal plant by producing a single treated gas stream instead of two streams, each with a different sulfur specification.

\section{Study Objective}

The objective of this study is to determine the cost savings for a coal-based methanol production facility operating with a sulfur-tolerant catalyst instead of a conventional catalyst. The cost saving, which is realized through design differences in the sulfur removal plant, is the metric by which the catalyst developers/manufacturers can determine whether or not there is sufficient incentive to develop a sulfur-tolerant catalyst.

\section{Study Basis}

Gasification Conditions Oxygen-blown, 450-psig operating pressure

Syngas Composition Determined for each gasifier/feedstock combination

Syngas composition is not adjusted to methanol synthesis stoichiometry

Syngas Flow Rate

The flow rate of each clean syngas corresponds to a higher heating value of $515 \mathrm{MW}$

Syngas Sulfur Species

All organic sulfur in feedstock is assumed to be gasified and distributed between $\mathrm{H}_{2} \mathrm{~S}$ and $\mathrm{COS}$

Treated Syngas Total $<0.1$ ppmv - conventional methanol synthesis catalyst

Sulfur Specification 20-30 ppmv - sulfur-tolerant methanol synthesis catalyst

Treated Syngas Delivery 1100 psig

Pressure

\section{Sulfur Removal Plant - Equipment Scope}

- Regenerable solvent system plus its associated utilities

- Pre-solvent treating - if required to protect a particular solvent

- Post-solvent treating - if required to achieve the sulfur specification

- Syngas compression

Syngas compression is included because there is an increase in capital and operating costs as a result of pressure losses associated with post-solvent treating. 


\section{Sulfur Removal Technologies}

\section{Regenerable Solvents}

The underlying principle of regenerable solvent sulfur removal is that a solute (sulfur species in the syngas) can be removed from the gas by dissolution on contacting a suitable solvent. The solvent has to be carefully selected such that, under a moderate change in operating conditions, the dissolution process can be reversed, releasing the solute in its original form and regenerating the solvent, which is then reused.

\section{Chemical Solvents}

Chemical solvents offer the advantage of being able to reduce the solute concentration in the treated gas to low levels at low operating pressure, but are limited in the amount of solute that can be absorbed by reaction stoichiometry and chemical equilibrium.

\section{Physical Solvents}

Physical solvents offer the advantage of high capacity for the solute, the capacity being directly proportional to the operating pressure. Lower solvent temperatures increase the solubility of the solute. In addition, the solvent is largely regenerated by pressure reduction alone compared to chemical solvents, which require significant heat input to regenerate the solvent.

\section{Mixed Solvents}

Mixed solvents are mixtures of chemical and physical solvents and exhibit features of both solvents.

\section{Direct Oxidation}

Wet oxidation has a major advantage over traditional solvents, as the need for a dry-oxidation sulfur recovery unit (Claus Plant) is eliminated. However, the state of the technology is such that wet oxidation is only competitive with the Solvent-Claus combinations at sulfur recoveries below 20 tons per day.

\section{Pre-Solvent Purification}

Depending on the particular sulfur removal technology, it is sometimes necessary to include upstream treating as part of the sulfur removal technology, to either protect the solvent from degradation, or to convert a sparingly soluble sulfur species to a more soluble form.

\section{Post-Solvent Purification}

For all regenerable solvents used in commercial sulfur removal operations, the cost of sulfur removal increases rapidly as the sulfur specification of the treated syngas approaches the gas phase equilibrium concentration of the sulfur species in the regenerated solvent. Therefore, it is often necessary to provide a final purification stage to reduce the sulfur content of the syngas to the $<0.1$ ppmv requirement. Traditionally, the system-of-choice has been a fixed-bed of nonregenerable sorbent, such as zinc oxide. $\mathrm{H}_{2} \mathrm{~S}$ in the syngas reacts irreversibly with the sorbent, converting zinc oxide to zinc sulfide. 
For a sulfur removal plant with post-solvent treating, one has to decide how much sulfur to remove with the regenerable solvent, and how much to remove with the nonregenerable sorbent. The cutoff point is determined when the cost of removing the next increment of sulfur from the syngas with solvent exceeds the cost of removing that increment with sorbent.

The cutoff point chosen for all solvents in the study is 5 ppmv total sulfur. Rectisol was evaluated at both 5 ppmv and $<0.1 \mathrm{ppmv}$.

\section{Process Selection}

Table 4.2.1 lists the four different combinations of feedstock, gasifier, and sulfur removal technology evaluated in the study.

\section{Table 4.2.1 Evaluated Combinations of Feedstock, Gasifier, and Sulfur Removal Technology}

\begin{tabular}{|c|c|}
\hline Sulfur Removal Technology & Feedstock/Gasifier \\
\hline $\begin{array}{c}\text { MEA - aqueous alkanolamine } \\
\text { (Chemical Solvent) }\end{array}$ & Petroleum Coke/Shell Coal Gasification Process (SCGP) \\
\hline $\begin{array}{c}\text { Rectisol - chilled methanol } \\
\text { (Physical Solvent) }\end{array}$ & Illinois No. 6 Coal/Texaco Gasification Process (TGP) \\
\hline $\begin{array}{c}\text { Sulfinol - sulfolane/diisopropanolamine/water } \\
\text { (Mixed Solvent) }\end{array}$ & Illinois No. 6 Coal/SCGP \\
\hline $\begin{array}{c}\text { SulFerox - Wet oxidation } \\
\text { (Direct Oxidation) }\end{array}$ & Powder River Basin Coal/TGP \\
\hline
\end{tabular}

\section{Costs Basis}

The equipment costs were developed from in-house data for sulfur removal plants and from vendor quotations. Total project capital costs were developed from estimates for the total field costs, the home-office engineering costs, and a $20 \%$ contingency.

The annual operating costs for the sulfur removal plant were developed from utilities consumption (power, steam and cooling water), catalyst, chemical and solvent consumption, labor costs, maintenance costs, local taxes, insurance, and overheads.

\section{Economic Analysis}

Given the capital costs and annual operating costs for the sulfur removal plant, a discountedcash-flow analysis was performed to determine the annual revenue (a positive cash flow) required to provide a $15 \%$ internal-rate-of-return (IRR) for the sulfur removal plant. The basis for the calculation is as follows:

- Twenty year project life

- $100 \%$ equity financing 
- After-tax basis for IRR

- Double-declining balance depreciation

\section{Economic Incentive}

The economic incentive is defined as the difference in the required annual revenues for a plant designed to achieve $<0.1 \mathrm{ppmv}$ total sulfur in the treated syngas (conventional catalyst) and a plant designed to achieve $20 \mathrm{ppmv}$ (sulfur-tolerant catalyst) using the same solvent.

\section{Figure 4.2.1 Comparison of Sulfur Removal Systems - for Different 0.1 and 20 ppmv Sulfur Specifications}

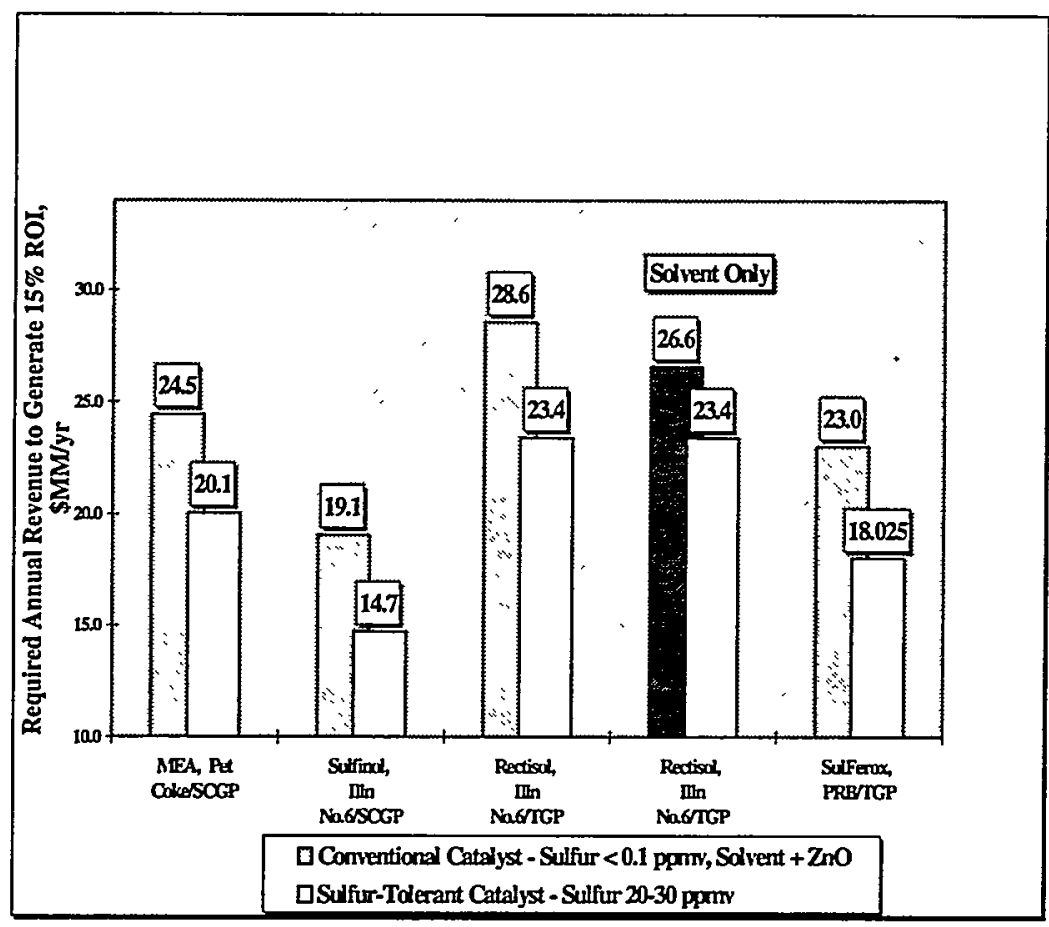

The economic incentive can be considered the net saving between the two different sulfur removal plant designs.

\section{Study Results}

The study results are the economic incentives for each of the four cases. Figure 4.2.1 shows the required annual revenue from product sales to provide a $15 \%$ IRR for the sulfur removal plant for all four solvents when designed to both sulfur specifications. Two sets of results are shown for Rectisol: the first set for solvent sulfur removal to $5 \mathrm{ppmv}$ followed by zinc oxide final purification, and the second set for solvent-alone sulfur removal to $<0.1 \mathrm{ppmv}$ (i.e., no final purification required).

Figure 4.2.2 shows the economic incentive - the difference in required annual revenues for each solvent/syngas combination. 
Figure 4.2.2 Economic Incentive to Develop a Sulfur-Treated Synthesis Catalyst

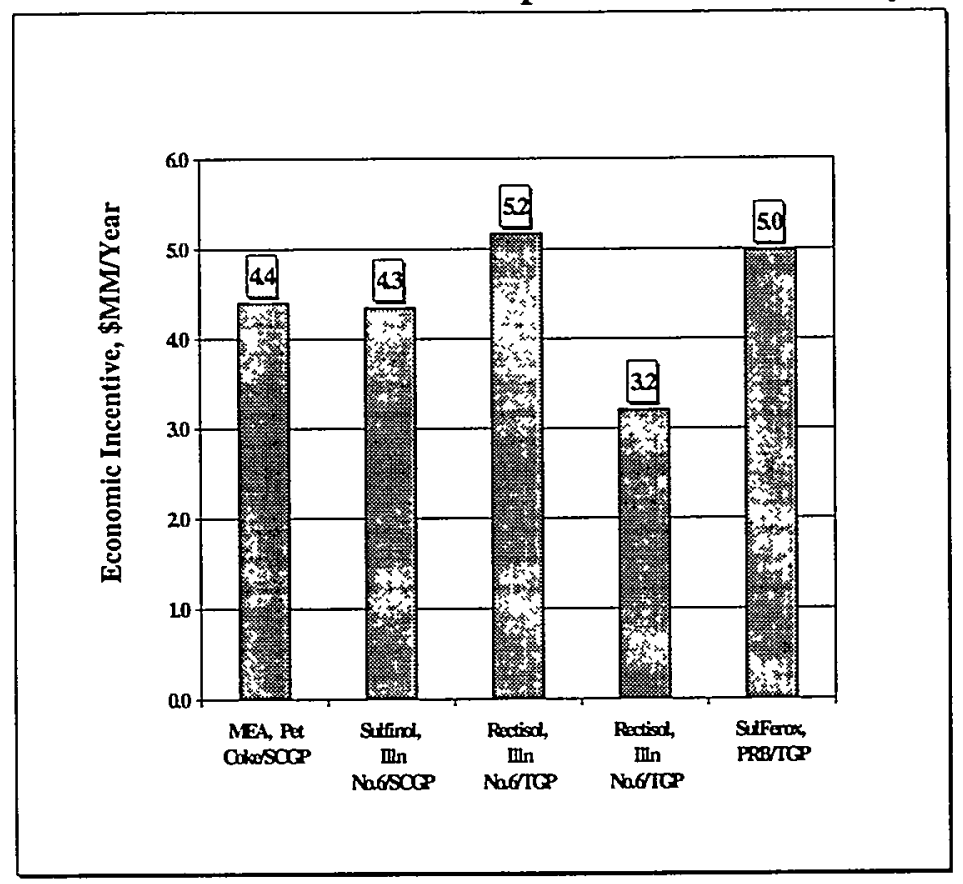

To put the economic incentive in the producer's perspective, it is worth comparing this saving to the cash flows for the complete methanol production facility. If it can be accepted that the revenue from methanol sales exactly balances the negative cash flows, plus a $15 \% \mathrm{IRR}$, then the ratio of the economic incentive to total revenues provides an idea of the savings relative to the total project cash flows.

An 1,800 stpd Pet.Coke, SCGP, MEA facility can produce 1,660 stpd of methanol, in stoichiometric mode of operation. According to Figure 4.2.2, the economic incentive is 4.4 $\$ M M / y r$. For a stable market price of 50 cents/gal of methanol, the annual sales revenue would be approximately $88 \$ \mathrm{MM} / \mathrm{yr}$. Therefore, if one assumes that the producer has sole access to the incentive and that the incentive is not discounted in any way, then the economic incentive would be $5 \%\left(\frac{4.4 \times 100}{88}\right)$ of the total revenue needed to generate a $15 \%$ after-tax IRR. For a number of reasons, it is unlikely that the producer will receive the full incentive.

\section{Conclusions}

The economic incentive for sulfur-tolerant catalyst development is between $\$ 3-5$ million per year; assuming all other costs remain the same within a particular solvent case. The economic incentive is a maximum saving that, in practice, can never be fully realized by either the methanol producer or the catalyst developer/supplier. Several other economic factors discount its value to either party.

This study is a preliminary investigation. There are other syngas/solvent combinations that should be evaluated to complete the distribution curve of economic incentives needed to develop a sulfur-tolerant methanol synthesis catalyst. 


\section{TASK 5: PROJECT MANAGEMENT}

\subsection{Reports and Presentations}

A draft of a topical report detailing the methanol/isobutanol campaign at LaPorte in the spring of 1994 was completed. The draft was first reviewed internally in February and then sent to DOE for review in March.

Monthlies for January, February and March were issued, and a draft quarterly for October through December 1995 was in preparation.

\subsection{Management Activities}

A meeting was held with Washington University personnel to discuss the results of the tracer study conducted during the LaPorte run in June 1995. Typically, an axial dispersion model, lumping different mixing mechanisms into a single dispersion coefficient, is used to model liquid mixing in bubble columns. The Washington University group has developed a two-dimensional model which accounts for convective as well as turbulence effects. Initial results indicate that the model is able to predict both the radial and axial movement of the tracer in the column. A Washington University/Air Products joint paper will be written based on this work.

A meeting was held with DOE personnel at PETC during January to discuss the F-T III run. The current plan as discussed between Air Products and Shell in mid December was presented. In general, the plan was well received, and DOE is looking forward to the run. Some issues raised by DOE need attention from Shell: DOE is going to need the LaPorte product analysis so that DOE and its contractors can study downstream processing. Shell should consider including the tracer study if Air Products/Washington University's current analysis of the 1995 hydrodynamic run shows significant understanding and the value of doing more under F-T III. ICI-Tracerco expenses can be covered under DOE's separate hydrodynamic program; however, operation time has to come out of the 30-day program. Data/results from the optical fiber probe (if obtained) need to be shared. Sparger information is needed to feed the data into DOE's Hydrodynamic program. The information will have to be shared with other subcontractors.

A meeting was held in March with personnel from Energy International (EI) to discuss a FischerTropsch demonstration run at LaPorte for EI. Their overall process scheme and specific LaPorte objectives were discussed. Funding and timing for the run are key issues. The run would need to be fully funded by EI because all available DOE and Air Products funding is already committed. Furthermore, due to the existing schedule for F-T III and the Kingsport start-up, the next window for a LaPorte run is mid 1997, and that window may be used for an oxygenates run such as DME synthesis. EI prefers a demonstration at an earlier time. 